Willians Roberto Alves de Godoy

\title{
PROJETO, ANÁLISE E OTIMIZAÇÃO DE UM ABSORVEDOR DINÂMICO DE VIBRAÇÕES NÃO LINEAR
}

Tese apresentada à Escola de Engenharia de São Carlos, da Universidade de São Paulo, como parte dos requisitos para obtenção do título de Doutor em Engenharia Mecânica.

Área de Concentração: Dinâmica de Máquinas e Sistemas.

Orientador:

Prof. Dr. Marcelo Areias Trindade

ESTE EXEMPLAR TRATA-SE DA VERSÃO CORRIGIDA.

A VERSÃO ORIGINAL ENCONTRASE DISPONÍVEL JUNTO AO DEPARTAMENTO DE ENGENHARIA MECANICA DA EESC-USP.

São Carlos 
AUTORIZO A REPRODUC̃̃O TOTAL OU PARCIAL DESTE TRABALHO,

POR QUALQUER MEIO CONVENCIONAL OU ELETRÔNICO, PARA FINS

DE ESTUDO E PESQUISA, DESDE QUE CITADA A FONTE.

Godoy, Willians Roberto Alves de

PROJETO, ANÁLISE E OTIMIZAÇÃO DE UM ABSORVEDOR

DINÂMICO DE VIBRAÇÕES NÃO LINEAR / Willians Roberto

Alves de Godoy; orientador Marcelo Areias Trindade.

São Carlos, 2016.

Tese (Doutorado) - Programa de Pós-Graduação em Engenharia Mecânica e Área de Concentração em Dinâmica das Máquinas e Sistemas -- Escola de Engenharia de São Carlos da Universidade de São Paulo, 2016.

1. absorvedor dinâmico de vibrações não linear. 2. projeto e otimização. 3. controle passivo de vibração. I. Título. 


\section{FOLHA DE JULGAMENTO}

Candidato: Licenciado WILLIANS ROBERTO ALVES DE GODOY.

Título da tese: "Projeto, análise e otimização de um absorvedor dinâmico de vibrações não linear".

Data da defesa: 22/02/2017.

Comissão Julgadora:

Prof. Associado Marcelo Areias Trindade

(Orientador)

(Escola de Engenharia de São Carlos/EESC)

Prof. Titular Paulo Sergio Varoto

(Escola de Engenharia de São Carlos/EESC)

Prof. Dr. Carlos Alberto Bavastri

(Universidade Federal do Paraná/UFPR)

Prof. Dr. Domingos Alves Rade

(Instituto Tecnológico de Aeronáutica/ITA)

Prof. Dr. Michael John Brennan

APROVADO

(Universidade Estadual Paulista "Júlio de Mesquita Filho"/UNESP - Ilha Solteira)
Resultado:

Aprovado

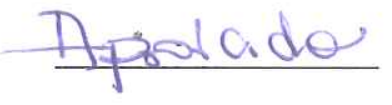

APROVADO

Coordenador do Programa de Pós-Graduação em Engenheira Mecânica: Prof. Associado Gherhardt Ribatski

Presidente da Comissão de Pós-Graduação:

Prof. Associado Luís Fernando Costa Alberto 

À minha mãe, guerreira que lutou toda sua vida pela educação dos dois filhos. Que esse trabalho seja o símbolo da gratidão e amor que sinto. 



\section{Agradecimentos}

Tenho certeza que palavras nunca representarão corretamente toda a gratidão que sinto neste momento por todos que colaboraram com este trabalho.

Agradeço a CAPES pelo suporte financeiro e a USP - São Carlos pela ótima estrutura fornecida.

Agradeço também aos meus companheiros de laboratório e amigos, especialmente ao Kleber, Ricardo, Augusto e Jaime, que sempre colaboraram com o desenvolvimento deste projeto. Sem essa ajuda esse caminho teria sido trilhado com dificuldades muito maiores.

Deixo um grande agradecimento ao Leandro, técnico do laboratório, que colaborou inúmeras vezes para que eu fizesse uso da estrutura computacional disponível. Também à Cristina, secretária do laboratório, que não deixou faltar nada ao laboratório.

Não sei se há palavras para expressar a gratidão que sinto pela Iara e Ana Paula da secretaria, desde o início as duas sempre fizeram de tudo para ajudar e tornar esse período mais proveitoso, se colocando a disposição com toda a experiência que ambas adquiriram ao acompanhar tantos alunos ao longo dos anos. Sou extremamente grato às duas.

Ao meu orientador, Marcelo A. Trindade, posso dizer que trabalhar com alguém tão competente, dedicado, comprometido, paciente e correto no que faz, fez ampliar minha capacidade profissional. $\mathrm{O}$ aprendizado das nossas longas conversas eu levarei para sempre. Muito obrigado!

Por fim, quero agradecer a minha família, minha mãe Geralda, minha irmã Adele, minha esposa Fernanda, minha madrinha Zilda, meu pai Wilson e minha avó Jovelina 
que já se foram, e tantas outras pessoas importantes que estão no meu coração. Todos colaboraram, torceram e me apoiaram nessa jornada. Muito obrigado por tudo que me proporcionaram, sem vocês esse caminho não teria sido trilhado. 
“Sempre há o que aprender, ouvindo, vivendo e, sobretudo, trabalhando. Mas só aprende quem se dispõe a rever suas certezas."

(Darcy Ribeiro) 



\section{Resumo}

GODOY, W.R.A. Projeto, análise e otimização de um absorvedor dinâmico de vibrações não linear. 2016, Tese (Doutorado) - Escola de Engenharia de São Carlos, Universidade de São Paulo, São Carlos - SP.

Absorvedores de vibração são comumente usados em aplicações com intuito de reduzir indesejadas amplitudes de vibração de estruturas e máquinas vibrantes. $\mathrm{O}$ conceito de um absorvedor de vibração linear consiste na ideia de projetar um subsistema com frequência de ressonância coincidente com uma dada frequência de interesse, tal que a amplitude de vibração do sistema primário é significantemente reduzida quando comparada à situação original, sem o absorvedor de vibração. Porém, uma deficiência dos absorvedores de vibração lineares típicos é sua estreita faixa de frequência de operação. Para superar essa deficiência, muitas tentativas de solução usando subsistemas não lineares têm sido propostas na literatura, já que se apropriadamente projetados, eles podem aumentar a faixa de frequência de absorção de vibração e/ou melhorar a redução das amplitudes de vibração do sistema primário. Contudo, a síntese e o projeto de tais absorvedores não lineares não é tão simples e direta como no caso linear. Baseado na geometria de uma topologia proposta e encontrada na literatura, que compreende a inclusão de uma montagem do tipo snap through truss no lugar da mola linear do absorvedor de vibração, este trabalho tem intenção de apresentar um estudo sobre o projeto e otimização de um absorvedor dinâmico de vibrações não linear. Portanto, o efeito dos parâmetros do absorvedor é analisado quanto às perspectivas de redução das amplitudes de vibração do sistema principal como também de aumento da faixa de frequência de operação. A análise paramétrica do absorvedor foi promovida para responder questões sobre as variáveis de projeto, tanto físicas como geométricas. Realizou-se otimização do absorvedor com objetivo de sintonizá-lo à frequência de trabalho desejada, através de busca extensiva e algoritmos genéticos. Os resultados mostram que o absorvedor não linear proposto pode ser mais efetivo que seu correspondente linear em ambos os aspectos, na redução da máxima amplitude de vibração e no aumento da faixa de frequência de absorção. Portanto, apesar da dificuldade inicial de projeto, esse tipo de absorvedor representa uma alternativa interessante na atenuação das amplitudes de vibração ao longo de uma extensa faixa de frequência.

Palavras-chaves: absorvedor dinâmico de vibrações não linear, projeto e otimização, controle passivo de vibração. 



\section{Abstract}

GODOY, W.R.A. Design, analysis and optmization of a nonlinear dynamic vibration absorber. 2016, Tese (Doutorado) - São Carlos School of Enginnering, University of São Paulo, São Carlos - SP, Brazil.

Dynamic vibration absorbers are commonly used in several applications in order to reduce undesired vibration amplitudes of vibrating machinery and structures. The concept of a linear vibration absorber is based on the idea of designing a subsystem with a resonance frequency coincident with a given frequency of interest such that the vibration amplitude of the primary system is significantly reduced when compared to the original situation (without the vibration absorber). But one of the known handicaps of typical linear vibration absorbers is their narrow frequency range of operation. To overcome this handicap, a number of tentative solutions have been proposed in the literature using nonlinear subsystems. If properly designed, they could enlarge the frequency range of vibration absorption and/or improve vibration reduction of the primary system. However, the synthesis and design of such nonlinear absorbers are not as straightforward as for their linear counterpart. A proposed design found in the open literature consists of replacing the linear spring of the vibration absorber by a nonlinear snap-through truss. This work aims to present a study on the design and optimization of a nonlinear dynamic vibration absorber based on snap-through absorber geometry. The effect of the absorber parameters was analyzed on both, the primary system vibration amplitude reduction and the frequency range of operation. Parametric analyses of the absorber were carried out to answer questions about the physical and geometric design variables. The absorber optimization was performed in two different ways, by extensive search and genetic algorithms, in order to tune it in the desired working frequency. The results show that the proposed nonlinear vibration absorber may be more effective than its linear counterpart both in terms of maximum vibration amplitude reduction and absorption frequency-range. Therefore, despite the increased design complexities such an absorber is an interesting alternative in attenuating vibration amplitudes over a wide frequency range.

Keywords: nonlinear dynamic vibration absorber, design and optimization, passive vibration control 



\section{Sumário}

Resumo

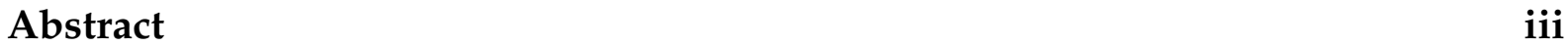

Lista de Figuras $\quad$ vii

Lista de Tabelas $\quad$ xi

1 Introdução 1

1.1 Revisão Bibliográfica . . . . . . . . . . . . . . . . . . . 3

1.1.1 Síntese e otimização de absorvedores dinâmicos de vibração . . 3

1.1.2 Métodos de otimização aplicados ao projeto de absorvedores de vibrações . . . . . . . . . . . . . . . . . . . 6

1.1.3 Otimização por algoritmos genéticos . . . . . . . . . . . 9

1.1.4 Absorvedor tipo snap-through truss (STTA) . . . . . . . . . . 11

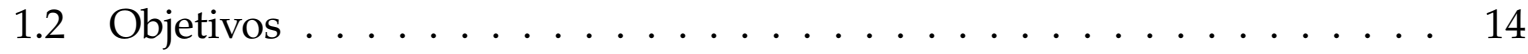

1.3 Organização do trabalho . . . . . . . . . . . . . . . . . . 14

2 Modelo base para estudo $\quad 17$

2.1 Descrição do sistema . . . . . . . . . . . . . . . . . . . . 17

2.2 Equações de movimento . . . . . . . . . . . . . . . . . . . . 18

2.3 Discussão acerca dos pontos críticos e sua estabilidade . . . . . . . . . 20

2.4 Inclusão de amortecimento equivalente no absorvedor . . . . . . . . . 24

2.5 Projeto do absorvedor $\ldots \ldots \ldots \ldots \ldots \ldots \ldots$ 
3 Estudo Preliminar $\quad 31$

3.1 Metodologia para obtenção da Resposta em Frequência . . . . . . . . . . 32

3.2 Procedimento para cálculo de $k_{s n} \ldots \ldots \ldots \ldots$

3.3 Análise preliminar de desempenho do absorvedor não linear proposto . 35

4 Otimização por busca extensiva $\quad 41$

4.1 Otimização do absorvedor não linear usando busca extensiva para $k_{s n}$. 42

4.1 .1 Critérios de avaliação . . . . . . . . . . . . . . 44

4.2 Análise dos resultados obtidos com busca extensiva . . . . . . . . . . 46

5 Otimização por algoritmo genético $\quad 55$

5.1 Otimização do absorvedor não linear usando algoritmos genéticos para $k_{s n} \ldots \ldots \ldots \ldots \ldots \ldots \ldots \ldots \ldots \ldots \ldots \ldots \ldots \ldots \ldots \ldots \ldots \ldots \ldots \ldots$

5.1 .1 Terceiro critério de avaliação . . . . . . . . . . . . . . 59

5.2 Análise dos resultados obtidos com algoritmos genéticos . . . . . . . . 61

5.3 Limitações do absorvedor não linear empregado . . . . . . . . . . . . 80

5.4 Projeto do absorvedor e suas dificuldades . . . . . . . . . . . . . 84

6 Conclusões e Trabalhos Futuros $\quad 89$

6.1 Conclusões . . . . . . . . . . . . . . . . . . . 89

6.2 Trabalhos futuros . . . . . . . . . . . . . . . 91

$\begin{array}{ll}\text { Referências Bibliográficas } & 93\end{array}$ 


\section{Lista de Figuras}

1.1 As duas frequências de ressonância em função da razão das massas

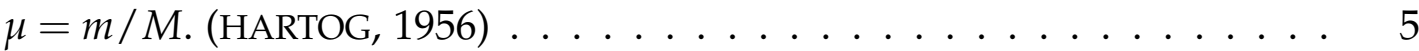

1.2 Ilustração da faixa de supressão (RICE; MCCRAITH, 1987). . . . . . . . . . . 8

1.3 Modelo estudado por Avramov e Mikhlin (2004a) . . . . . . . . . . . . . 12

1.4 Modelo estudado por Avramov e Mikhlin (2004b) . . . . . . . . . . . . . 13

1.5 Estrutura não ideal com STTA acoplado proposta por Felix e Balthazar

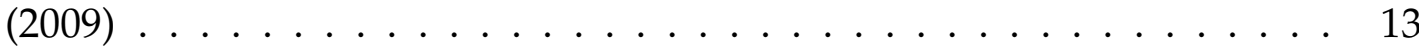

2.1 Representação do absorvedor não linear acoplado ao sistema principal 18

2.2 Representação das posições de equilíbrio. . . . . . . . . . . . . . . . 23

2.3 Representação dos pontos de equilíbrio em função de $L_{0}$. . . . . . . . . . 24

2.4 Esquema utilizado para linearização do amortecimento . . . . . . . . . . 25

2.5 Sistema primário sob força harmônica com absorvedor linear acoplado.

3.1 Esquema da obtenção do valor da amplitude de vibração ( $a m p)$ no histórico do tempo. . . . . . . . . . . . . . . . 32

3.2 Amplitude do PS com absorvedor não linear acoplado para diferentes valores de rigidez das molas, $k_{s n} \ldots \ldots \ldots \ldots \ldots$

3.3 Resposta em Frequência do sistema primário (PS) sem absorvedor (pontilhada), com absorvedor linear (tracejada) e com absorvedor não linear (contínua) para os dois valores de rigidez do absorvedor não linear, $k_{s n}$.

3.4 Deslocamento nas direções horizontal, $u_{s}$, e vertical, $v_{s}$, do absorvedor não linear para os dois valores ótimos de rigidez do absorvedor e para excitação do sistema primário na frequência de 20,55 Hz. . . . . . . . . . 37 
4.1 Representação dos critérios de redução de amplitude e faixa de frequência de supressão.

4.2 Valores de faixa de frequência de supressão $\left(\delta \omega_{n l}\right)$ e redução da amplitude de vibração $\left(\delta A_{n l}\right)$ para diferentes valores de massa do absorvedor, $m_{s}$, e de comprimento indeformado das molas, $L_{0}$. . . . . . . . . .

4.3 FRF do sistema primário (PS) sem absorvedor (pontilhada), com absorvedor linear (tracejada) e com absorveddor não linear (contínua) para as 8 combinações ótimas obtidas. . . . . . . . . . . . . . . . . . . . . 49

4.4 Diagrama de bifurcação da combinação C1 e seu correspondente linear. 51

4.5 Deslocamento do correspondente absorvedor linear da combinação C1 com amplitude da força, $f$, igual a $500 \mathrm{~N} \ldots \ldots . \ldots 52$

4.6 Deslocamento do correspondente absorvedor linear da combinação C1 com amplitude da força, $f$, igual a $2500 \mathrm{~N} \ldots \ldots . \ldots . \ldots 52$

4.7 Deslocamentos da combinação C1 com amplitude da força, $f$, igual a

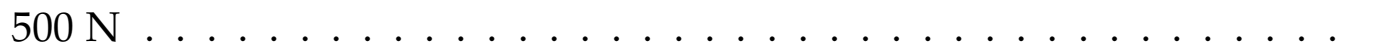

4.8 Deslocamentos da combinação C1 com amplitude da força, $f$, igual a

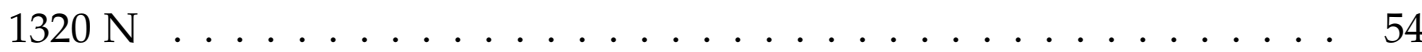

5.1 Exemplo para a medida da Área. . . . . . . . . . . . . . . . . . . 60

5.2 Valores da faixa de supressão $\left(\delta \omega_{n l}\right)$, redução da amplitude de vibração $\left(\delta A_{n l}\right)$ e Área para diferentes valores de massa do absorvedor $\left(m_{s}\right)$ e comprimento da mola indeformada $\left(L_{0}\right) \ldots \ldots \ldots$

5.3 Curvas Amplitude x Frequência das cinco melhores combinações resultantes de acordo com cada critério de avaliação. PS sem absorvedor: linha pontilhada; PS com absorvedor não linear: demais linhas contínuas. 64

5.4 Amplitudes dos elementos do sistema observadas, quando $L_{0}=0,15 \mathrm{~m}$ e $m_{s}=7 \mathrm{~kg}$, em uma faixa maior de frequência. . . . . . . . . . . 65

5.5 Curva Amplitude x Rigidez da combinação $9-L_{0}=0.150$ m e $m_{s}=7.0$

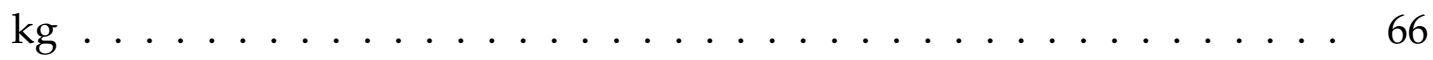

5.6 Frequência x Amplitude $-L_{0}=0.150 \mathrm{~m}$ e $m_{s}=7.0 \mathrm{~kg} \ldots \ldots 7$ 
5.7 Desempenho para cada conjunto de parâmetros conforme critérios normalizados incluindo penalização. . . . . . . . . . . . . . . . . . 68

5.8 Comparação entre Absorvedor Linear e Não Linear. PS sem absorvedor: linha pontilhada; PS com absorvedor linear: linha e ponto; PS com absorvedor não linear: linha contínua. . . . . . . . . . . . . . . . . . . 70

5.9 Características das molas (NAYFEH; MOOK, 1995) . . . . . . . . . . . . . . 71

5.10 Características de um oscilador não linear Duffing (NAYFEH; MOOK,

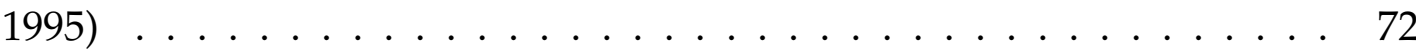

5.11 Curvatura da ressonância segundo a variação da amplitude da força. 73

5.12 Fenômeno do Salto. . . . . . . . . . . . . . . . . . . . . . . . 74

5.13 Amplitudes de movimento do absorvedor nas direções horizontal e vertical até $80 \mathrm{~Hz} \ldots \ldots \ldots \ldots \ldots \ldots$. . . . . . . . . . . . . . . . . . . . . .

5.14 Comparação dos absorvedores linear e não linear até 80 Hz. . . . . . . . . 76

5.15 Melhores resultados para os três critérios para diferentes valores de massa do absorvedor $m_{s} \ldots \ldots \ldots \ldots \ldots \ldots$

5.16 Curvas de Frequência x Amplitude dos 4 melhores desempenhos para diferentes massas do absorvedor. . . . . . . . . . . . . . . . . 79

5.17 Diagrama de bifurcação do sistema principal $\left(u_{p}\right)$ excitado na frequência de ressonância. . . . . . . . . . . . . . . . . . . . . . 81

5.18 Comportamento do sistema para diferentes amplitudes da força aplicada. 82

5.19 Rigidez calculada (linha sólida) x Rigidez obtida (pontos). . . . . . . . . 86

5.20 Curvas de Frequência x Amplitude para casos de rigidez calculada (tracejada) e rigidez obtida via otimização (linha sólida) quando $L_{0}=0,151$

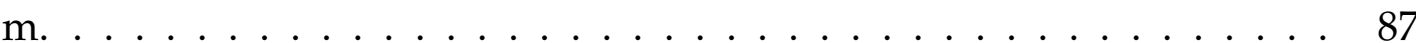

5.21 Curvas de Frequência x Amplitude para casos de rigidez calculada (tracejada) e rigidez obtida via otimização (linha sólida) quando $L_{0}=0,152$

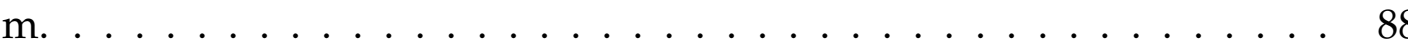




\section{Lista de Tabelas}

2.1 Valores do parâmetros do sistema utilizados para análise de estabili-

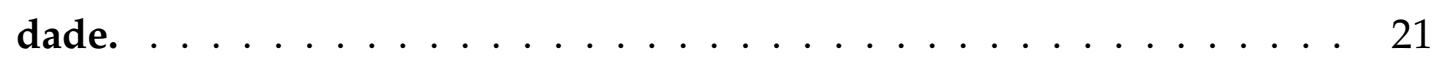

2.2 Estabilidade das soluções válidas . . . . . . . . . . . . . 23

3.1 Valores dos parâmetros para os sistemas com absorvedor linear e não

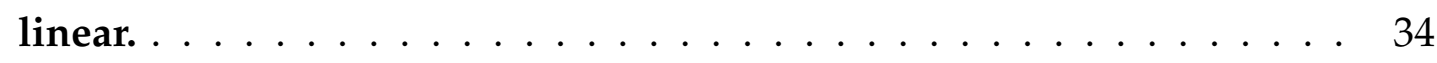

4.1 Valores dos parâmetros para o sistema com absorvedor não linear. . . 46

4.2 Melhores conjuntos de parâmetros para o absorvedor não linear . . 48

4.3 Resultados dos melhores conjuntos de parâmetros para o absorvedor não linear $\ldots \ldots \ldots \ldots \ldots \ldots \ldots$

5.1 Valores dos parâmetros para o sistema com absorvedor não linear. . . 56

5.2 Cinco melhores configurações do absorvedor não linear . . . . . . . 69

5.3 Resultados dos melhores parâmetros para o absorvedor não linear . 70

5.4 Configurações do absorvedor não linear para os casos da Fig. 5.16 . 80 


\section{Capítulo 1}

\section{Introdução}

As vibrações excessivas consistem em um importante problema a ser superado no projeto e uso de máquinas em geral, pois podem causar danos estruturais, ruído excessivo ou desperdício energético; por isso, um grande número de aplicações requer o uso de controles dinâmicos. Eles permitem reduzir, por exemplo, a vibração que é transmitida dos motores às estruturas que os contêm, como carrocerias de automóveis e asas de avião no caso das turbinas, dentre outros. Com isso, é necessário escolher e empregar uma forma de controle de vibração de acordo com as possibilidades e os custos.

Um primeiro critério permite a classificação dos sistemas de controle em ativo, híbrido ou passivo. O primeiro exige o fornecimento de energia, o segundo pode exigir ou não o fornecimento de energia consoante o cenário existente, enquanto o último não necessita de qualquer fonte de alimentação de energia do exterior. Visando diminuir as dificuldades de emprego, optou-se por desenvolver neste trabalho um mecanismo passivo, ou seja, que não necessite de energia para atuar.

Um absorvedor dinâmico de vibrações é o dispositivo responsável por controlar as amplitudes de vibração de um sistema principal através da absorção da maior parte da energia de vibração. De acordo com a necessidade de emprego, o dispositivo de controle passivo pode ser projetado de diferentes formas e utilizando diferentes estruturas, podendo ser um pêndulo, uma massa ou uma viga dentre várias das configurações que podem ser usadas como absorvedor. Uma vez que será desenvolvido um dispositivo de controle passivo, deve-se olhar para o mais simples caso desse tipo, o absorvedor dinâmico linear. Em um processo chamado "sintonização", o absorvedor linear é projetado de modo a ter a frequência de ressonância coincidente com uma dada frequência de interesse. Quando um sistema principal, com este absorvedor acoplado, vibra numa frequência próxima daquela para a qual o dispositivo foi projetado, as amplitudes de vibração de tal sistema são significantemente reduzidas, se comparadas com aquelas que ocorreriam para o sistema sem absorvedor. Entretanto, esse tipo de absorvedor apresenta uma pequena faixa de frequência na qual ele atua de forma satisfatória, o que limita o seu uso. 
Com intuito de superar essa limitação, vários tipos de absorvedores foram propostos, dentre eles, os não lineares. Estes são capazes de atuar reduzindo as amplitudes do sistema primário, porém em uma faixa de frequência maior do que a obtida com dispositivos lineares semelhantes.

Portanto, este trabalho considera o desenvolvimento de um novo tipo de absorvedor essencialmente não linear. Nos últimos anos, esse tipo de dispositivo vem sendo estudado por pesquisadores de várias partes do mundo. O grande interesse em torno dessa forma de controle passivo de vibrações se deve a sua aplicabilidade em sistemas mais complexos.

Porém, o uso de um dispositivo não linear introduz algumas complicações, como a presença de múltiplos pontos de equilíbrio, que são capazes de definir as limitações e as configurações adequadas, o que resulta em um complexo processo de projeto e síntese do mesmo. Além dessas dificuldades de projeto, mesmo com a obtenção de uma faixa de frequência maior, há ainda a presença de dois altos picos de ressonância que são gerados com a introdução do absorvedor. No caso do absorvedor linear, a redução desses picos é possível através da teoria dos pontos fixos, com o aumento do amortecimento sobre o absorvedor e ao custo do aumento das amplitudes na antirressonância, ou seja, as amplitudes na frequência de interesse já não tendem a zero. Através da otimização e análise paramétrica do sistema espera-se encontrar uma solução para reduzir os picos e não aumentar as amplitudes na antirressonância de modo relevante.

O absorvedor desenvolvido neste trabalho é empregado com intuito de se explorar a não linearidade geométrica contida nele, que gera uma rigidez variável e com isso altera-se a frequência natural do objeto. Para isso, realizaram-se, em conjunto, a análise paramétrica e otimização dos parâmetros do absorvedor. A otimização foi realizada através de dois métodos, por busca extensiva e algoritmos genéticos. Com isso, foi possível analisar e comparar o desempenho do absorvedor não linear frente ao linear usado como referência. 


\subsection{Revisão Bibliográfica}

O texto a seguir visa situar o leitor dentro do tema e permitir o maior entendimento dos dispositivos e abordagens empregados neste trabalho. São expostos os principais trabalhos sobre projeto e otimização de absorvedores dinâmicos de vibrações, emprego de métodos de otimização em projeto de absorvedores e sobre otimização por algoritmos genéticos.

\subsubsection{Síntese e otimização de absorvedores dinâmicos de vibração}

Um sistema mecânico submetido a uma força, na qual a frequência de excitação atua próxima à frequência natural do sistema, responde com vibrações e amplitudes excessivas. Quando esse tipo de situação ocorre, deve-se buscar uma solução, tal como: reduzir a amplitude da força de excitação ou mudar o espectro de frequência no qual esta força atua; alterar o sistema principal, seja através da rigidez, da massa ou pela introdução de amortecimento; ou introduzir um ou mais sistemas secundários ao sistema principal. Sabe-se que as duas primeiras alternativas nem sempre são possíveis, dado o fato de o sistema principal, ou sistema primário, muitas vezes já estar preestabelecido ou não poder sofrer grandes alterações. Além disso, a força excitadora tem de atuar numa certa faixa de frequência para garantir o desempenho desejado pelo operador. Sendo assim, muitas vezes a introdução de um sistema secundário é a alternativa que convém ser empregada.

Esse sistema secundário é conhecido como absorvedor dinâmico de vibrações, tal como será tratado neste trabalho, porém há casos na literatura em que este também é chamado de neutralizador dinâmico de vibrações. A inclusão do absorvedor de vibração visa criar um sistema composto no qual as frequências de ressonância serão diferentes da apresentada pelo sistema primário sozinho.

O primeiro trabalho destinado à inclusão de um sistema secundário para o controle de vibrações foi realizado e patenteado por Frahm em 1911, porém, foi só em 1928 que Ormondroyd e Hartog (1928) publicaram o primeiro tratamento matemático a respeito do absorvedor dinâmico de vibrações. Este dispositivo adicionado ficou conhecido, posteriormente, como tuned vibration absorber (TVA) ou dynamic vibration absorber (DVA), sendo em português absorvedor de vibrações sintonizado ou absorvedor dinâmico de vibrações. Atualmente o TVA é o mais popular dispositivo de redução de vibrações em estruturas mecânicas, sendo empregado comumente em estruturas civis e eletromecânicas. Sua ampla gama de aplicações se deve, principalmente, ao seu caráter linear e aos sólidos fundamentos teóricos e matemáticos em que se baseia. Entretanto, o projeto de tal absorvedor ainda é um desafio quando deve ser acoplado a estruturas mais complexas, já que ele possui uma teoria bem estabelecida para sistemas primários simples.

Ormondroyd e Hartog (1928) estudaram primeiramente o modelo mais simples, 
que tratava de um sistema principal com um grau de liberdade e um absorvedor dinâmico, também com um grau de liberdade, acoplado a ele. Hartog (1956) considerou um absorvedor com e sem amortecimento, com intuito de determinar os parâmetros ótimos para atenuação das vibrações do sistema principal. Conclui-se que, para o sistema com absorvedor sem amortecimento, a vibração do sistema principal tende a zero quando a frequência natural do absorvedor coincide com a frequência natural do sistema principal. A aplicação dessa técnica é chamada de sintonização, que dá nome ao absorvedor, e pode ser verificada através da equação de sintonização. Essa técnica gera uma nova resposta para o sistema composto, introduzindo duas novas frequências naturais perto daquela que era a frequência natural do sistema primário sozinho. Isto gera, na função resposta-frequência, dois picos bem próximos ao ponto onde a amplitude tende a zero, caracterizando uma faixa estreita de atuação do absorvedor, também chamada de faixa de supressão. Hartog (1956) não deixou evidente em suas conclusões, embora tenha deixado implícito através da figura reproduzida na Fig. 1.1, que existe uma a relação entre o tamanho da faixa de frequência de atuação do absorvedor e a razão entre as massas do absorvedor $(m)$ e do sistema principal $(M)$ - $\mu=m / M$. Um dos trabalhos que posteriormente confirmou a natureza aproximadamente linear na relação entre $\mu$ e a faixa de supressão foi o de Jordanov e Cheshankov (1988). Em (HARTOG, 1956) também foi mostrado que um TVA com mecanismo de dissipação de energia pode ser projetado para aumentar a faixa de supressão através da redução da amplitude dos picos de ressonância e ao custo do aumento da amplitude na antirressonância. Esse método ficou conhecido como Regra dos Pontos Fixos. Assim, o TVA amortecido proposto hoje é conhecido como o absorvedor dinâmico de vibrações tipo Voigt, que é composto de uma mola linear em paralelo com um amortecedor, e desde então, muitos estudos com foco na otimização do TVA amortecido foram propostos.

Apesar dos trabalhos que buscaram otimizar o TVA amortecido em função do amortecimento, os absorvedores sintonizados ainda continuaram apresentando como restrições a efetividade limitada à vizinhança de um modo de vibração, a incapacidade de atenuar os vários modos de uma estrutura primária de múltiplos graus de liberdade e a incapacidade de reduzir as vibrações de uma estrutura não linear primária. Buscando conseguir um dispositivo capaz de trabalhar com estruturas mais complexas e lidar com um ou todos os obstáculos presentes no TVA, surgiram os primeiros estudos a respeito de um dispositivo com não linearidade incluída, o absorvedor dinâmico de vibrações não linear.

Os primeiros estudos sobre esse tipo de dispositivo são de Roberson (1952), Pipes (1953) e Arnold (1955), que estudaram a influência da não linearidade sobre largura da faixa de frequência de supressão. Roberson (1952) considerou o caso do absorvedor com uma mola linear e outra cúbica em paralelo, concluindo que, teoricamente, 


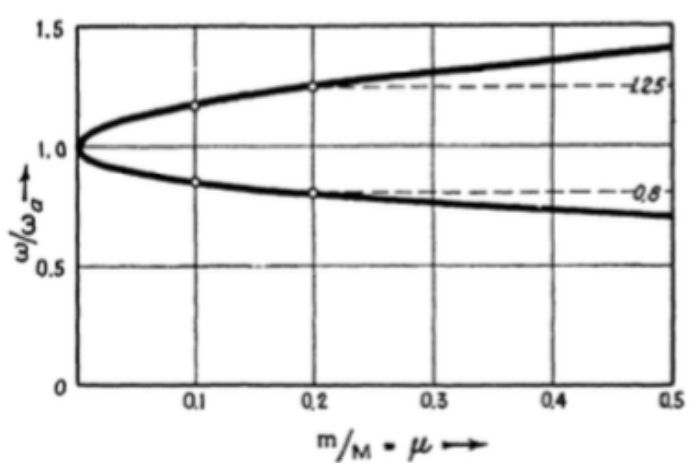

Figura 1.1: As duas frequências de ressonância em função da razão das massas $\mu=$ $m / M$. (HARTOG, 1956)

uma mola softening produziria o aumento da largura da faixa frequência de supressão. Na sequência, Pipes (1953) considerou uma mola de comportamento hiperbólico senoidal de natureza hardening e sem amortecimento. Um pouco depois, Arnold (1955) confirmou os resultados de Roberson (1952) e também considerou o dispositivo sem amortecimento. Após quase duas décadas, Masri (1972) estudou o caso das duas massas sob oscilação forçada. Miller e Gartner (1975) superaram o problema da faixa de supressão estreita introduzindo uma mola pneumática de rigidez variável sem amortecimento na qual a frequência natural do absorvedor poderia ser variada de acordo com a frequência de excitação externa.

Hunt e Nissen (1982) estudaram um absorvedor não linear de forma experimental, assim como (RICE; MCCRAITH, 1987) e (KOJIMA; YAMAKAWA, 1981), quando analisaram um sistema de um oscilador forçado amortecido com um absorvedor não linear amortecido desenvolvido a partir de um conjunto de arruelas cônicas (Bellerville washer springs). Dentro dos exemplos práticos desse tipo de absorvedor pode-se encontrar também o pêndulo (EASON et al., 2015), o absorvedor por impacto (EGLE, 1967), o absorvedor de vibrações auto-paramétrica (HAXTON; BARR, 1972) e outros. Em recente trabalho, Brennan e Gatti (2012) promoveram um estudo acerca do absorvedor não linear e constataram que a utilização deste gera um deslocamento da curva de resposta em frequência semelhante à adição de massa ao sistema.

Entretanto, algumas complicações podem surgir com a introdução de um absorvedor não linear, tal como presença de múltiplos pontos de equilíbrio, já que tais pontos definem as limitações e as configurações ideais para o absorvedor. Desta forma, isto pode levar a um processo de projeto e síntese do absorvedor muito mais complexo quando comparado ao caso do dispositivo linear.

Como resultado do crescente interesse sobre os absorvedores não lineares, uma variedade de trabalhos foi produzida para permitir um melhor entendimento sobre o seu comportamento, por exemplo (SHAW et al., 1989) e (PAI; SCHULZ, 2000). Recentemente, estudos sobre a transferência de energia (GENDELMAN et al., 2001; GENDELMAN, 
2001; VAKAKIS; GENDELMAN, 2001; VAKAKIS et al., 2008) e sintonização de frequência (VIGUIE; KERSCHEN, 2009; VIGUIE; KERSCHEN, 2010) foram feitos. Estes trabalhos mais recentes visam relacionar a energia absorvida/dissipada ao comportamento do sistema primário.

Apesar das crescentes publicações acerca do projeto e emprego de um dispositivo não linear que atenue as vibrações do sistema principal, tanto para uma faixa de frequência, bem como para sistemas com múltiplas frequências de ressonância, ainda há poucas informações sobre a otimização desses dispositivos de forma prática, o que vai além de sua sintonização.

\subsubsection{Métodos de otimização aplicados ao projeto de absorvedores de vibrações}

O emprego de métodos de otimização em sistemas dinâmicos, sobretudo em sistemas com absorvedores não é muito antigo e nem tão difundido. Dada a falta de recursos computacionais que havia há algumas décadas, muitos dos trabalhos realizavam sobretudo a análise analítica dos sistemas e empregavam os recursos computacionais para confirmar alguns poucos resultados.

Bartel e Krauter (1971) foram uns dos primeiros a lançar mão desse tipo de recurso quando utilizaram o método de Descida Mais Íngreme (Constrained Steepest Descent) para minimizar a máxima força transmitida entre as duas massas e o tempo necessário para dissipação de energia no sistema com absorvedor por impacto. Kwak et al. (1975) também usaram o método de Descida Mais Íngreme para solucionar o caso do clássico absorvedor em uma faixa de frequência finita e mostraram que para intervalos finitos de frequência o projeto do absorvedor pode ser melhor que o ótimo usual. Soom e Lee (1983) usaram técnicas de otimização não linear para obter os parâmetros ótimos de sintonização e amortecimento. Eles minimizaram a amplitude dos deslocamentos do sistema principal para os casos com um absorvedor linear e um não linear. Kitis et al. (1983) apresentaram um eficiente algoritmo para minimizar a resposta vibratória em uma gama de frequências de excitação, ao aplicarem este à concepção de dois absorvedores dinâmicos de vibrações. Eles foram simultaneamente aplicados a um sistema de 22 graus de liberdade não amortecido, com quatro variáveis de projeto. Também foi demonstrada a aplicabilidade desse método para sistemas dinâmicos em grande escala. Jordanov e Cheshankov (1988) minimizaram a resposta do sistema principal amortecido e não amortecido empregando tanto um absorvedor linear quanto um não linear. No caso linear foram consideradas como variáveis de projeto o amortecimento e o parâmetro de sintonização, já no não linear consideraram-se os dois coeficientes de rigidez do absorvedor.

Um pouco mais recentemente, o trabalho de Bavastri et al. (1998) empregou um método híbrido, Algoritmos Genéticos e otimização não linear, para projeto ótimo de neutralizadores viscoelásticos em uma faixa de frequências. A otimização não linear 
e por Algoritmos Genéticos também foi empregada por Rade e Steffen (2000), alternadamente, de modo a superar a dificuldade do ponto inicial proposto no caso da otimização não linear. Eles otimizaram os parâmetros de um ou mais TVA aplicados a diferentes estruturas. Xue et al. (2002) realizaram a otimização do absorvedor de coluna líquida através da busca extensiva, método que foi aplicado de forma similar neste trabalho.

Viana et al. (2008) fizeram uso da técnica de otimização Colônia de Formigas para reduzir as amplitudes de vibração de sistemas principais empregando dois tipos de absorvedores de vibrações, um multi-modos e outro da lâmina vibrante. Já Saravanamurugan et al. (2015) fizeram uso dos Algoritmos Genéticos para otimizar os parâmetros de um TVA amortecido para controlar as trepidações durante a usinagem de metais.

O que se pôde verificar com os trabalhos encontrados na literatura é que os absorvedores de vibrações têm sido alvo constante de estudos com intuito de fornecer as melhores respostas dada a situação em que se apresentam. Quanto ao TVA, os principais estudos para otimizá-lo referem-se à influência de seu amortecimento sobre as amplitudes de vibração do sistema principal. Esses estudos iniciaram-se com Ormondroyd e Hartog (1928) e seguiram por décadas, uma vez que para sistemas principais amortecidos a teoria dos pontos fixos já não era mais válida.

Um fato pouco explorado ao longo desses estudos foi a influência da massa do absorvedor sobre o tamanho da faixa de frequência de supressão. Para os absorvedores lineares verificou-se a tendência de aumento da mesma com o aumento da massa, contudo essa relação e a determinação do que seria uma "massa ótima" não estão explicitas. Para os absorvedores não lineares, as conclusões ficam ainda mais distantes, apesar de muitos trabalhos terem afirmado a capacidade da não linearidade alargar a faixa de supressão. Contudo, também não fica claro o papel da massa do absorvedor no alongamento de faixa. Uma possível explicação para esse fato é que muitos trabalhos utilizaram um parâmetro de sintonização, referente às frequências naturais do sistema principal e do absorvedor, o que oculta a atuação da massa do absorvedor. Outra possibilidade é que alguns autores optam por fixar um valor de massa para o absorvedor por levar em consideração o espaço disponível e a restrição quanto à massa limite ou ideal que deve ser adicionada à estrutura.

Desde os estudos iniciais sobre a síntese e otimização de um absorvedor de vibrações não foram muitos os critérios propostos para avaliar seu desempenho, uma vez que critérios podem mudar de acordo com as características do sistema. Assim como neste atual trabalho, que utiliza um sistema não linear, em outros também discutiuse sobre como extrair da resposta do sistema uma medida que permitisse avaliar o desempenho do absorvedor. Essa discussão também foi proporcionada por Roberson (1952) durante a síntese de um absorvedor não linear, que listou três possíveis 
critérios:

1- Máximo valor de amplitude;

2- Amplitude média;

3- Amplitude média quadrática.

Segundo Roberson (1952), a terceira opção é melhor de ser tratada analiticamente, porém pode permitir amplitudes de resposta relativamente grandes num pequeno intervalo. Dessas três opções, definiu-se o valor máximo de amplitude, em regime estacionário, como critério indireto de avaliação. É dito indireto, pois o critério que será mostrado mais adiante é a redução de amplitude quando comparado ao sistema sem absorvedor. A amplitude máxima foi escolhida por se entender que essa abordagem satisfaz a necessidade do projeto e é facilmente extraída do movimento ao sistema.

Além disso, na literatura também encontra-se como um critério a largura da faixa de supressão, conceito que foi introduzido por Roberson (1952). Segundo Roberson esse valor corresponde à faixa de frequência na qual a razão entre a amplitude de movimento do sistema principal e o deslocamento estático, dado por $X_{\text {stat }}=F / K$, é menor ou igual a $1\left(X / X_{\text {stat }} \leqslant 1\right)$. Rice e McCraith (1987) ilustrou essa faixa de supressão através da Fig. 1.2. Neste trabalho considerou-se a faixa de supressão como um dos critérios, contudo, a forma estabelecida para calcular esse valor foi diferente e será mostrada na seção 4.1.1.

O trabalho de Wang e Cheng (1989) comparou quatro métodos de otimização, de fato a otimização é feita considerando quatro diferentes funções objetivo, duas aplicadas ao domínio da frequência e duas ao domínio do tempo. Esse trabalho é interessante, pois compara métodos usados em outros trabalhos e insere um método próprio. Nele há a comparação, através da curva de resposta em frequência, da performance do absorvedor otimizado de acordo com os quatro modos. A avaliação dos resultados produzidos foi realizada com objetivo de minimizar a área sob cada curva resultante.

Essa ideia de avaliar o desempenho do absorvedor medindo-se a área sob a curva foi empregada neste trabalho, como será visto na seção 5.1.1, inserindo-a como um terceiro critério de avaliação além da amplitude máxima e da faixa de supressão.

\subsubsection{Otimização por algoritmos genéticos}

Em praticamente todas as áreas do conhecimento busca-se determinar a melhor resposta para um determinado questionamento. Desde que as respostas possam ser medidas por um número, esses problemas podem ser solucionados com emprego da otimização matemática, que consiste em obter o melhor resultado sob determinadas circunstâncias, seja minimizando o esforço necessário ou aumentando o benefício esperado. Sendo assim, otimização pode ser definida como um processo que encontra 


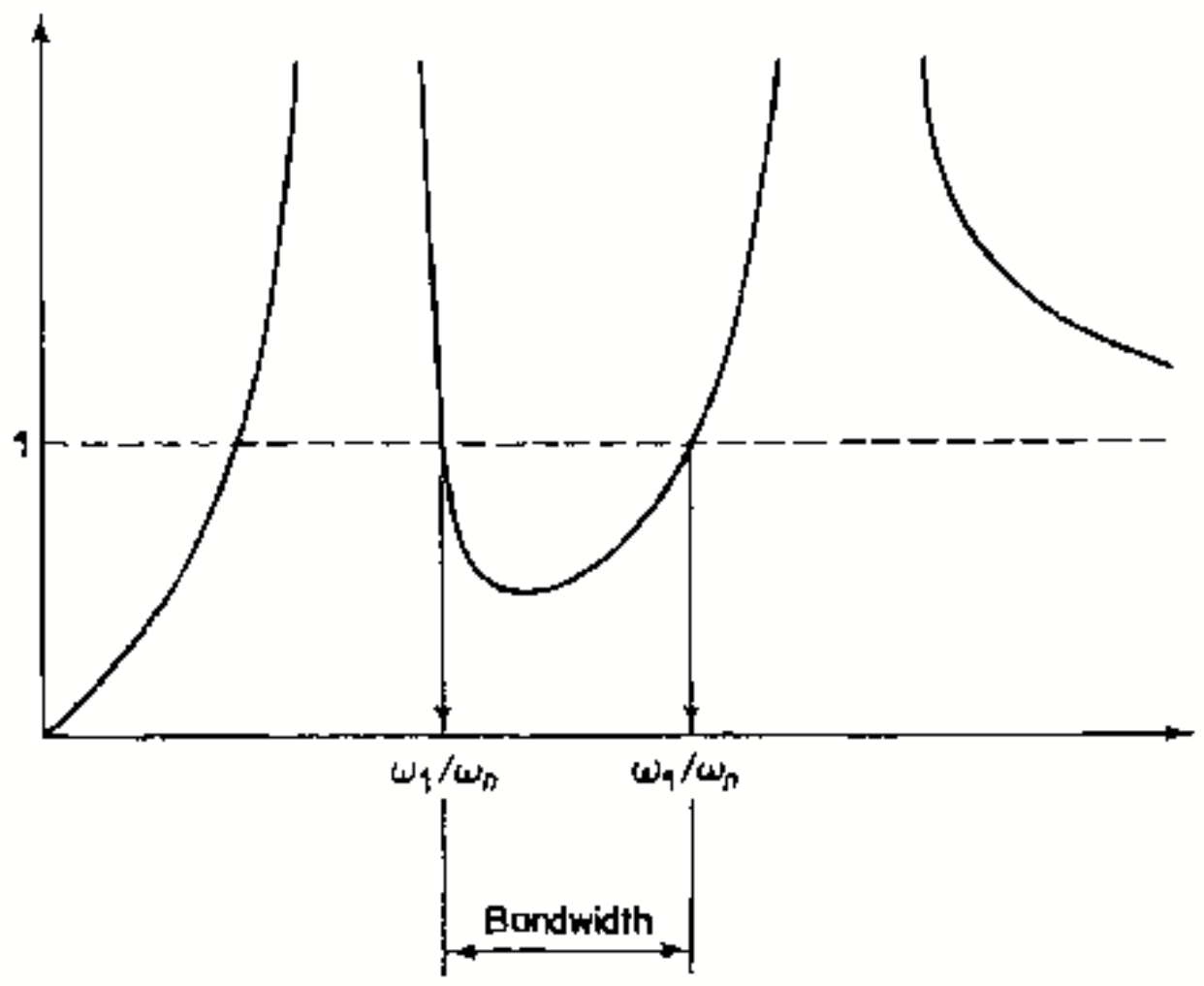

Figura 1.2: Ilustração da faixa de supressão (RICE; MCCRAITH, 1987).

as condições que minimizam ou maximizam a função que relaciona as variáveis de decisão e o benefício ou esforço requerido. As técnicas de otimização são também conhecidas na literatura como mathematical programming techniques.

Uma classificação muito básica pode dividir as técnicas de otimização em dois grupos, dos métodos Determinísticos e os Heurísticos. Os Determinísticos são os que sempre chegarão à mesma resposta se sempre partirem do mesmo ponto inicial. Contudo, por, geralmente, utilizarem derivadas da função objetivo, esse métodos são inviáveis quando: houver descontinuidade na função objetivo; houver mais de um mínimo na função, a função objetivo não puder ser escrita de forma diferenciável; e o cálculo de derivadas for inviável. Já os Heurísticos são os métodos que, simplificadamente, utilizam o conhecimento adquirido ao longo do processo na tomada de decisão. Para isso, muitas vezes utilizam somente o valor da função objetivo e não empregam o cálculo de derivadas, o que supera as limitações dos métodos que dependem desta última.

Atualmente, novos métodos de otimização caracterizados como não tradicionais ou modernos têm sido desenvolvidos. A maioria desses métodos são baseados em características ou comportamentos de sistemas biológicos, moleculares e neurobiológicos. Alguns desses métodos são: Algoritmos Genéticos ou Genetic Algorithms, Recozimento Simulado ou Simulated annealing, Enxame de Partículas ou Particle swarm optimization, Colônia de Formigas ou Ant colony optimization, dentre outros. A maioria 
desses métodos foi desenvolvido atualmente para solucionar problemas complexos de engenharia, sendo que a maioria necessita apenas do valor da função objetivo e não das derivadas. Os Algoritmos Genéticos são baseados nos princípios da genética e seleção natural, enquanto o Recozimento Simulado é fundamentado na simulação de recozimento térmico de sólidos aquecidos criticamente. Ambos, Algoritmos Genéticos e Recozimento Simulado, são métodos estocásticos que podem encontrar o mínimo global com uma probabilidade elevada e são naturalmente aplicáveis à solução de problemas de otimização discreta. $\mathrm{O}$ método de Enxame de Partículas foi baseado no comportamento de uma colônia de seres vivos, como um enxame de insetos ou um cardume de peixes. A optimização da Colônia de Formigas é baseado no comportamento cooperativo de colônias de formigas reais, que são capazes de encontrar o caminho mais curto do seu ninho a uma fonte de alimento.

De acordo com Rao (2009), muitos problemas práticos são caracterizados por variáveis mistas contínuas-discretas, descontínuas e não convexas. $\mathrm{O}$ uso de técnicas do tipo non-linear programming para esse tipo de problema resultaria em algo ineficiente e computacionalmente custoso. Para esses casos, a otimização por Algoritmos Genéticos (GAs - Genetic algorithms) foi projetada, de modo a encontrar a solução global ótima com uma alta probabilidade.

Os algoritmos genéticos foram baseados nos princípios da genética e seleção natural (reprodução, cruzamento e mutação) que são usados no procedimento de busca da solução ótima. Mesmo os GAs tendo sido apresentado por Holland (1975), as conceitos básicos de projeto e análise baseados na evolução biológica podem ser encontrados no trabalho de Rechenberg (1965).

Os GAs diferem dos métodos tradicionais nos seguintes pontos:

1- Uma população de pontos é utilizada inicialmente ao invés de um único ponto de partida.

2- Usa apenas os valores da função objetivo, derivadas não são usadas no procedimento.

3- As variáveis de projeto são representadas como linhas de variáveis binárias, que correspondem aos cromossomos na genética natural, onde se aplica o método de busca para solucionar problemas discretos e contínuos.

4- O valor da função objetivo referente ao vetor de variáveis de projeto corresponde à aptidão do indivíduo na genética natural.

5- A cada nova geração um novo conjunto de indivíduos é criada usando seleção e cruzamento de pais aleatoriamente. Mesmo aleatórios, os algoritmos genéticos exploram as novas combinações utilizando o conhecimento disponível para criar 
uma nova geração que vai se adaptar melhor ou entregar melhores valores pela função objetivo.

Uma vez que o caso em estudo apresenta uma diversidade de curvas a serem analisadas como consequência da diversas combinações entre os parâmetros considerados do absorvedor, e dada a condição não linear do sistema, em uma etapa do projeto optou-se por realizar a otimização de um dos parâmetros do absorvedor através do método dos Algoritmos Genéticos. Como se pôde verificar durante o desenvolvimento do projeto, as curvas analisadas para obtenção da rigidez ótima do absorvedor apresentavam mais de um mínimo local e diferentes comportamentos dada a natureza do problema. Por isso, optou-se por tal método para a busca do mínimo global.

\subsubsection{Absorvedor tipo snap-through truss (STTA)}

Um dos vários modelos sugeridos na literatura como absorvedor não linear trata do absorvedor tipo snap-through truss (STTA). Esse tipo de dispositivo permite o uso da não linearidade geométrica contida nele, a fim de superar todas aquelas dificuldades encontradas junto ao absorvedor linear. No presente trabalho, utiliza-se um absorvedor baseado na geometria do STTA, com intuito de também explorar a não linearidade geométrica, mas que não é essencialmente um STTA. Para tanto, faz-se aqui uma revisão dos últimos trabalhos acerca do STTA.

A aplicação da estrutura snap-through truss como absorvedor (STTA) no controle das vibrações longitudinais de um sistema vibratório, em que a energia de oscilação do sistema principal é transferida ao STTA, vem sendo estudada nos últimos anos. O emprego dessa estrutura também pode ser visto dentre os isoladores não lineares, como revisado por Ibrahim (2008).

Em publicações mais recentes, uma análise da supressão das oscilações de um sistema livre e ideal (Fig. 1.3) foi feita por Avramov e Mikhlin (2004a). Nesse trabalho, estudaram a dinâmica do sistema através da aproximação por modos normais não lineares (NNM), tendo como principais conclusões que a absorção de vibrações ocorre quando o STTA desempenha grandes amplitudes, enquanto o sistema elástico tem pequenas amplitudes. Segundo os autores, o sistema sem amortecimento foi considerado por se entender que, ao verificar a absorção de vibração, o amortecimento somente melhoraria esses resultados.

Mais tarde, Avramov e Mikhlin (2004b) e Avramov e Mikhlin (2006) estudaram o sistema forçado com o STTA acoplado (Fig. 1.4). No primeiro desses trabalhos, a análise do sistema foi feita utilizando o método de múltiplas escalas. No trabalho seguinte, um modelo sem amortecimento foi considerado para análise analítica, feita através dos modos normais não lineares (NNM) e da aproximação de Rauscher. Já para as simulações numéricas, o modelo com amortecimento foi considerado.

Além disso, em recente trabalho, Avramov e Gendelman (2009), analisaram a in- 


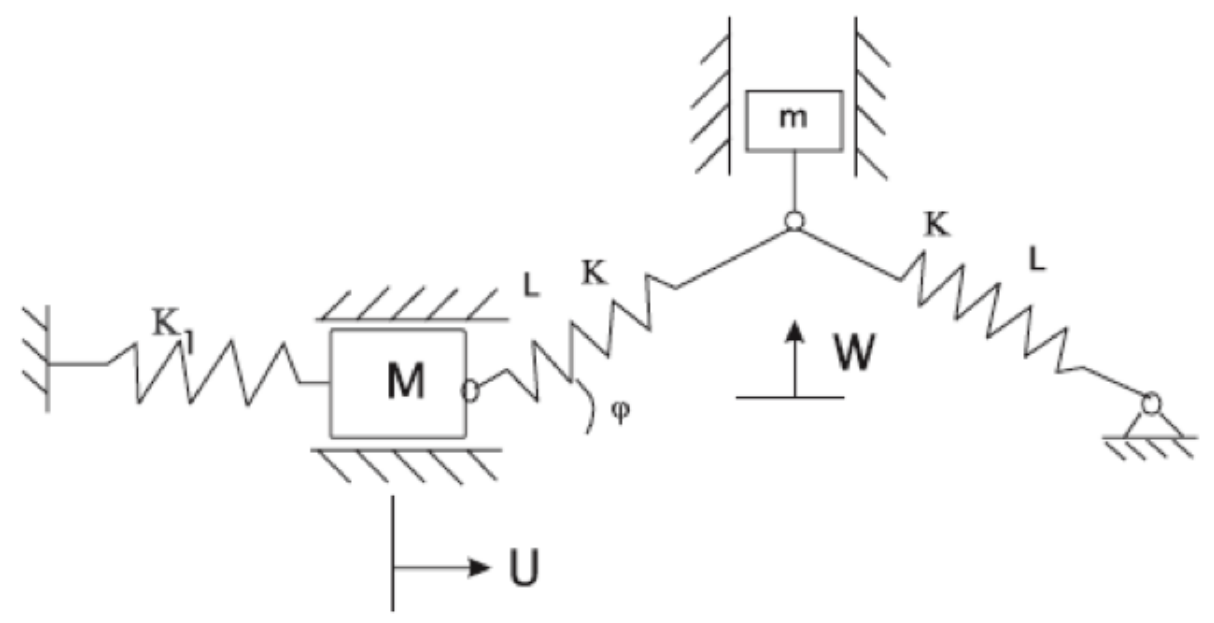

Figura 1.3: Modelo estudado por Avramov e Mikhlin (2004a)

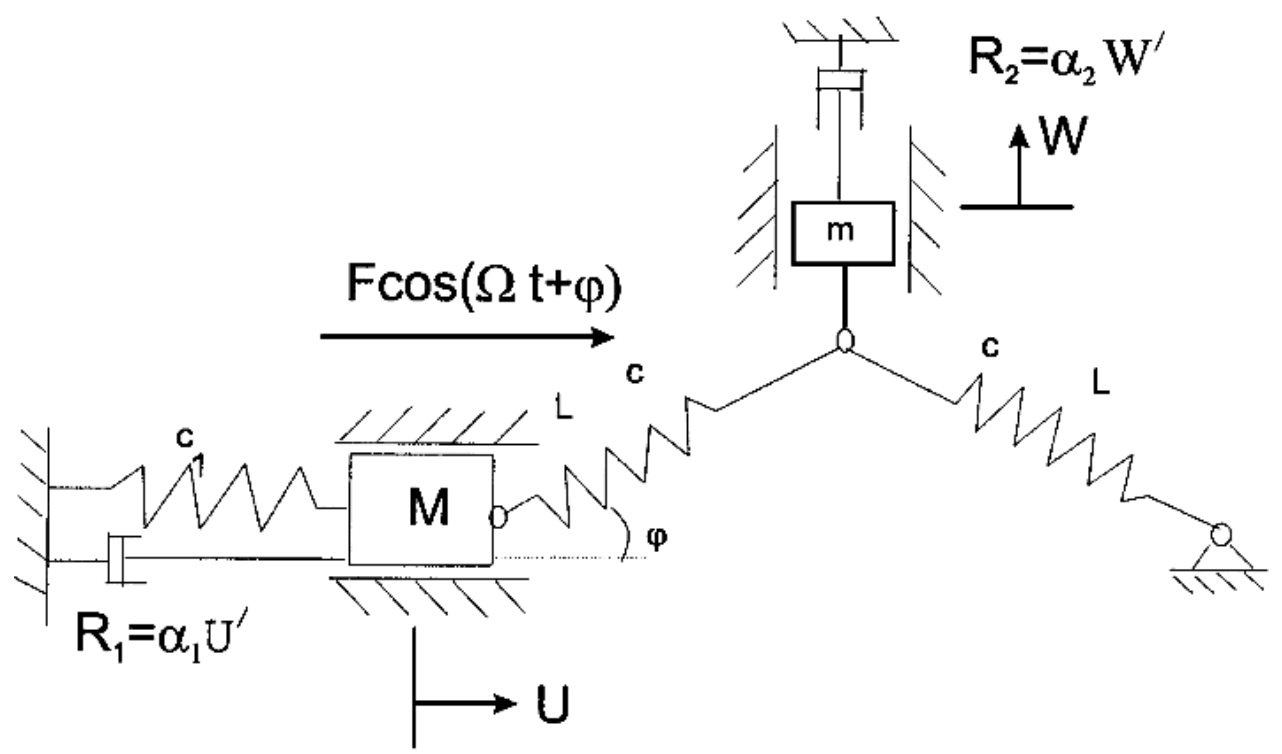

Figura 1.4: Modelo estudado por Avramov e Mikhlin (2004b)

teração entre o STTA e um sistema elástico, concluindo que no sistema de equações modulares, os pontos de equilíbrio são quase sempre instáveis. Quando apresenta estabilidade, os movimentos periódicos estáveis do STTA correspondem às vibrações quase periódicas do sistema mecânico principal, representado por um oscilador linear. Também em prévio trabalho, Felix e Balthazar (2009) realizaram o estudo das vibrações de um sistema não ideal com acoplamento do STTA, Fig. 1.5, verificando a eficiência do absorvedor na redução das amplitudes de vibração durante a ressonância do sistema principal. Concluiu-se também que dois pontos de equilíbrio do sistema dependem do ângulo que define a posição de equilíbrio estável do STTA.

Dentre os últimos trabalhos feitos sobre a atenuação de vibraç̃oes utilizando o STTA estão Godoy et al. (2012) e Godoy et al. (2013). Contudo, em todos esses trabalhos anteriores, o deslocamento horizontal não foi considerado como um grau de 


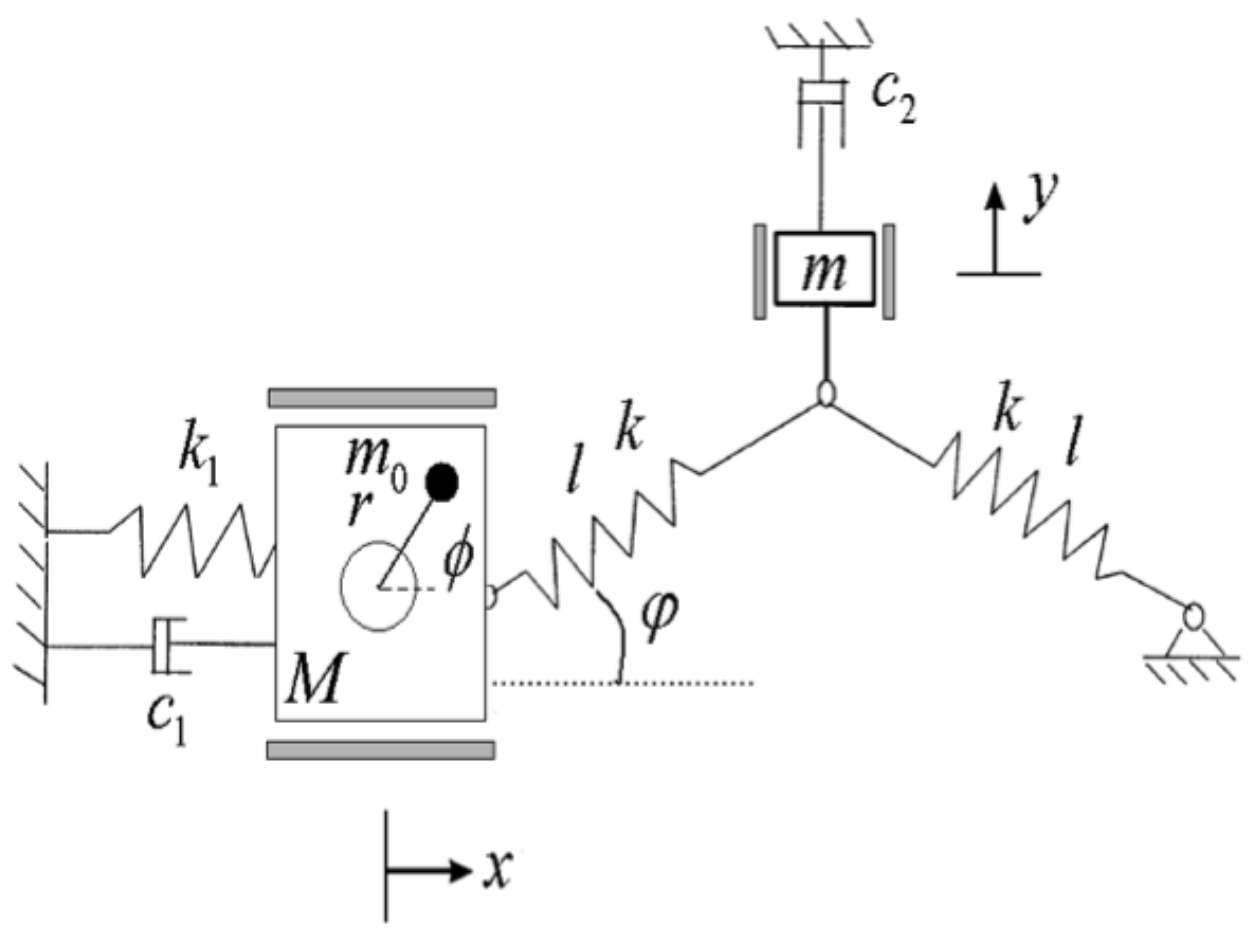

Figura 1.5: Estrutura não ideal com STTA acoplado proposta por Felix e Balthazar (2009)

liberdade adicional ao absorvedor. Considerar este outro grau de liberdade permitiu que ambos, o absorvedor linear e o não linear, fossem estudados em um mesmo modelo, como será mostrado a seguir. Além disso, neste trabalho é mostrado que, sem desempenhar o movimento de snap, o absorvedor não linear pode ser efetivo na redução das amplitudes de vibração do sistema principal e ainda trabalhar em uma faixa de frequência mais ampla. 


\subsection{Objetivos}

De acordo com os temas levantados na introdução e principalmente na revisão bibliográfica constatou-se que havia espaço para o desenvolvimento, ainda que em estágio teórico neste trabalho, de um absorvedor não linear que englobe elementos estruturais simples para formar a não linearidade, basicamente duas molas e uma massa rígida, ao contrário de uma rigidez não linear induzida por uma mola cúbica ou quadrática. Fora isto, notou-se a necessidade de resultados claros que mostrassem a efetividade do dispositivo numa ampla faixa de frequência, bem como o comportamento resultante deste acoplamento ao longo dessa faixa. Percebeu-se também que apesar de o uso de técnicas de otimização não ser tão difundido nesse tipo de estudo, com a estrutura computacional adequada seria viável servir-se de um método de otimização para ultrapassar as dificuldades impostas pelo problema estudado. Assim, dado o contexto no qual o trabalho está inserido e as lacunas a serem preenchidas, consideraram-se dois conjuntos de objetivos, um a respeito da tese apresentada e outro sobre o dispositivo, e explana-se a seguir sobre as metas almejadas em ambos os casos.

O desenvolvimento do dispositivo tem como meta essencial promover a ampliação da faixa de frequência de efetiva redução das amplitudes de vibração, sendo esta a primeira barreira a ser superada em relação ao absorvedor linear. É fundamental que a redução da amplitude de vibração na frequência de ressonância seja a maior possível, porém é ideal que o alargamento da faixa de supressão, ou uma possível redução dos picos de ressonância resultantes, não produza o aumento das amplitudes na antirressonância. Em outro objetivo espera-se conseguir superar as dificuldades que podem se apresentar em relação aos múltiplos pontos de equilíbrio. Com essas metas, pretende-se criar um dispositivo capaz de atuar em sistemas mais complexos, onde o sistema com absorvedor não alcançará amplitudes excessivas semelhantes àquelas encontradas na ressonância do sistema primário sem absorvedor.

Em resumo, os objetivos específicos deste trabalhos são os seguintes: demonstrar a capacidade do absorvedor de atenuar as amplitudes de vibração na frequência desejada, sendo neste caso a frequência de ressonância na qual o sistema é excitado; deixar evidente o desempenho do absorvedor ao longo de uma gama satisfatória de frequências; mostrar que o absorvedor é versátil em sua configuração, permitindo mais de uma solução a ser empregada; discutir sobre suas dificuldades e restrições de funcionamento; e tentar sintetizar a melhor forma para configurar o dispositivo, uma vez que esse processo não é tão simples quanto no caso linear.

\subsection{Organização do trabalho}

A seguir descreve-se brevemente a organização desse trabalho através de seus capítulos. É um texto destinado a fornecer ao leitor informações breves para que este 
possa encontrar o conteúdo que deseja ao longo do trabalho escrito. Portanto, este documento está organizado da seguinte maneira:

Capítulo 1: Introdução - Apresenta o assunto estudado de modo sucinto, enquadrando o trabalho dentro do seu campo de estudo, descreve sua importância e contribuição para o campo de absorvedores não lineares. Citam-se também as principais ferramentas empregadas durante o projeto e qual a referência adotada para comparação de desempenho. Há ainda uma seção que situa o leitor ao longo dos principais trabalhos publicados sobre os temas que foram relevantes à realização do estudo, como os absorvedores dinâmicos de vibração, absorvedor do tipo snap-through truss, formas de otimização e otimização por algoritmo genético. Por fim, há uma seção que descreve os principais objetivos e esta referente à organização do trabalho escrito;

Capítulo 2: Modelo base para estudo - A descrição, equacionamento e discussão sobre o modelo do absorvedor não linear são feitos neste capítulo. Também está colocada a maneira como o amortecimento do dispositivo será implementado em algumas etapas desse trabalho;

Capítulo 3: Estudo Preliminar - Esta parte do texto discute sobre como retirar do sistema não linear as informações de interesse para análise do mesmo. Também analisa-se esse sistema quanto a seus pontos críticos e estabilidade. Em seguida, apresenta-se o procedimento para encontrar o valor ótimo da rigidez das molas do absorvedor e por último, exibem-se os primeiros resultados e discussões que propiciaram a continuação do trabalho;

Capítulo 4: Otimização por busca extensiva - Discute-se sobre o método utilizado para otimizar a rigidez do dispositivo e apresenta-se o procedimento seguido para obtenção dos resultados mostrados nesse capítulo. Há ainda uma seção que trata dos critérios de análise empregados para avaliar o desempenho do dispositivo;

Capítulo 5: Otimização por Algoritmo Genético - Esse capítulo explana sobre as razões em empregar a otimização por algoritmo genético, suas dificuldades e conveniências. Um terceiro critério de avaliação é adicionado e discutido em uma de suas seções e por último apresentam-se os resultados obtidos com a utilização do procedimento adotado;

Capítulo 6: Conclusões e trabalhos futuros - Este capítulo trará as conclusões que podem ser retiradas acerca da implementação do absorvedor não linear como dispositivo de atenuação das amplitudes de vibração de um sistema principal. Também são discutidos os futuros trabalhos que podem ser executados a partir das conclusões conseguidas nessa etapa e listam-se as publicações derivadas desta tese. 


\section{Capítulo 2}

\section{Modelo base para estudo}

Este capítulo apresenta o modelo que foi usado como base para os estudos realizados. O principal interesse neste trabalho é desenvolver um novo absorvedor de vibração que possa atender às necessidades de projeto e superar as dificuldades citadas anteriormente. Para isso, adotou-se um modelo de absorvedor não linear que pode ser construído com elementos de fácil obtenção, no qual a não linearidade é dada pela geometria, ao contrário da introdução de uma não linearidade matemática ao modelo.

\subsection{Descrição do sistema}

O trabalho atual se diferencia dos recentes que adotaram o STTA (GODOY et al., 2012); (GODOY et al., 2013) por alguns aspectos. O primeiro, pode ser observado na Fig. 2.1, na qual a massa $m_{s}$ tem um grau de liberdade a mais, agora podendo se mover vertical e horizontalmente $\left(v_{s}, u_{s}\right)$. O segundo trata do movimento oscilatório do absorvedor e poderá ser observado no Capítulo 3, quando será discutido que aparentemente é mais vantajoso que o absorvedor não desempenhe o movimento de snap quando oscila verticalmente, o que faz com que ele não passe pelo ponto de origem do eixo vertical.

A Fig. 2.1 mostra o sistema primário de um grau de liberdade (1-GDL), dado pela massa $m_{p}$, a mola de rigidez linear $k_{p}$ e o amortecimento viscoso $c_{p}$. Sobre o sistema primário (PS) atua uma força harmônica de amplitude $f$ e frequência $\omega$. Todos os elementos apresentados no texto que contém o subíndice $p$ indicam que estes se referem ao sistema primário. O absorvedor não linear acoplado ao PS configura-se por uma massa $m_{s}$ e duas molas de rigidez linear $\left(k_{1 s}\right.$ e $\left.k_{2 s}\right)$, as quais têm a mesma denominação somente quando ambas tem o mesmo valor, ou seja, $k_{1 s}=k_{2 s}=k_{s}$. Assim como no PS, o subíndice $s$ indica que certo componente se refere ao sistema secundário ou absorvedor não linear (non linear absorber, NLAbs). $L_{0}$ é o comprimento indeformado das molas ligadas ao absorvedor e $L$ é o comprimento destas molas quando as massas estão na posição original $\left(u_{p}=u_{s}=v_{s}=0\right)$. 


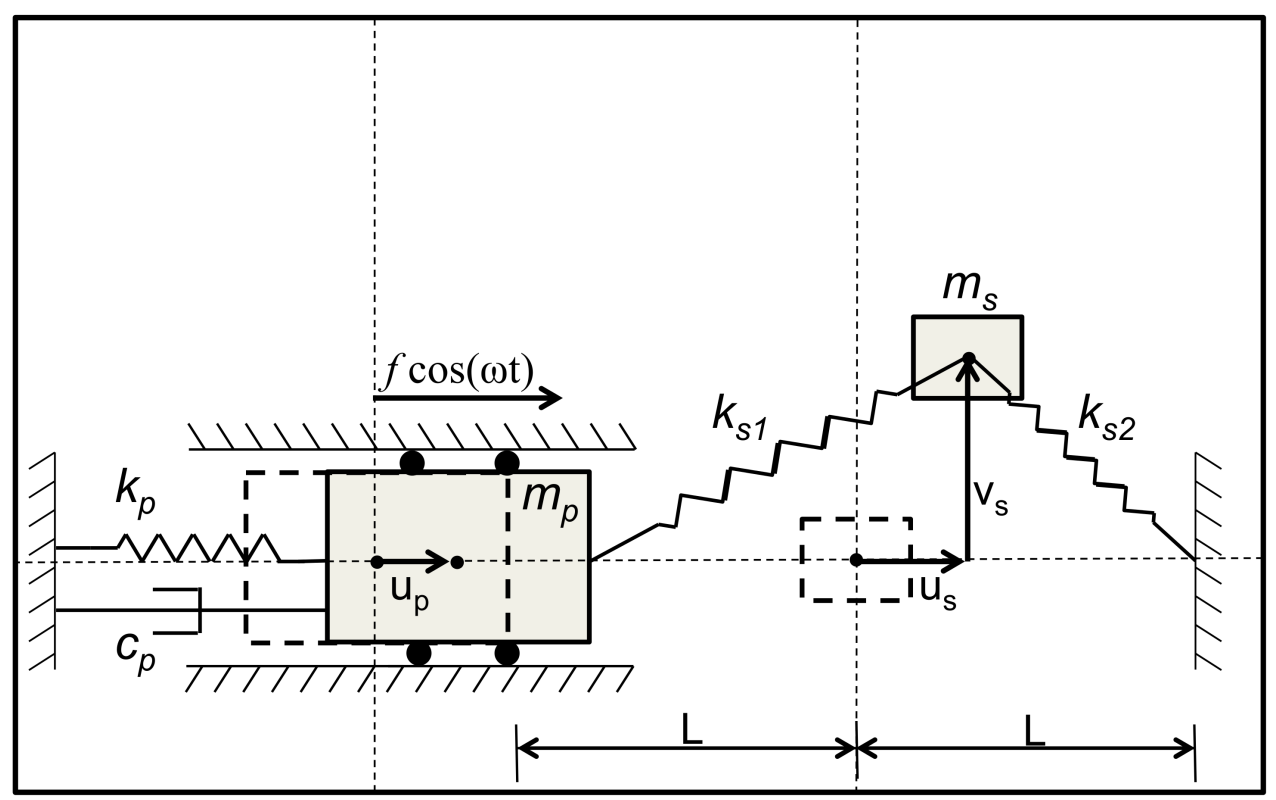

Figura 2.1: Representação do absorvedor não linear acoplado ao sistema principal

\subsection{Equações de movimento}

A representação matemática do modelo estudado é feita por um sistema de equações diferenciais, obtido através das Equações de Lagrange e utilizando como coordenadas generalizadas: o deslocamento, $u_{p}$, do sistema primário (PS) e os deslocamentos horizontal, $u_{s}$, e vertical, $v_{s}$, do absorvedor (NLAbs). As Equações de Lagrange podem ser escritas da seguinte forma:

$$
\frac{d}{d t}\left(\frac{\partial T}{\partial \dot{q}_{i}}\right)-\frac{\partial T}{\partial q_{i}}+\frac{\partial V}{\partial q_{i}}=N_{i}
$$

em que $T$ e $V$ representam, respectivamente, energia cinética e energia potencial do sistema. $N_{i}$ são as forças não conservativas generalizadas atuantes no sistema e $q_{i}$ são as coordenadas generalizadas consideradas, sendo $q_{1}=u_{p}, q_{2}=u_{s}$ e $q_{3}=v_{s}$.

A parcela de energia potencial referente à mola que conecta os dois corpos é calculada da seguinte maneira: uma vez que a energia potencial elástica é dada pela metade do produto entre a constante elástica e o quadrado da variação de comprimento da mola, em relação ao comprimento indeformado, $(1 / 2) k x^{2}$, deve-se escrever esta quantidade $x$ em função das coordenadas generalizadas consideradas. Conforme pode ser observado na Fig. 2.1, a componente horizontal do comprimento deformado da mola $k_{s 1}$ pode ser dado por $u_{s}-u_{p}+L$ enquanto que a sua componente vertical é dada por $v_{s}$. Assim, o tamanho da mola $k_{s 1}$ quando deformada pode ser escrito como $\sqrt{\left(u_{s}-u_{p}+L\right)^{2}+v_{s}^{2}}$. A partir disto, a variação de comprimento da mola $k_{s 1}$, 
em relação ao seu comprimento indeformado, $L_{0}$, é dado por

$$
x_{s 1}=\sqrt{\left(u_{s}-u_{p}+L\right)^{2}+v_{s}^{2}}-L_{0}
$$

De modo análogo a deformação da mola contida entre $m_{s}$ e a extremidade fixa pode ser calculada considerando que a parcela horizontal é influenciada apenas por $u_{s}$, que resulta em:

$$
x_{s 2}=\sqrt{\left(-u_{s}+L\right)^{2}+v_{s}^{2}}-L_{0}
$$

Desse modo, as energias cinética e potencial do sistema são dadas por:

$$
\begin{gathered}
T=\frac{m_{p} \dot{u}_{p}^{2}}{2}+\frac{m_{s}\left(\dot{u}_{s}^{2}+\dot{v}_{s}^{2}\right)}{2} \\
V=\frac{k_{p} u_{p}^{2}}{2}+\frac{k_{s 1}}{2}\left(\sqrt{\left(u_{s}-u_{p}+L\right)^{2}+\left(v_{s}\right)^{2}}-L_{0}\right)^{2}+\frac{k_{s 2}}{2}\left(\sqrt{\left(-u_{s}+L\right)^{2}+\left(v_{s}\right)^{2}}-L_{0}\right)^{2}
\end{gathered}
$$

Além dos termos conservativos dados pelas Eqs. (2.4) e (2.5), a força harmônica externa aplicada sobre o sistema primário e a força de amortecimento viscoso linear, a qual é proporcional a velocidade do PS pela constante $c_{p}$, são termos não conservativos das Equações de Lagrange dados por:

$$
N_{1}=f \cos (\omega t)-c_{p} \dot{u}_{p}
$$

Portanto, as equações do sistema são escritas como:

$$
\begin{aligned}
& m_{p} \ddot{u}_{p}+c_{p} \dot{u}_{p}+k_{p} u_{p}+\frac{k_{s 1}\left(u_{p}-u_{s}-L\right)\left(\sqrt{\left(u_{s}-u_{p}+L\right)^{2}+v_{s}^{2}}-L_{0}\right)}{\sqrt{\left(u_{s}-u_{p}+L\right)^{2}+v_{s}^{2}}}=f \cos (\omega t) \\
& m_{s} \ddot{u}_{s}+\frac{k_{s 1}\left(u_{s}-u_{p}-L\right)\left(\sqrt{\left(u_{s}-u_{p}+L\right)^{2}+v_{s}^{2}}-L_{0}\right)}{\sqrt{\left(u_{s}-u_{p}+L\right)^{2}+v_{s}^{2}}}+ \\
& +\frac{k_{s 2}\left(u_{s}-L\right)\left(\sqrt{\left(-u_{s}+L\right)^{2}+v_{s}^{2}}-L_{0}\right)}{\sqrt{\left(-u_{s}+L\right)^{2}+v_{s}^{2}}}=0 \\
& m_{s} \ddot{v}_{s}+\frac{k_{s 1} v_{s}\left(\sqrt{\left(u_{s}-u_{p}+L\right)^{2}+v_{s}^{2}}-L_{0}\right)}{\sqrt{\left(u_{s}-u_{p}+L\right)^{2}+v_{s}^{2}}}+\frac{k_{s 2} v_{s}\left(\sqrt{\left(-u_{s}+L\right)^{2}+v_{s}^{2}}-L_{0}\right)}{\sqrt{\left(-u_{s}+L\right)^{2}+v_{s}^{2}}}=0
\end{aligned}
$$

Neste ponto é possível perceber que o sistema acima pode ser reduzido a um sistema formado por um absorvedor linear (linear absorber, LAbs) acoplado ao PS. Para 
isso, basta que o absorvedor se mova apenas na direção de $u_{s}$, então $v_{s}=0$ ao longo de todo tempo. Essa condição pode ser alcançada desde que a posição vertical inicial de $m_{s}$ seja $v_{s}=0$. O absorvedor linear mencionado se refere ao TVA mencionado no capítulo anterior e uma nomenclatura diferente é usada apenas para facilitar o entendimento ao longo do texto.

\subsection{Discussão acerca dos pontos críticos e sua estabilidade}

Esta seção tem o objetivo de obter e discutir sobre os pontos de equilíbrio do sistema (2.7). Para isso, reescreve-se o atual sistema em um de seis equações de primeira ordem. Seis novas variáveis são introduzidas da seguinte maneira: $x_{1}=u_{p}, x_{2}=\dot{u}_{p}$, $x_{3}=u_{s}, x_{4}=\dot{u}_{s}, x_{5}=v_{s}, x_{6}=\dot{v}_{s}$. A partir disto, o sistema (2.7) é escrito como:

$$
\begin{aligned}
& \dot{x}_{1}=x_{2} \\
& \dot{x}_{2}=\frac{1}{m_{p}}\left[-c_{p} x_{2}-k_{p} x_{1}-\frac{k_{s 1}\left(x_{1}-x_{3}-L\right)\left(\sqrt{\left(x_{3}-x_{1}+L\right)^{2}+x_{5}^{2}}-L_{0}\right)}{\sqrt{\left(x_{3}-x_{1}+L\right)^{2}+x_{5}^{2}}}+f \cos (\omega t)\right] \\
& \dot{x}_{3}=x_{4} \\
& \dot{x}_{4}=\frac{1}{m_{s}}\left[-\frac{k_{s 1}\left(x_{3}-x_{1}-L\right)\left(\sqrt{\left(x_{3}-x_{1}+L\right)^{2}+x_{5}^{2}}-L_{0}\right)}{\sqrt{\left(x_{3}-x_{1}+L\right)^{2}+x_{5}^{2}}}-\right. \\
& \left.\dot{x}_{5}=x_{6}-\frac{k_{s 2}\left(x_{3}-L\right)\left(\sqrt{\left(-x_{3}+L\right)^{2}+x_{5}^{2}}-L_{0}\right)}{\sqrt{\left(-x_{3}+L\right)^{2}+x_{5}^{2}}}\right] \\
& \dot{x}_{6}=\frac{1}{m_{s}}\left[-\frac{k_{s 1} x_{5}\left(\sqrt{\left(x_{3}-x_{1}+L\right)^{2}+x_{5}^{2}}-L_{0}\right)}{\sqrt{\left(x_{3}-x_{1}+L\right)^{2}+x_{5}^{2}}}-\frac{k_{s 2} x_{5}\left(\sqrt{\left(-x_{3}+L\right)^{2}+x_{5}^{2}}-L_{0}\right)}{\sqrt{\left(-x_{3}+L\right)^{2}+x_{5}^{2}}}\right]
\end{aligned}
$$

Para encontrar os pontos de equilíbrio em (2.8), basta que $\dot{x}_{1}=\dot{x}_{2}=\dot{x}_{3}=\dot{x}_{4}=\dot{x}_{5}=$ $\dot{x}_{6}=0$. A partir desse ponto, um sistema com três incógnitas é alcançado, porém o número elevado de parâmetros no sistema não permite que se obtenha relações matemáticas simples para $x_{1}, x_{3}$ e $x_{5}$, sem que alguns valores de parâmetros sejam introduzidos no sistema. Antes de inserir alguns valores, uma análise permite ver que os parâmetros que interferem diretamente na geometria do problema são $L$ e $L_{0}$. Como a posição dos pontos de equilíbrio será determinada pela relação de $L$ e $L_{0}$, mantém-se um valor fixo de $L$ e faz-se a variação $L_{0}$. Para isso utilizou-se a tabela de valores 2.1 e realizou-se a análise desejada.

Com o auxílio do $M A T L A B \circledR$, realizou-se a manipulação simbólica do sistema 
Tabela 2.1: Valores do parâmetros do sistema utilizados para análise de estabilidade.

\begin{tabular}{|c|c|c|}
\hline Parâmetro & Símbolo & Valor \\
\hline Massa Primária (kg) & $m_{p}$ & 60 \\
\hline Massa do absorvedor (kg) & $m_{p}$ & 6 \\
\hline Coeficiente de rigidez primário (N/m) & $k_{p}$ & $10^{6}$ \\
\hline Coeficiente de rigidez do absorvedor $(\mathrm{N} / \mathrm{m})$ & $k_{s 1}, k_{s 2}$ & $4,158 \times 10^{5} ; 4,158 \times 10^{5}$ \\
\hline Coeficiente de amortecimento (N.s/m) & $c_{p}$ & 0 \\
\hline Amplitude da força (N) & $f$ & 0 \\
\hline Comprimento da mola comprimida $(\mathrm{m})$ & $L$ & 0,15 \\
\hline
\end{tabular}

resultante e o seguinte conjunto de soluções foi obtido:

$$
\left[\begin{array}{cccc}
\text { Soluo } & x_{1}(m) & x_{3}(m) & x_{5}(m) \\
1 & \frac{1239}{24130}-\frac{826 L_{0}}{2413} & \frac{1239}{48260}-\frac{413 L_{0}}{2413} & 0 \\
2 & 0 & 0 & 1 / 2 \sqrt{\frac{\left(20 L_{0}-3\right)\left(20 L_{0}+3\right)}{100}} \\
3 & 0 & 0 & -1 / 2 \sqrt{\frac{\left(20 L_{0}-3\right)\left(20 L_{0}+3\right)}{100}} \\
4 & \frac{1239}{24130} & L_{0}+\frac{1239}{48260} & 0 \\
5 & \frac{1239}{24130} & \frac{1239}{42860}-L_{0} & 0 \\
6 & \frac{826 L_{0}}{2413}+\frac{1239}{24130} & \frac{413 L_{0}}{2413}+\frac{1239}{48260} & 0
\end{array}\right]
$$

Antes de tentarmos entender a relação de $L_{0}$ e a posição dos pontos de equilíbrio, é realizada uma breve análise sobre os seis conjuntos de pontos obtidos, com propósito de destacar quais são pertinentes e quais não estão de acordo com o sistema real. Com esse objetivo, considerou-se $L_{0}=0.16 \mathrm{~m}$ no conjunto de soluções (2.9), o que resultou em:

$$
\left[\begin{array}{cccc}
\text { Soluo } & x_{1}(m) & x_{3}(m) & x_{5}(m) \\
1 & -0,0034 & -0,0017 & 0 \\
2 & 0 & 0 & 0,0557 \\
3 & 0 & 0 & -0,0557 \\
4 & 0,0513 & 0,1857 & 0 \\
5 & 0,0513 & -0,1343 & 0 \\
6 & 0,1061 & 0,0531 & 0
\end{array}\right]
$$

Seguindo a ordem em que são apresentadas, classificam-se abaixo as soluções encontradas como válida ou inválida. A representação esquemática dessas soluções é exibida na Fig. 2.2, que está subdividida em dois grupos. À esquerda estão posicionadas as soluções válidas e à direita as inválidas.

Solução 1: Válida. Esta situação é válida, pois as molas ligadas ao absorvedor, $k_{s 1} \mathrm{e}$ $k_{s 2}$, tendem a retornar ao seu tamanho original, deslocando o PS à esquerda. 
Solução 2: Válida. Neste caso, o sistema principal permanece na posição de origem e o absorvedor está deslocado verticalmente, no sentido positivo, de modo a deixar as molas em seu tamanho original.

Solução 3: Válida. O sistema principal permanece na posição de origem e o absorvedor está deslocado verticalmente, no sentido negativo, de modo a deixar as molas em seu tamanho original.

Solução 4: Inválida. O valor de $u_{s}=0.1858 \mathrm{~m}$ indica que o absorvedor está posicionado horizontalmente além dos limites do sistema, passando a superfície à direita onde a mola $k_{s 2}$ está fixada.

Solução 5: Inválida. Os valores de $u_{p}$ e $u_{s}$ indicam que o absorvedor está localizado à esquerda do sistema primário.

Solução 6: Inválida. Embora pareça um caso válido, essa situação indica que o sistema principal posiciona-se à direita de $u_{p}=0$ e mantém as molas do absorvedor mais comprimidas do que estavam na posição inicial. Apesar dos posicionamentos das massas estarem dentro dos limites do sistema, essa opção não é válida fisicamente. Essa condição só seria possível se uma dessas duas situações, que não acontecem aqui, ocorresse: ou com a aplicação de uma força externa para manter $m_{p}$ em $u_{p}=0,1065$ ou com $L_{0}<L$. Ressalta-se que não há força aplicada nesta análise e exemplo, e para $L_{0}$ foi imposto o comprimento de $0,16 \mathrm{~m}$, que é maior que $L=0,15 \mathrm{~m}$.

A partir da matriz de soluções (2.9) representam-se graficamente somente as 3 soluções válidas, de modo a entender como o valor de $L_{0}$ atua sobre os pontos de equilíbrio. A Fig. 2.3 mostra apenas os pontos correspondentes às posições $u_{p}$ e $v_{s}$, pois $u_{s}$ é nulo nas soluções 2 e 3 e na solução 1 seu valor é metade do valor de $u_{p}$ e por isso optou-se por não representá-lo. De acordo com o valor de $L_{0}$, as soluções instáveis são representadas por linhas tracejadas e as estáveis por linhas contínuas.

Quanto as soluções 2 e 3, para $L_{0}<0.15$ há a ocorrência de valores com parte real nula e parte imaginária não nula, sendo estas instáveis, já para $L_{0} \geq 0.15$ essas soluções são reais e estáveis, sendo tais valores dados pela equação 2.11, no qual $L=0.15$. Quanto à solução 1 , para todos os casos ela apresenta valores reais, sendo que para $L_{0}<0.15$ ela é estável e para $L_{0} \geq 0.15$ ela é instável.

$$
v_{S}=\sqrt{L_{0}^{2}-L^{2}}
$$

Para determinar a estabilidade dos pontos, obteve-se a matriz Jacobiana do sistema e a partir dela, com a substituição dos valores de cada solução válida, calcularam-se os valores dos autovalores do sistema. A presença de, no mínimo, um autovalor com 


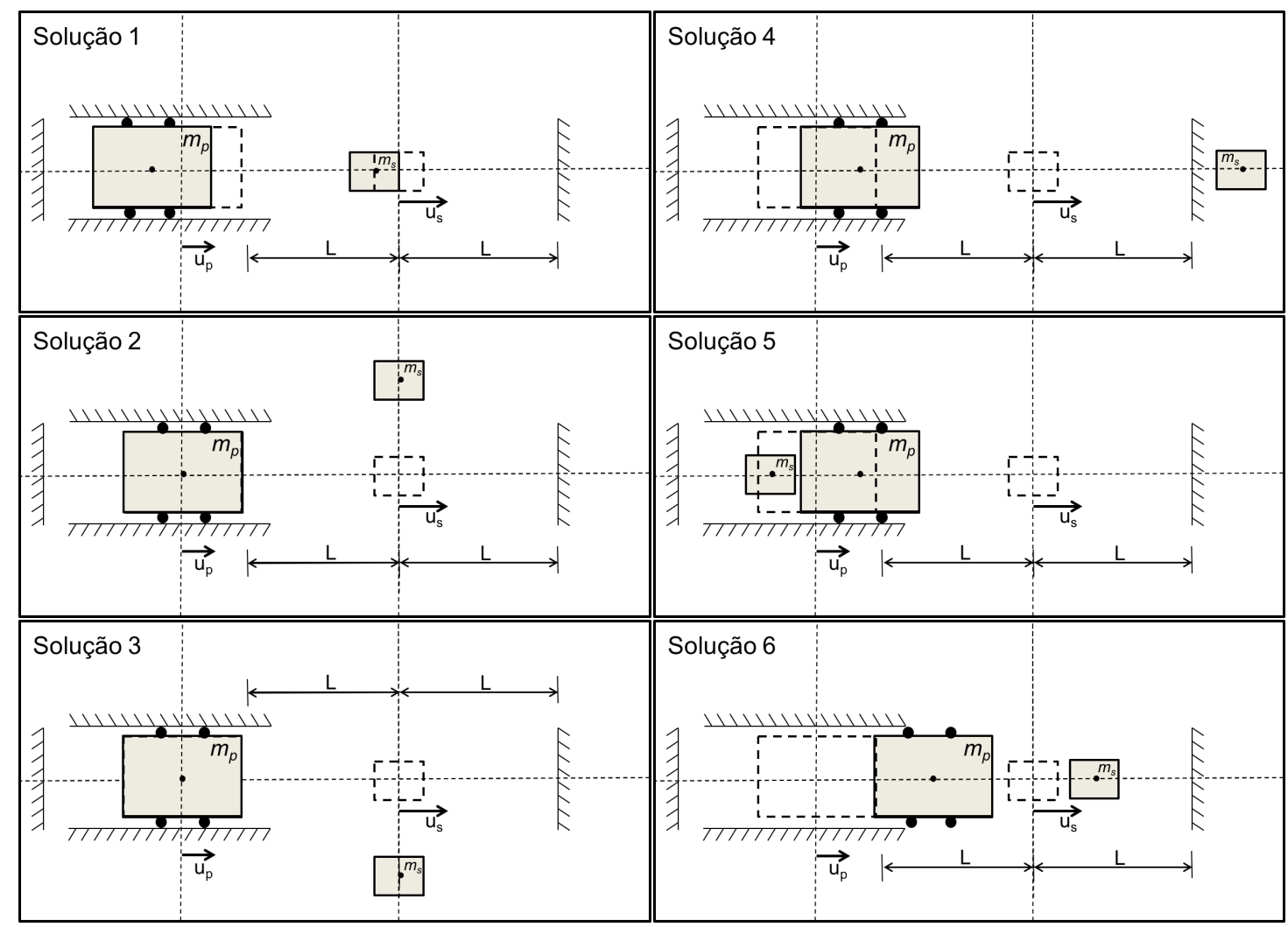

(a) Soluções válidas.

(b) Soluções inválidas.

Figura 2.2: Representação das posições de equilíbrio.

parte real $(\mathbb{R})$ positiva indica um sistema instável e o caso contrário, onde a parte real dos autovalores são todas negativas ou nulas e negativas, indica um sistema estável. Deste modo, foi determinada a estabilidade de cada solução, conforme a Tab. 2.2.

Tabela 2.2: Estabilidade das soluções válidas

\begin{tabular}{|c|c|c|c|}
\hline$L_{0}$ & Solução & Sinais dos Autovalores $(\mathbb{R})$ & Estabilidade \\
\hline \multirow{3}{*}{$L_{0} \geq 0.15$} & 1 & 1 positivo e 2 negativos & instável \\
\cline { 2 - 4 } & 2 & 3 negativos & estável \\
\cline { 2 - 4 } & 3 & 3 negativos & estável \\
\hline \multirow{3}{*}{$L_{0}<0.15$} & 1 & 3 negativos & estável \\
\cline { 2 - 4 } & 2 & 1 positivo e 2 negativos & instável \\
\cline { 2 - 4 } & 3 & 1 positivo e 2 negativos & instável \\
\hline
\end{tabular}

Dentre as soluções que foram descartadas por serem inválidas quando $L_{0}<0,15$ $\mathrm{m}$ há de se mencionar que quando $L_{0}>0,15 \mathrm{~m}$ a solução 6 se torna válida porém é instável. As outras duas restantes, 4 e 5, permanecem inválidas e devem continuar a serem desconsideradas.

As informações apresentadas nesta seção nos orientam a respeito de onde o posicionar o absorvedor no instante inicial, para que se obtenham os resultados desejados futuramente. Inicialmente, acredita-se que o absorvedor deva ser posicionado pró- 


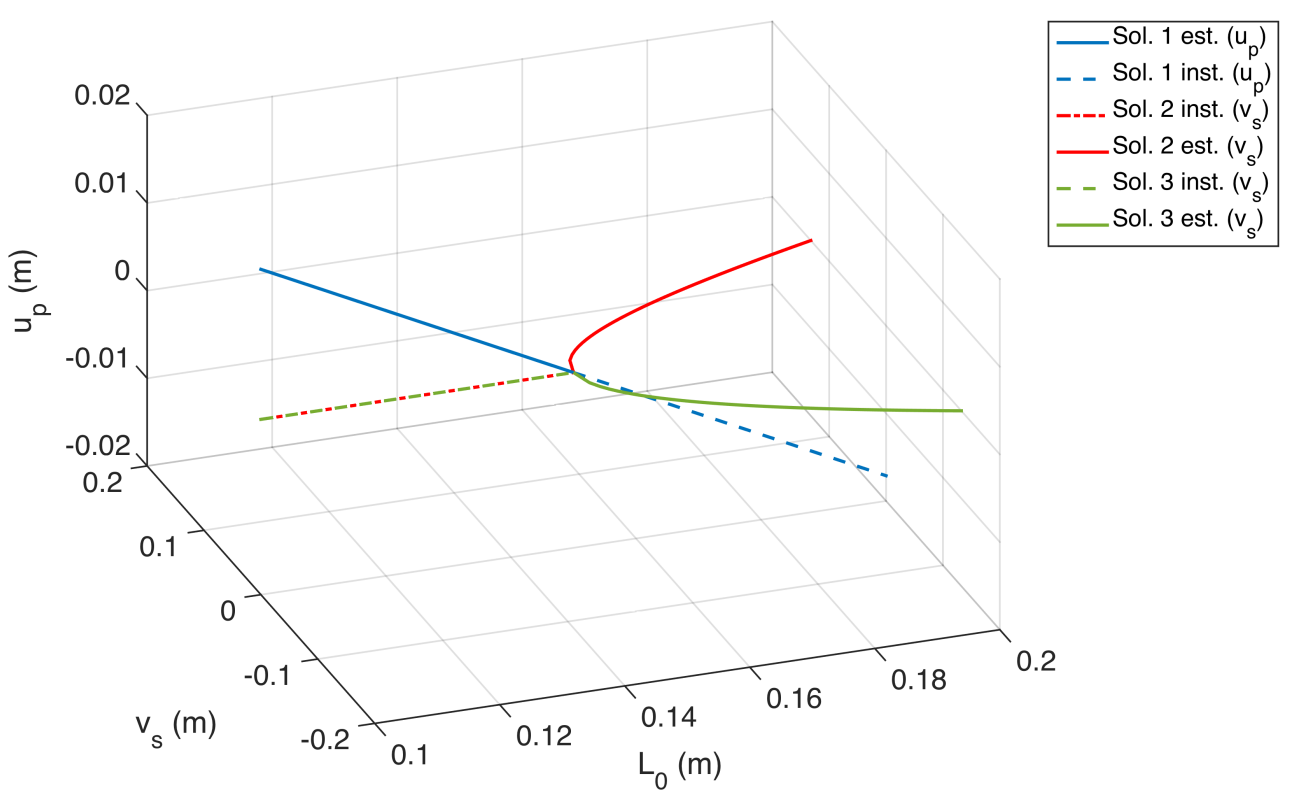

Figura 2.3: Representação dos pontos de equilíbrio em função de $L_{0}$.

ximo a um de seus pontos de equilíbrio estável, para que este vibre em torno de tal posição e esta funcione como um sumidouro de energia.

\subsection{Inclusão de amortecimento equivalente no absorvedor}

A inclusão do amortecimento associado ao absorvedor não linear é abordada nessa subseção. A inclusão no modelo de uma força não conservativa faz parte da aproximação desse modelo a um sistema mais coerente com a realidade.

$\mathrm{O}$ amortecimento associado ao absorvedor pode ser entendido inicialmente como dois amortecedores viscosos em paralelo às duas molas do absorvedor. Incluir esses amortecimentos nas mesmas direções que as molas $k s 1$ e $k_{s 2}$, implicaria a inclusão de outros termos não lineares ao sistema. Diante da possibilidade dessas novas não linearidades dificultarem a análise do sistema proposto, optou-se por incluir esses amortecimentos sob a forma de duas forças equivalentes, uma na direção horizontal e outra na direção vertical, mediante a linearização do sistema em torno de uma das posições de equilíbrio estável, a solução 2.

Assim, ao final, têm-se os coeficientes de amortecimento em cada direção $-c_{s h}$ (horizontal) e $c_{S v}$ (vertical) - equivalentes aos dois amortecedores viscosos em paralelo às molas do absorvedor para movimentos em torno da posição de equilíbrio estável.

Dada a Fig. 2.4, admite-se que as vibrações não alterem os ângulos $\phi$ e $\theta$ significativamente, pois trata-se de um sistema com pequenos deslocamentos. Da Fig. 2.4, nota-se que $\beta=180-(\alpha+\theta)$ e que $W_{s}$ é vetor deslocamento da massa $m_{s}$. Dessa 


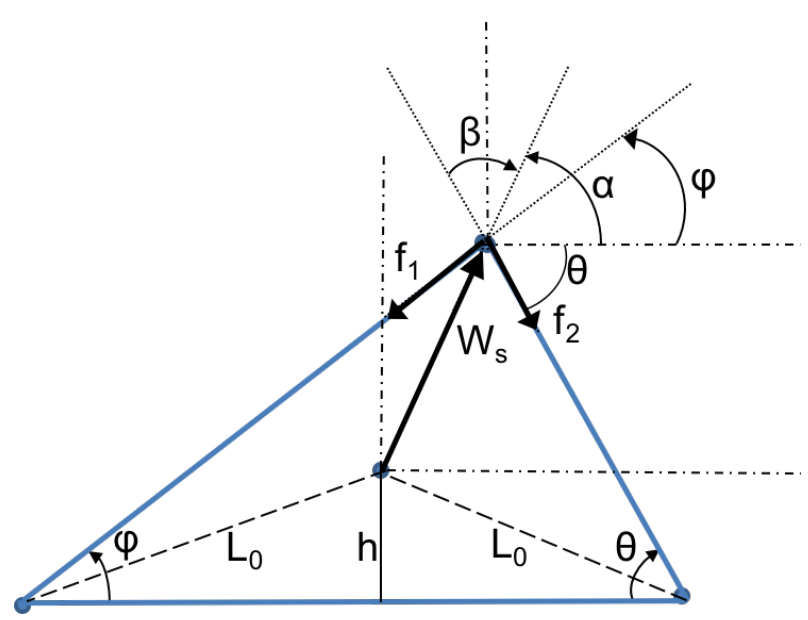

Figura 2.4: Esquema utilizado para linearização do amortecimento

forma, temos que os módulos das forças $f_{1}$ e $f_{2}$ são dados por:

$$
\begin{gathered}
\left\|\vec{f}_{1}\right\|=k_{s 1} W_{1 s}=k_{s 1} W_{s} \cos (\alpha-\phi) \\
\left\|\vec{f}_{2}\right\|=k_{s 2} W_{2 s}=k_{s 2} W_{s} \cos (\beta)=k_{s 2} W_{s} \cos [180-(\alpha+\theta)]=-k_{s 2} W_{s} \cos (\alpha+\theta)
\end{gathered}
$$

nas quais $k_{s 1}=k_{s 2}=k_{s n}$ e $W_{1 s}$ e $W_{2 s}$ são os vetores deslocamento da massa $m_{s}$ nas direções das forças $f_{1}$ e $f_{2}$, respectivamente. E portanto, os vetores $\vec{f}_{1}$ e $\vec{f}_{2}$ são da forma:

$$
\begin{gathered}
\vec{f}_{1}=k_{s n} W_{s} \cos (\alpha-\phi)[\cos (\phi) \vec{i}+\sin (\phi) \vec{j}] \\
\vec{f}_{2}=-k_{s n} W_{s} \cos (\alpha+\theta)[-\cos (\theta) \vec{i}+\sin (\theta) \vec{j}]
\end{gathered}
$$

Uma vez que a força resultante $\vec{F}_{k}$ é formada por $\vec{F}_{k}=\vec{f}_{1}+\vec{f}_{2}$, resulta que suas componentes são obtidas como:

$$
\begin{aligned}
& F_{k x}=\left(\vec{f}_{1}+\vec{f}_{2}\right) \cdot(\vec{i})=k_{s n} W_{s}[\cos (\alpha-\phi) \cos (\phi)+\cos (\alpha+\theta) \cos (\theta)] \\
& F_{k y}=\left(\vec{f}_{1}+\vec{f}_{2}\right) \cdot(\vec{j})=k_{s n} W_{s}[\cos (\alpha-\phi) \sin (\phi)-\cos (\alpha+\theta) \sin (\theta)]
\end{aligned}
$$

Uma vez que foram considerados pequenos deslocamentos em torno da posição de equilíbrio estático que tem $v_{s}$ não nulo, para o qual $\phi=\theta$, temos que:

$$
\left\{\begin{array}{l}
F_{k x}=k_{s n} W_{s} \cos (\theta)[\cos (\alpha-\theta)+\cos (\alpha+\theta)] \\
F_{k y}=k_{s n} W_{s} \sin (\theta)[\cos (\alpha-\theta)-\cos (\alpha+\theta)]
\end{array}\right.
$$


Dados $F_{k x}$ e $F_{k y}$, através das relações trigonométricas (2.19), é possível simplificar o sistema (2.18) e reescrevê-lo como em (2.21).

$$
\begin{gathered}
\cos (\alpha-\theta)=\cos (\alpha) \cos (\theta)+\sin (\alpha) \sin (\theta) \\
\cos (\alpha+\theta)=\cos (\alpha) \cos (\theta)-\sin (\alpha) \sin (\theta) \\
\cos (\alpha-\theta)+\cos (\alpha+\theta)=2 \cos (\alpha) \cos (\theta) \\
\cos (\alpha-\theta)-\cos (\alpha+\theta)=2 \sin (\alpha) \sin (\theta) \\
\begin{cases}F_{k x}= & 2 k_{s n} W_{s} \cos (\theta) \cos (\alpha) \cos (\theta)=2 k_{s n} W_{s} \cos ^{2}(\theta) \cos (\alpha) \\
F_{k y}= & 2 k_{s n} W_{s} \sin (\theta) \sin (\alpha) \sin (\theta)=2 k_{s n} W_{s} \sin ^{2}(\theta) \sin (\alpha)\end{cases}
\end{gathered}
$$

Através do agrupamento dos termos semelhantes, temos:

$$
\left\{\begin{array}{l}
F_{k x}=2 k_{s n} \cos ^{2}(\theta) W_{s x} \\
F_{k y}=2 k_{s n} \sin ^{2}(\theta) W_{s y}
\end{array}\right.
$$

em que $W_{s x}=W_{s} \cos (\alpha)$ e $W_{s y}=W_{s} \sin (\alpha)$. Portanto, se a força elástica é da forma $F=k w$, em que $w$ é a deformação da mola, conclui-se que $k_{s h}=2 k_{s n} \cos ^{2}(\theta)$ e $k_{s v}=$ $2 k_{s n} \sin ^{2}(\theta)$. Logo, a relação entre $k_{s h}, k_{s v}$ e $k_{s n}$ é dada no sistema (2.23).

$$
\left\{\begin{array}{l}
k_{s h}=2 k_{s n} \cos ^{2}(\theta) \\
k_{s v}=2 k_{s n} \sin ^{2}(\theta)
\end{array}\right.
$$

Assim, se o coeficiente de amortecimento equivalente é dado por $c_{e q}=2 \xi \sqrt{k_{e q} m_{e q}}$, no qual $k_{e q}$ consiste no coeficiente de rigidez equivalente e $m_{e q}$ é a massa equivalente do sistema, considera-se $k_{e q}^{x}=k_{s h}, k_{e q}^{y}=k_{s v}, c_{e q}^{x}=c_{s h}, c_{e q}^{y}=c_{s v}$ e $m_{e q}=m_{s}$, o amortecimento equivalente em ambas as direções é dado em (2.24)

$$
\left\{\begin{array}{l}
c_{e q}^{x}=2 \xi \sqrt{k_{e q}^{x} m_{e q}}=2 \xi \sqrt{k_{s h} m_{s}} \\
c_{e q}^{y}=2 \xi \sqrt{k_{e q}^{y} m_{e q}}=2 \xi \sqrt{k_{s v} m_{s}}
\end{array}\right.
$$

Para o sistema (2.24), considerou-se $\xi=0,005$ e observou-se no sistema 2.1 que $\cos (\theta)=$ $\frac{L}{L 0}$ e $\sin (\theta)=\frac{h}{L 0}$, em que $h$ é dado por $h=\sqrt{L_{0}^{2}-L^{2}}$. Portanto, a Eq. (2.25) exibe os amortecimentos empregados no sistema nos capítulos 4 e 5 .

$$
\begin{aligned}
& c_{s h}=0,01 \sqrt{2 k_{s n}\left(L / L_{0}\right)^{2} m_{s}} \\
& c_{s v}=0,01 \sqrt{2 k_{s n}\left(h / L_{0}\right)^{2} m_{s}}
\end{aligned}
$$

Portanto, a partir dos amortecimentos do absorvedor determinados, as novas equações de movimento do sistema são dadas por: 


$$
\begin{aligned}
& m_{p} \ddot{u}_{p}+c_{p} \dot{u}_{p}+k_{p} u_{p}+\frac{k_{s 1}\left(u_{p}-u_{s}-L\right)\left(\sqrt{\left(u_{s}-u_{p}+L\right)^{2}+v_{s}^{2}}-L_{0}\right)}{\sqrt{\left(u_{s}-u_{p}+L\right)^{2}+v_{s}^{2}}}=f \cos (\omega t) \\
& m_{s} \ddot{u}_{s}+c_{s h} \dot{u}_{s}+\frac{k_{s 1}\left(u_{s}-u_{p}-L\right)\left(\sqrt{\left(u_{s}-u_{p}+L\right)^{2}+v_{s}^{2}}-L_{0}\right)}{\sqrt{\left(u_{s}-u_{p}+L\right)^{2}+v_{s}^{2}}}+ \\
& +\frac{k_{s 2}\left(u_{s}-L\right)\left(\sqrt{\left(-u_{s}+L\right)^{2}+v_{s}^{2}}-L_{0}\right)}{\sqrt{\left(-u_{S}+L\right)^{2}+v_{s}^{2}}}=0 \\
& m_{s} \ddot{v}_{s}+c_{s v} \dot{v}_{s}+\frac{k_{s 1} v_{s}\left(\sqrt{\left(u_{s}-u_{p}+L\right)^{2}+v_{s}^{2}}-L_{0}\right)}{\sqrt{\left(u_{s}-u_{p}+L\right)^{2}+v_{s}^{2}}}+\frac{k_{s 2} v_{s}\left(\sqrt{\left(-u_{s}+L\right)^{2}+v_{s}^{2}}-L_{0}\right)}{\sqrt{\left(-u_{s}+L\right)^{2}+v_{s}^{2}}}=0
\end{aligned}
$$

\subsection{Projeto do absorvedor}

Como dito anteriormente, o modelo matemático adotado permite, a partir dele, a simulação de um sistema com um absorvedor linear acoplado. Quando o absorvedor não tem movimento vertical as equações de movimento (2.26) são simplificadas, uma vez que $v_{s}=0$ a terceira equação é identicamente satisfeita. Neste caso, o sistema é reduzido a um linear de dois graus de liberdade (2-GDL) para o qual a frequência de antirressonância da função de resposta em frequência (FRF) medida do deslocamento do sistema primário coincide com a frequência de ressonância do absorvedor sozinho. Portanto, um jeito simples de projetar o absorvedor linear (LAbs) é definindo a massa e rigidez do absorvedor como mostrado por Ormondroyd e Hartog (1928), que afirmaram que o projeto de um absorvedor linear deve definir a frequência natural do absorvedor igual à frequência na qual se quer atenuar as vibrações. Essa afirmação pôde ser provada através das seguintes colocações.

Dado um sistema massa-mola primário, representado por uma massa $M$ e uma mola $K$, sob influência de uma força harmônica $P_{0} \sin \omega t$. A esse sistema tem-se acoplado um absorvedor de massa $m$ e mola $k$, como na figura 2.5. As equações de movimento desse sistema podem ser estabelecidas da seguinte forma:

$$
\left\{\begin{array}{l}
M \ddot{x_{1}}+K x_{1}+k\left(x_{1}-x_{2}\right)=P_{0} \sin \omega t \\
m \ddot{x_{2}}+k\left(x_{2}-x_{1}\right)=0
\end{array}\right.
$$

Como a resposta desse sistema forçado pode ser expressa na forma das equações do sistema (2.28) e as mesmas após duas derivadas no tempo são dadas como em (2.29), pode-se reescrever as equações de movimento substituindo (2.28) e (2.29) em (2.27). Isso resultará num sistema com todos os termos proporcionais a $\sin \omega t$ e a elimina- 


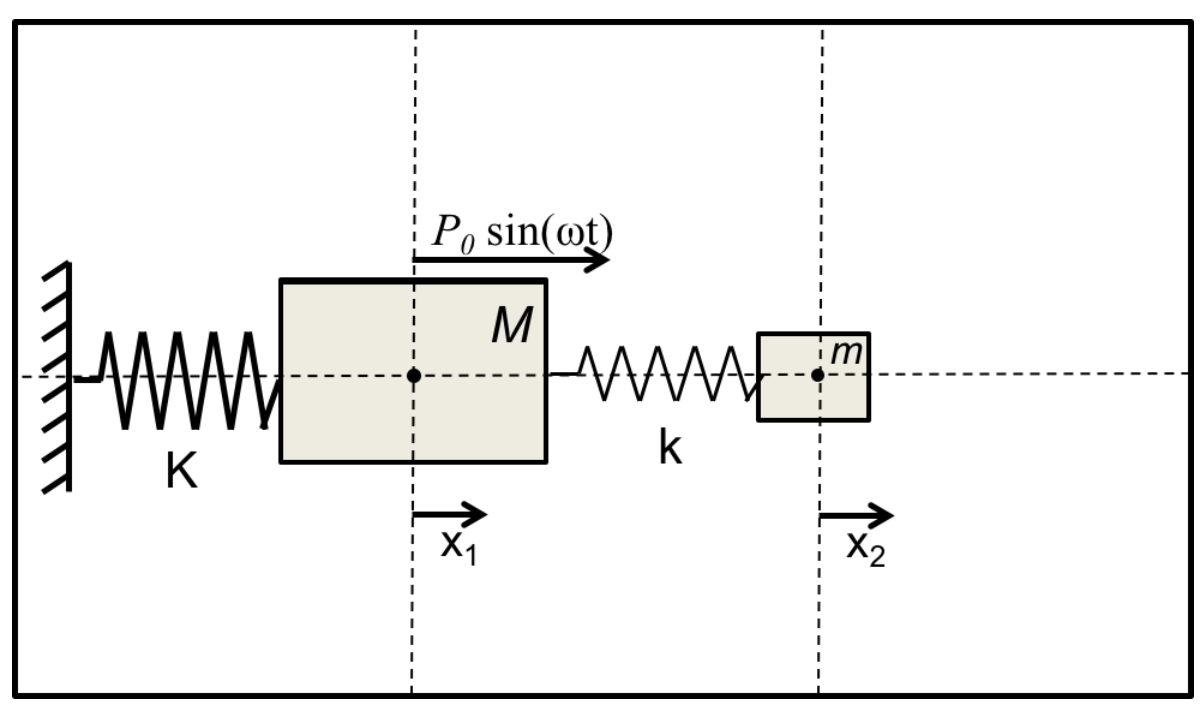

Figura 2.5: Sistema primário sob força harmônica com absorvedor linear acoplado.

ção destes transforma o sistema de equações diferenciais em um sistema equações algébricas.

$$
\begin{gathered}
\left\{\begin{array}{l}
x_{1}=a_{1} \sin \omega t \\
x_{2}=a_{2} \sin \omega t
\end{array}\right. \\
\left\{\begin{array}{l}
\ddot{x}_{1}=-\omega^{2} a_{1} \sin \omega t \\
\ddot{x}_{2}=-\omega^{2} a_{2} \sin \omega t
\end{array}\right.
\end{gathered}
$$

Assim, o sistema resultante é escrito como

$$
\left\{\begin{array}{l}
a_{1}\left(-M \omega^{2}+K+k\right)-k a_{2}=P_{0} \\
-k a_{1}+a_{2}\left(-m \omega^{2}+k\right)=0
\end{array}\right.
$$

Para simplificar, torna-se adimensional o sistema (2.30) através da introdução dos seguintes parâmetros:

$$
\begin{array}{r}
x_{s t}=P_{0} / K \\
\omega_{a}^{2}=k / m \\
\Omega_{n}^{2}=K / M \\
\mu=m / M
\end{array}
$$

onde $x_{s t}$ é a deflexão estática do sistema primário, $\omega_{a}^{2}$ é a frequência natural do absorvedor ao quadrado, $\Omega_{n}^{2}$ é a frequência natural do sistema primário ao quadrado e $m / M$ é a razão das massas. Portanto, a Eq. (2.30) se torna

$$
\left\{\begin{array}{l}
a_{1}\left(1+\frac{k}{K}-\frac{\omega^{2}}{\Omega_{n}^{2}}\right)-a_{2} \frac{k}{K}=x_{s t} \\
a_{1}=a_{2}\left(1-\frac{\omega^{2}}{\omega_{a}^{2}}\right)
\end{array}\right.
$$


E resolvendo para $a_{1}$ e $a_{2}$ têm-se que

$$
\left\{\begin{array}{l}
\frac{a_{1}}{x_{s t}}=\frac{1-\frac{\omega^{2}}{\omega_{a}^{2}}}{\left(1-\frac{\omega^{2}}{\omega_{a}^{2}}\right)\left(1+\frac{k}{K}-\frac{\omega^{2}}{\Omega_{n}^{2}}\right)-\frac{k}{K}} \\
\frac{a_{2}}{x_{s t}}=\frac{1}{\left(1-\frac{\omega^{2}}{\omega_{a}^{2}}\right)\left(1+\frac{k}{K}-\frac{\omega^{2}}{\Omega_{n}^{2}}\right)-\frac{k}{K}}
\end{array}\right.
$$

Assim, da solução de $a_{1}$ em (2.33) pode-se ver o fundamento para a afirmação de Ormondroyd e Hartog (1928). A amplitude $a_{1}$ da massa primária é zero quando o numerador $1-\frac{\omega^{2}}{\omega_{a}^{2}}$ é igual a zero. Esta situação acontece quando a frequência da força de excitação é igual à frequência natural do absorvedor.

Portanto, como o absorvedor linear adotado neste estudo contém duas molas, $k_{s 1}$ e $k_{s 2}$, e o sistema primário é excitado em sua frequência natural, $\omega=\omega_{p}$, o projeto do absorvedor linear pode ser definido como

$$
w_{p}=w_{s}=\sqrt{\frac{k_{s 1}+k_{s 2}}{m_{s}}} \Longrightarrow k_{s 1}+k_{s 2}=m_{s} w_{p}^{2}
$$

Contudo, ao contrário dos LAbs, a síntese e projeto do NLAbs não é tão direta. Dessa forma, por causa do seu comportamento, muitas vezes imprevisível, é impossível empregar o NLAbs em um sistema primário sem um dado modelo e sem realizar as correspondentes análises de performance. Por causa disso, o absorvedor não linear proposto é submetido a um conjunto de simulações numéricas e análises paramétricas. 


\section{Capítulo 3}

\section{Estudo Preliminar}

Trabalhar com sistemas não lineares é, em grande parte, desafiador devido a imprevisibilidade destes, pois um certo parâmetro pode influenciar de maneira significativa a dinâmica do sistema, ao contrário do que imaginamos inicialmente. Cientes desse desafio, um estudo prévio torna-se necessário para que se possa ao menos inferir sobre possíveis tendências ou expectativas de comportamento. Além disso, pelo fato de a configuração do absorvedor envolver características físicas e geométricas, é importante saber como essas características podem atuar sobre a resposta do sistema.

Porém, antes de pensar em como cada característica pode atuar sobre a resposta do sistema, é primordial estabelecer como extrair as informações almejadas e analisálas. Por isso, esse estudo preliminar tem como objetivo principal definir os métodos para obtenção das informações fundamentais para análise do sistema.

Como um dos objetivos desta tese é alcançar uma boa configuração para o absorvedor, realizou-se a variação dos parâmetros do absorvedor para que se pudesse tomar familiaridade com o sistema. Uma vez mais familiarizado com o sistema, é possível discutir sobre um conjunto de valores para o sistema que permita trabalhar de forma consistente.

Todas as simulações numéricas foram realizadas no software MATLAB® ${ }^{\circ}$ com o integrador numérico ODE45, baseado em Método Explícito Runge-Kutta de $4^{a} / 5^{a}$ ordem (Dormand-Prince Pair), o tempo de final 60 segundos, passo de tempo de 0,002 segundos e tolerância de erro relativa de $10^{-6}$. Para simular o sistema com absorvedor linear acoplado, no modelo empregado admitiu-se que $L=L_{0}=0,15 \mathrm{~m}$ e as condições iniciais nulas. Para o sistema com absorvedor não linear acoplado, considerou-se $L=$ 0,15 m e os valores de $L_{0}$ e das condições iniciais foram determinados posteriormente. A fim de simplificar o estudo, adotou-se $k_{s 1}=k_{s 2}=k_{s n}$ em todos os casos estudados.

Este capítulo está divido em três seções. A primeira, seção 3.1, discute sobre como extrair as informações necessárias desse sistema não linear. A seção 3.2 trata do procedimento para se encontrar o valor ótimo de $k_{s n}$ para as molas do absorvedor. A última seção (3.3) expõe os primeiros resultados e faz a análise dos mesmos. 


\subsection{Metodologia para obtenção da Resposta em Frequência}

A principal maneira de se observar a atuação de um absorvedor linear de vibração sobre um sistema principal é através da função de resposta em frequência (FRF). Por se tratar de sistema dinâmico não linear, a Resposta em Frequência do sistema foi estimada usando a resposta no domínio do tempo obtida através de integração numérica. Mas resta um questionamento, como transformar o resultado de uma integração numérica no domínio do tempo em algo que se possa analisar o desempenho do absorvedor em um determinado espectro de frequência?

O primeiro modo de começar a responder essa questão é notar que é possível extrair a amplitude de vibração do sistema primário através do histórico no tempo. Para determinação da amplitude $(a m p)$ utilizou-se o seguinte método: obteve-se a reposta no tempo do sistema primário; descartou-se a primeira metade do vetor de resposta de modo a restar somente o histórico no tempo em estado estacionário; e anotou-se o máximo e o mínimo valor atingido pela posição do sistema principal de modo a calcular o valor da amplitude como $\operatorname{amp}=\max \left(x_{1}\right)-\min \left(x_{1}\right)$. A fim de exemplificar, a Fig. 3.1 ilustra como foi calculado o valor da amplitude de vibração a partir do histórico no tempo. Esta amplitude é conhecida como pico-a-pico, que é diferente, geralmente o dobro, da amplitude do sinal harmônico correspondente.

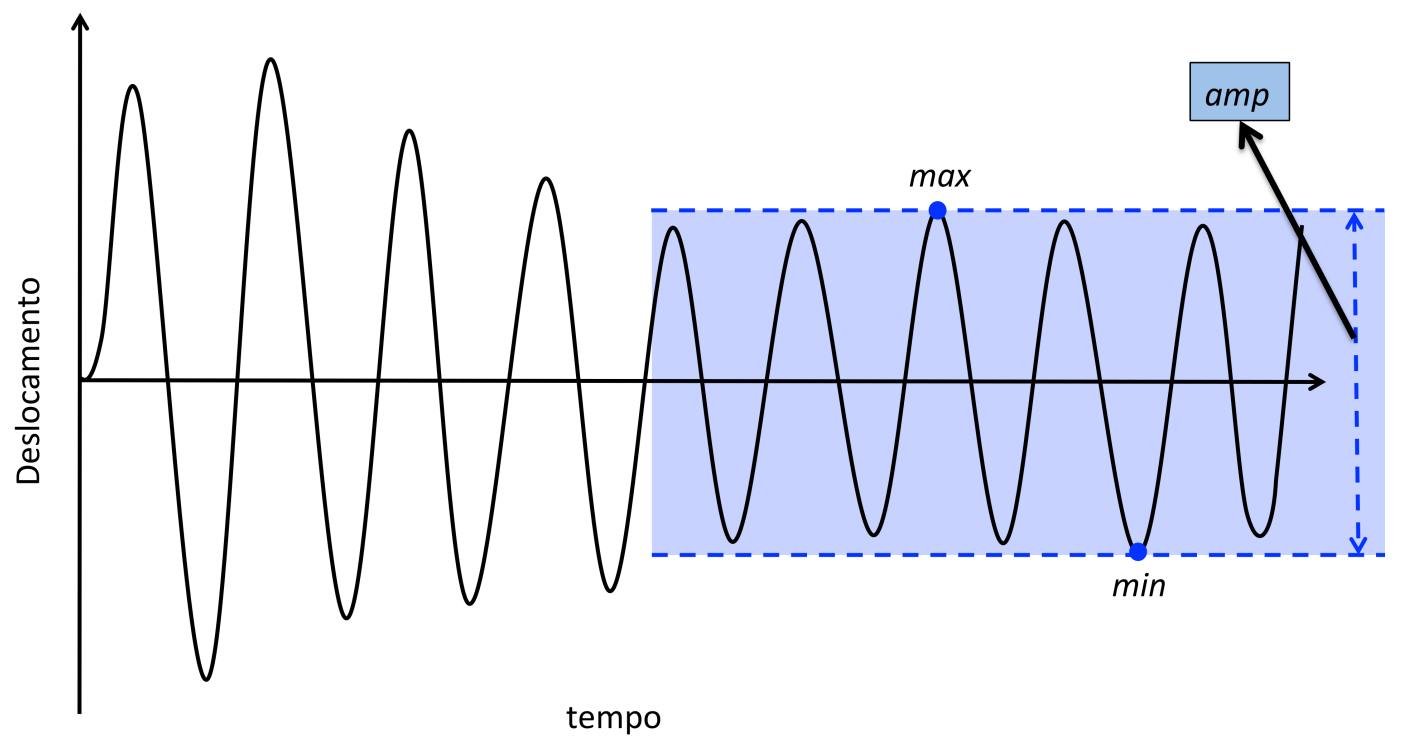

Figura 3.1: Esquema da obtenção do valor da amplitude de vibração ( $a m p)$ no histórico do tempo.

Para construir a Resposta em Frequência, pensou-se então em promover uma variação da frequência da força harmônica aplicada ao sistema principal e em cada integração numérica para um dado valor da frequência de excitação calcular o valor da amplitude como mostrado anteriormente. Dessa forma associou-se para cada valor da frequência de excitação um valor de amplitude de vibração. Para isso, determinou-se 
um intervalo no qual a frequência de ressonância do sistema principal estava contida na posição central. $\mathrm{O}$ estudo prévio de vários casos foi fundamental para estabelecer o tamanho dessa faixa de frequência de modo que nenhuma informação importante fosse perdida. Como resultado final, obteve-se um gráfico Amplitude x Frequência que será a principal ferramenta empregada no decorrer deste trabalho.

Como mencionado anteriormente, as condições de estabilidade são capazes de definir limitações e até as melhores condições de uso para um absorvedor. Por se tratar de um sistema complexo, o atual objeto de estudo tem uma forte dependência dessas condições e, portanto, é necessário um estudo de estabilidade que nos oriente sobre como trabalhar sobre esse sistema.

\subsection{Procedimento para cálculo de $k_{s n}$}

Após determinar como construir a Resposta em Frequência e analisar a estabilidade do sistema não linear, ainda resta o questionamento sobre como configurar adequadamente o absorvedor; assim, o primeiro parâmetro a ser investigado será a rigidez $k_{s n}$ das molas. Optou-se por, ao menos inicialmente, impor um valor de massa correspondente a $10 \%$ da massa do sistema principal, $m_{s}=0,05 \mathrm{~kg}$ e o tamanho da mola indeformada como $L_{0}=0,16 \mathrm{~m}$, deixando esses dois parâmetros fixos. Os valores dos outros parâmetros do sistema são mostrados na Tab. 3.1. Com intuito de precisar o valor ótimo da constante de rigidez do absorvedor, buscou-se o valor de $k_{s n}$ que tivesse como resposta a menor amplitude amp. Para isso, adotou-se o sistema principal excitado por uma força harmônica com frequência igual ao valor da frequência de ressonância do mesmo $(20,55 \mathrm{~Hz})$ e realizou-se a simulação no domínio do tempo variando a constante de rigidez $k_{s n}$ no intervalo de 1 a $1500 \mathrm{~N} / \mathrm{m}$, com passo de $1 \mathrm{~N} / \mathrm{m}$. Para cada $k_{s n}$ computou-se a amplitude de vibração amp correspondente, que foi obtida do envelope da resposta no tempo do sistema primário em estado estacionário. Todos os valores de amplitude de vibração foram divididos pela amplitude da força para evitar que mudanças posteriores na intensidade da força proporcionassem alteração na curva resultante.

A Tab. 3.1 mostra os parâmetros escolhidos. Uma vez que posteriormente haverá uma comparação do desempenho dos absorvedores linear e não linear, os parâmetros do linear também são fornecidos. Considerando $m_{p}$ e $k_{p}$, através da equação (2.34) foi possível calcular o melhor valor de $k_{s n}$ para o caso do absorvedor linear. Dentro da tabela também é possível ver que os valores dos coeficientes de amortecimento $c_{s h}$ e $c_{S v}$ são nulos. Este valor foi dado de modo a se trabalhar com uma situação ideal, uma vez que a presença do amortecimento pode ter um efeito desconhecido sobre o absorvedor não linear e ainda, se atuar como no caso linear, aumentar a amplitude obtida na antirressonância. Exceto pela posição inicial vertical do absorvedor não linear, $v_{s}=0,05 \mathrm{~m}$, todas as outras condições iniciais são nulas para o sistema não 
linear. No caso linear, todas as condições iniciais são nulas.

Tabela 3.1: Valores dos parâmetros para os sistemas com absorvedor linear e não linear.

\begin{tabular}{|c|c|c|c|}
\hline Parâmetros & Símbolo & Valor (LAbs) & Valor (NLAbs) \\
\hline Massa primária $(\mathrm{kg})$ & $m_{p}$ & 60 & 60 \\
\hline Massa do absorvedor $(\mathrm{kg})$ & $m_{s}$ & 6 & 6 \\
\hline Coef. rigidez primário $(\mathrm{N} / \mathrm{m})$ & $k_{p}$ & $1.10^{6}$ & $1.10^{6}$ \\
\hline Coef. rigidez do absorvedor $(\mathrm{N} / \mathrm{m})$ & $k_{s n}$ & 75 & definido adiante \\
\hline Coef. amortecimento primário (N.s/m) & $c_{p}$ & 155 & 154,92 \\
\hline Coef. amortecimento do absorvedor (N.s/m) & $c_{s h}, c_{s v}$ & 0 & $0 ; 0$ \\
\hline Amplitude da força(N) & $f$ & 500 & 500 \\
\hline
\end{tabular}

Foi imposto que a máxima deformação horizontal das molas do absorvedor deve ser de $5 \mathrm{~cm}$. Isto garante que o sistema não se torne inválido, uma vez que há uma limitação espacial de $30 \mathrm{~cm}(2 L=30 \mathrm{~cm})$. Isto também assegura que qualquer mola helicoidal do absorvedor não linear quando totalmente comprimida tem, pelo menos, $5 \mathrm{~cm}$ de comprimento. Como consequência, atribuiu-se à amplitude da força $(f) \mathrm{o}$ valor de $500 \mathrm{~N}$, pois este valor resulta em uma amplitude de vibração pico-a-pico igual a $5 \mathrm{~cm}$ para o sistema primário na ressonância.

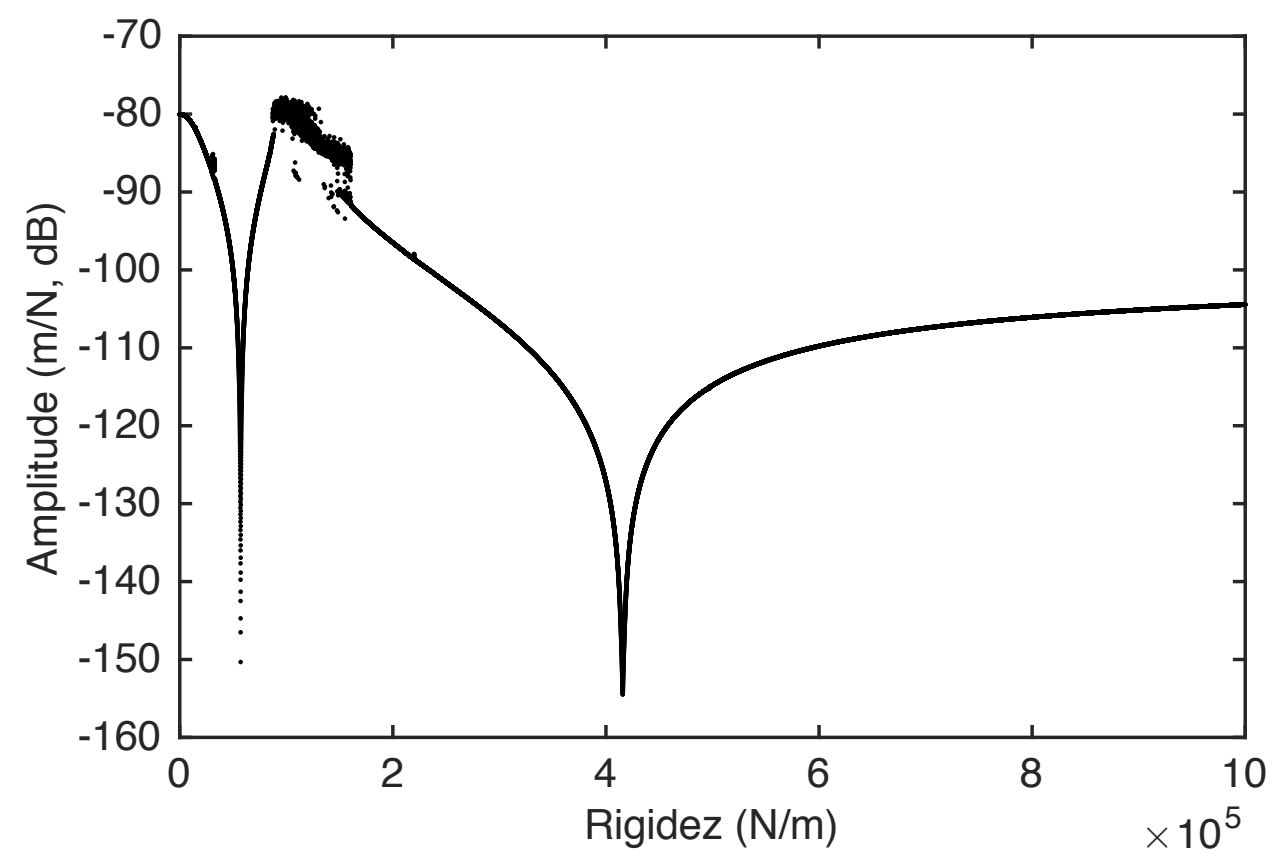

Figura 3.2: Amplitude do PS com absorvedor não linear acoplado para diferentes valores de rigidez das molas, $k_{s n}$.

A Fig. 3.2 mostra a amplitude de vibração do sistema principal de acordo com a variação da rigidez das molas do absorvedor. Pode ser observado que há dois mínimos locais, o primeiro em $k_{s n}=5,712 \times 10^{4} \mathrm{~N} / \mathrm{m}$ e o segundo em $k_{s n}=4,158 \times 10^{5}$ 
$\mathrm{N} / \mathrm{m}$, sendo o segundo a melhor solução. A partir dessa curva espera-se que, ao longo do desenvolvimento do projeto, para as demais configurações estudadas ocorra o mesmo tipo de comportamento através do fornecimento de dois mínimos bem definidos. Mesmo assim, percebe-se que ao lado do primeiro mínimo há uma região onde ocorrem valores de amplitude bem distintos e uma descontinuidade, fazendo com que se fique alerta quanto à presença de regiões instáveis e descontínuas nesta curva de Amplitude x Rigidez para a sequência do trabalho.

Computados os dois mínimos encontrados na Fig. 3.2, agora é importante checar o desempenho do sistema ao longo de uma faixa de frequência, como foi definido anteriormente na seção 3.1 .

\subsection{Análise preliminar de desempenho do absorvedor não linear proposto}

Para cada um dos dois valores de $k_{s n}$, foram obtidas as amplitudes das respostas do sistema primário quando sujeito a excitação harmônica com frequências dentro do intervalo de 20 a $90 \mathrm{rad} / \mathrm{s}$ ou de 3,2 a 14,3 Hz. Nos gráficos obtidos comparou-se a resposta do sistema primário sem a presença do absorvedor (PS), com a presença de absorvedor linear (LAbs) e com a presença de absorvedor não linear (NLAbs). Para o absorvedor linear correspondente, a sua massa foi considerada igual àquela do absorvedor não linear e sua rigidez foi calculada de acordo com a Eq. (2.34), tal que a sua frequência natural coincida com a frequência natural do sistema primário..

As Figs. 3.3a e 3.3b exibem as respostas em frequência do sistema primário com acoplamento do absorvedor não linear para os dois valores de rigidez encontrados, $k_{s n}=5,712 \times 10^{4} \mathrm{~N} / \mathrm{m}$ (Fig.3.3a) e $k_{s n}=4,158 \times 10^{5} \mathrm{~N} / \mathrm{m}$ (Fig.3.3b).

Na Fig. 3.3a, é possível observar que as respostas dos absorvedores linear e não linear são quase coincidentes quanto a faixa de frequência de supressão, que vai de $19,4 \mathrm{~Hz}$ a $21,8 \mathrm{~Hz}$ e totaliza 2,4 Hz de extensão com absorvedor não linear e de 19,5 $\mathrm{Hz}$ a $21,8 \mathrm{~Hz}$, para o linear, totalizando 2,3 Hz. A faixa de frequência de supressão foi calculada considerando o intervalo no qual as amplitudes de vibração são menores em comparação com o sistema original, sem absorvedor. Já em termos da mínima amplitude alcançada na antirressonância, o dispositivo linear alcança $-136,6 \mathrm{~dB}$ contra $-121,8$ dB do NLAbs, se mostrando a melhor opção.

Na Fig. 3.3b, que corresponde ao caso com melhor solução para o coeficiente de rigidez do absorvedor, é notável que o NLAbs tem desempenho superior ao apresentado no caso anterior, pois nesta circunstância o absorvedor não linear é mais efetivo que o linear nos dois aspectos, tanto na mínima amplitude alcançada, -136,6 dB para o LAbs e -139, a dB para o NLAbs na antirressonância, tanto quanto no tamanho da faixa de supressão, de $19,5 \mathrm{~Hz}$ a $21,8 \mathrm{~Hz}$ para o LAbs e de $17,5 \mathrm{~Hz}$ a $23,7 \mathrm{~Hz}$, somando 6,2 Hz de extensão, para o NLAbs. Esse valor de 6,2 Hz para o caso não linear é muito 


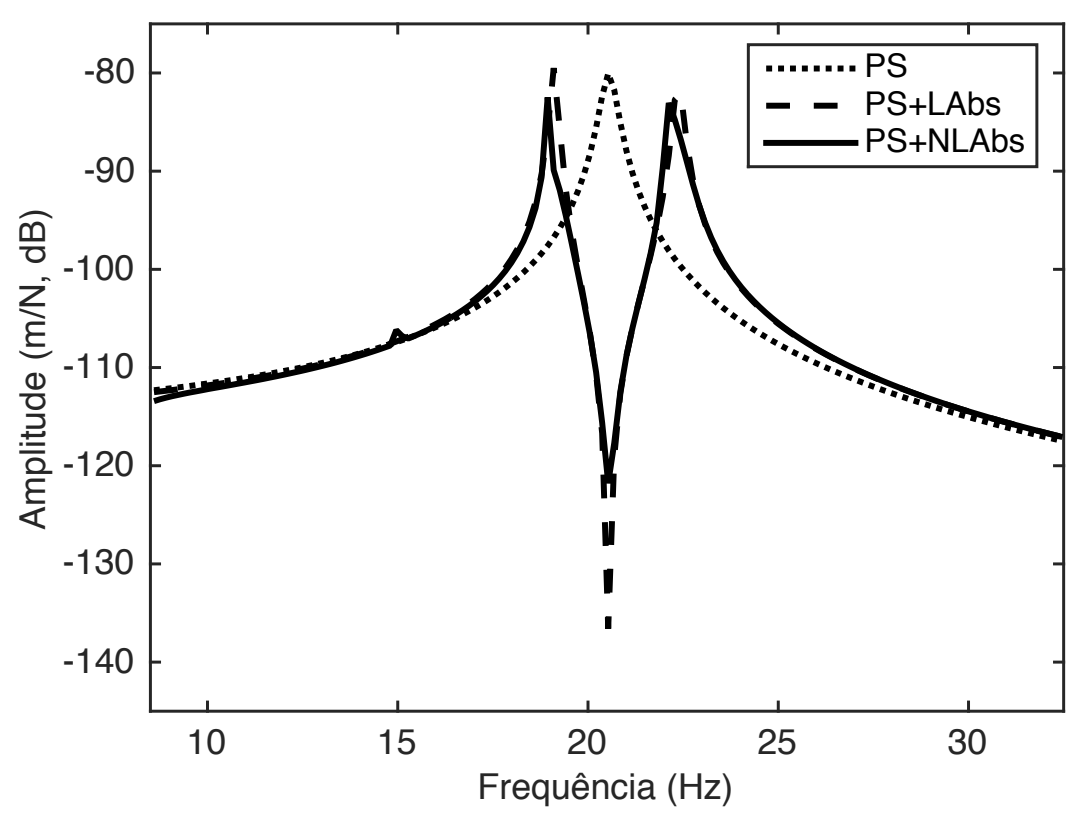

(a) $k_{\text {sn }}=5,712 \times 10^{4} \mathrm{~N} / \mathrm{m}$

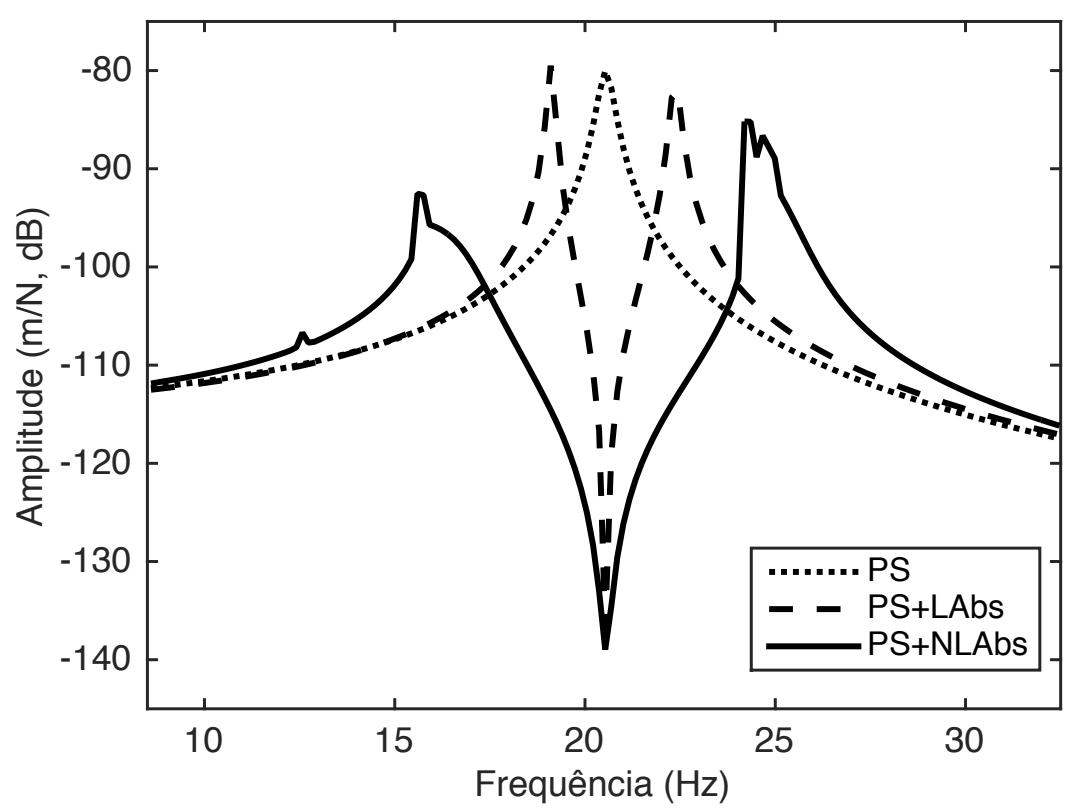

(b) $k_{s n}=4,158 \times 10^{5} \mathrm{~N} / \mathrm{m}$

Figura 3.3: Resposta em Frequência do sistema primário (PS) sem absorvedor (pontilhada), com absorvedor linear (tracejada) e com absorvedor não linear (contínua) para os dois valores de rigidez do absorvedor não linear, $k_{s n}$. 


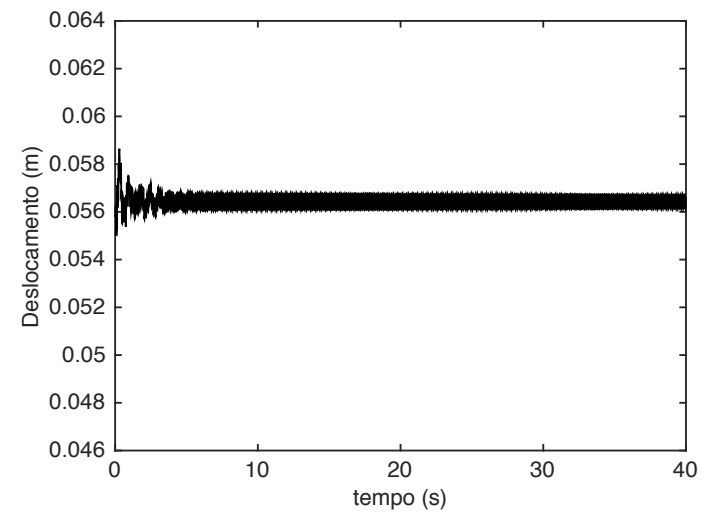

(a) Deslocamento na direção vertical, $v_{s}$, do absorvedor $\left(k_{s n}=5,712 \times\right.$ $\left.10^{4} \mathrm{~N} / \mathrm{m}\right)$.

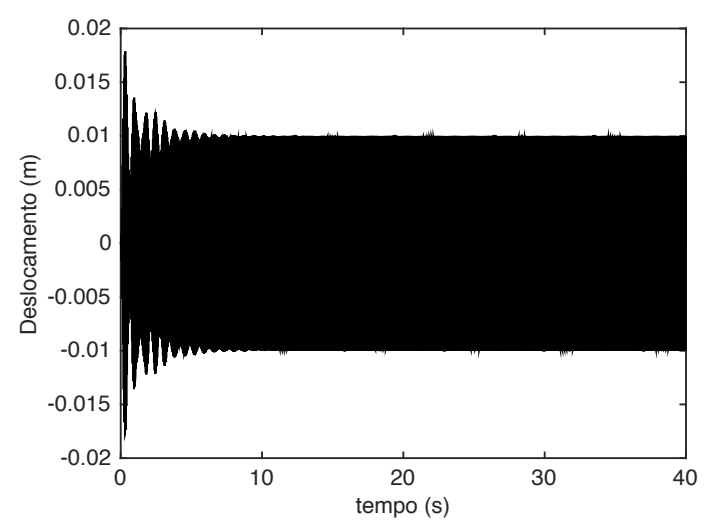

(c) Deslocamento na direção horizontal, $u_{s}$, do absorvedor $\left(k_{s n}=\right.$ $5,712 \times 10^{4} \mathrm{~N} / \mathrm{m}$ ).

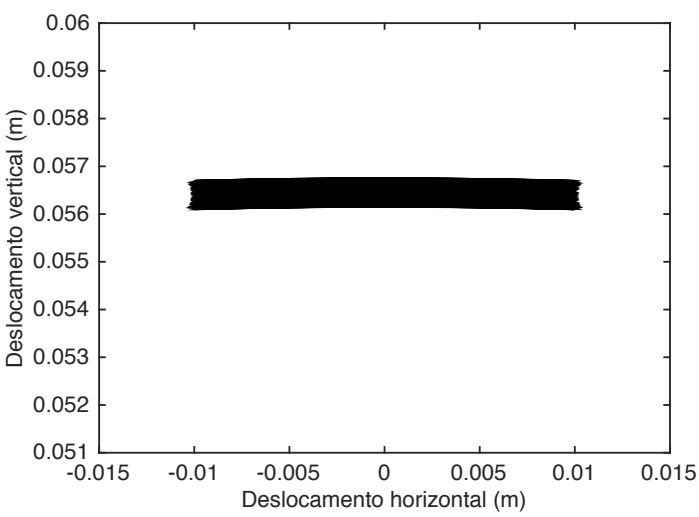

(e) Deslocamento na direção vertical, $v_{s}, \mathrm{x}$ deslocamento na direção horizontal, $u_{s}$, do absorvedor $\left(k_{s n}=\right.$ $\left.5,712 \times 10^{4} \mathrm{~N} / \mathrm{m}\right)$.

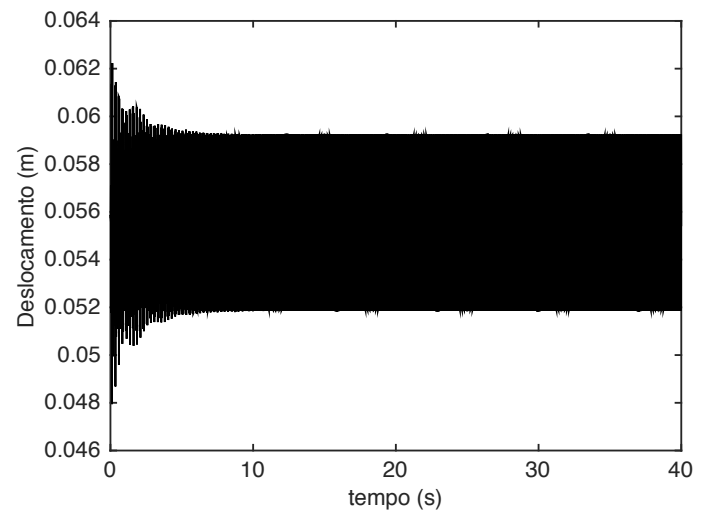

(b) Deslocamento na direção vertical, $v_{s}$, do absorvedor $\left(k_{s n}=4,158 \times\right.$ $10^{5} \mathrm{~N} / \mathrm{m}$ ).

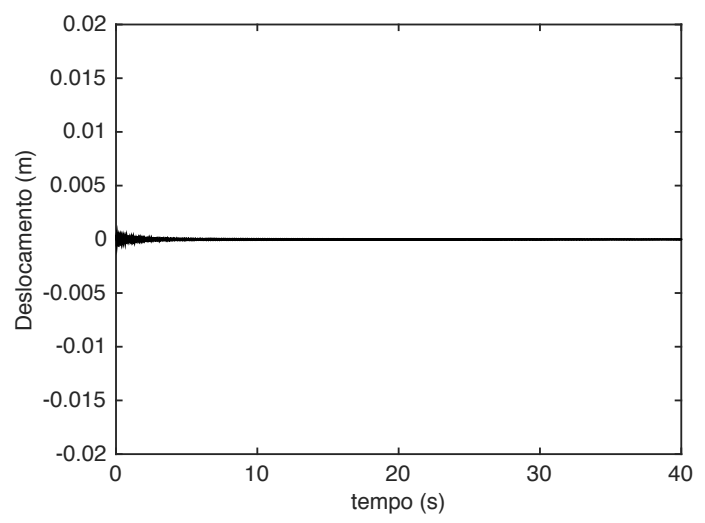

(d) Deslocamento na direção horizontal, $u_{s}$, do absorvedor $\left(k_{s n}=\right.$ $4,158 \times 10^{5} \mathrm{~N} / \mathrm{m}$ ).

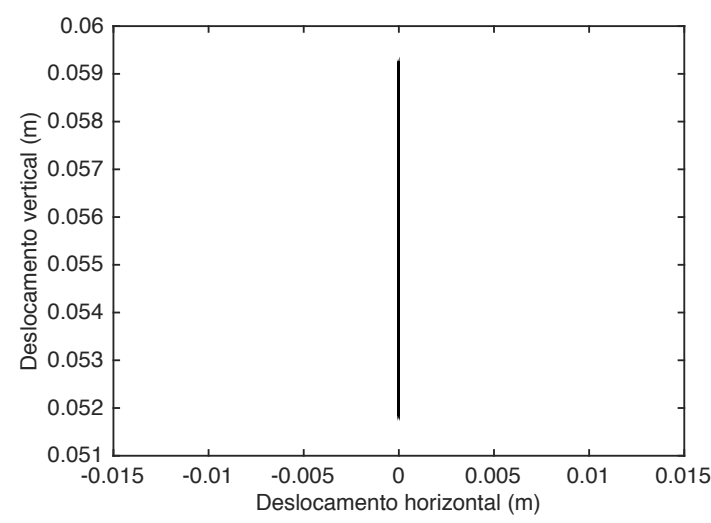

(f) Deslocamento na direção vertical, $v_{s}, \mathrm{x}$ deslocamento na direção horizontal, $u_{s}$, do absorvedor $\left(k_{s n}=\right.$ $\left.4,158 \times 10^{5} \mathrm{~N} / \mathrm{m}\right)$.

Figura 3.4: Deslocamento nas direções horizontal, $u_{s}$, e vertical, $v_{s}$, do absorvedor não linear para os dois valores ótimos de rigidez do absorvedor e para excitação do sistema primário na frequência de $20,55 \mathrm{~Hz}$. 
importante, pois corresponde a pouco mais de duas vezes e meia a faixa de frequência de supressão do caso linear e se considerarmos a frequência de ressonância do sistema próxima a $20,55 \mathrm{~Hz}$, esse valor equivale a $30 \%$ dela.

Ademais, na Fig. 3.3b, se nota a ocorrência de uma descontinuidade nos dois picos resultantes, fato que não aparece com o dispositivo linear e nem na Fig. 3.3a. Ainda não se sabe identificar o fenômeno e nem a causa deste fato, contudo, se for verificada a ocorrência do mesmo ao longo do estudo uma análise deverá ser desenvolvida para explicar tal acontecimento.

A seguir, além de obter os resultados analisados anteriormente, também é importante analisar as respostas no tempo para os dois casos mostrados, com intuito de verificar se há alguma diferença no comportamento do absorvedor que permita a realização de alguma inferência sobre os diferentes desempenhos.

A Fig. 3.4 mostra os deslocamentos nas direções horizontal e vertical do absorvedor não linear para os dois coeficientes de rigidez observados. Na coluna à esquerda estão os gráficos referentes a $k_{s n}=5,712 \times 10^{4} \mathrm{~N} / \mathrm{m}$ e na coluna à direita os gráficos para $k_{s n}=4,158 \times 10^{5} \mathrm{~N} / \mathrm{m}$. As duas últimas figuras de cada coluna descrevem o deslocamento da massa $m_{s}$ ao longo dos últimos 10 segundos no plano cartesiano e visam fornecer uma melhor perspectiva acerca do movimento descrito pelo absorvedor.

A comparação das Figs. 3.4a e 3.4b mostra que para $k_{s n}=4,158 \times 10^{5} \mathrm{~N} / \mathrm{m}$ o absorvedor desenvolve amplitudes muito maiores verticalmente que as observadas com o menor coeficiente de rigidez. Já a comparação dos deslocamentos na direção horizontal através das Figs. 3.4c e 3.4d revela oposto do ocorrido na direção vertical, agora os maiores deslocamentos ocorrem para $k_{s n}=5,712 \times 10^{4} \mathrm{~N} / \mathrm{m}$ e no segundo caso, $k_{s n}=4,158 \times 10^{5} \mathrm{~N} / \mathrm{m}$, esses deslocamentos são muito pequenos.

Com isso, as Figs. 3.4e e 3.4f tornam evidentes as diferenças visualizadas anteriormente, onde se vê que a menor rigidez, Fig. 3.4e resultou em movimento prioritariamente horizontal do absorvedor, ao passo que o segundo caso, Fig. 3.4f, mostrou-se com vibrações prioritariamente na direção vertical. Uma vez que as amplitudes na direção horizontal são muito pequenas, a Fig. 3.4f exibe praticamente uma reta vertical. Já na Fig. 3.4e, o fato das amplitudes na direção vertical não serem tão pequenas quanto as vistas na direção horizontal da Fig. 3.4d faz com que não se veja uma reta, ainda que horizontal, neste caso.

Portanto, parece que o fato do absorvedor desempenhar amplitudes muito menores horizontalmente e vibrar prioritariamente na direção vertical é benéfico para o desempenho na ampliação da faixa de supressão e também para a redução das amplitudes de vibração na ressonância do sistema principal. 


\section{Capítulo 4}

\section{Otimização por busca extensiva}

Após os resultados do Capítulo 3, se fez necessário conseguir um conjunto sólido de dados que nos permitisse analisar o comportamento e desempenho do absorvedor não linear. Esse conjunto de dados deveria levar em conta as três características do absorvedor (massa, rigidez das molas e geometria) e retornar, para cada combinação entre elas, dados que nos permitissem avaliar o desempenho de cada solução.

Com propósito de construir esse conjunto de dados, foi realizado um estudo a partir da resposta no tempo do sistema primário (PS), mediante a variação dos três parâmetros, $L_{0}, m_{s}$ e $k_{s n}$. O comprimento indeformado das molas do absorvedor, $L_{0}$, fez parte da análise pois seu valor é determinante quanto a geometria do sistema e, consequentemente, aos pontos do equilíbrio. Uma vez que a massa do sistema primário, $m_{p}$, é fixa, alterar o valor da massa do absorvedor, $m_{s}$, significa alterar a razão entre $m_{p}$ e $m_{s}$, um dado extremamente importante no caso de um absorvedor linear e que deve ser também estudado para o não linear. Já o coeficiente de rigidez das molas do absorvedor, $k_{s n}$, atua diretamente na frequência natural do absorvedor e na interação entre as duas massas do sistema. No entanto, determinar a rigidez das molas consistiu num maiores desafios desse projeto, uma vez que definir esse valor corretamente influencia diretamente o desempenho do absorvedor quando já se tem as outras duas características impostas. Dessa forma, em um primeiro momento, a fim de definir o $k_{s n}$ ótimo, foi empregado o método de otimização por busca extensiva. A seguir, é abordado como esse método e a sequência de trabalho foram empregados.

A sequência de obtenção dos resultados se constitui em:

Etapa 1: Planejamento dos conjuntos. Determinação dos conjuntos que envolvem os parâmetros do absorvedor considerando restrições de custo computacional e de tempo.

Etapa 2: Obtenção do $k_{s n}$. Definição do $k_{s n}$ ótimo a cada par $\left[L_{0}, m_{s}\right]$ através de busca extensiva como será mostrado na seção 4.1 .

Etapa 3: Variação da frequência. Cada trio $\left[L_{0}, m_{s}, k_{s n}\right]$ resultante é submetido a uma nova série de simulações numéricas, que varia a frequência de excitação $(\omega)$ 
do sistema. Os dados retornados permitem a construção da curva Amplitude x Frequência.

Etapa 4: Critérios de avaliação (subseção 4.1.1). A partir da comparação entre cada curva de Amplitude x Frequência do sistema PS + NLAbs com relação a curva do sistema original formado apenas pelo PS, foram propostas métricas que permitissem avaliar o desempenho de cada solução $\left[L_{0}, m_{s}, k_{s n}\right]$.

Etapa 5: Ordenação dos resultados. De acordo com as métricas propostas, as soluções foram ordenadas com desempenho decrescente para se identificar as melhores soluções para cada critério.

\subsection{Otimização do absorvedor não linear usando busca extensiva para $k_{s n}$}

A Etapa 2 citada consistiu em desenvolver ensaios numéricos que retornaram a resposta no tempo do deslocamento do sistema primário quando excitado por uma força harmônica, com frequência de excitação igual à frequência de ressonância do sistema primário de 20,55 Hz, para diferentes conjuntos de parâmetros do absorvedor, $\left[L_{0}, m_{s}, k_{s n}\right]$. Estas respostas foram utilizadas para se determinar a amplitude do sistema primário, conforme proposto no capítulo anterior (seção 3.1). Cada par [ $L_{0}$, $m_{s}$ ] gerou uma curva de Amplitude $x$ Rigidez semelhante àquela apresentada na Fig. 3.2, promovida pela variação de $k_{s n}$. Destas curvas, separaram-se os mínimos locais, que foram ordenados ascendentemente pelo valor de amplitude e salvou-se o primeiro mínimo em um grupo. Portanto, cada curva forneceu um $k_{s n}$ ótimo e gerou um sistema na forma $\left[L_{0}, m_{s}, k_{s n 1}\right]$, onde cada um foi levado à Etapa 3 do processo mencionado.

A tentativa de se encontrar o $k_{s n}$ que retorne a menor a amplitude pareceu uma tarefa simples à primeira vista. No estudo preliminar realizado observou-se apenas um caso, para um determinado par $\left[L_{0}, m_{s}\right]$, o que permitiu a análise visual da curva Amplitude x Rigidez. Contudo, nessa parte do estudo que envolve uma grande quantidade de casos a se analisar, é imprescindível que se automatize no MATLAB® o processo de determinação do $k_{s n}$ que retorna a menor amplitude de vibração. Encontrar tal valor de $k_{s n}$ nesta etapa tem como propósito evitar grandes amplitudes quando o sistema primário é excitado em sua frequência de ressonância. Além disso, encontrar esse $k_{s n}$ pode significar o aumento da faixa de supressão resultante, segundo observações realizadas previamente. Por fim, determinar essa rigidez para um par $\left[L_{0}, m_{s}\right]$ e posteriormente analisar a resposta em frequência, ao invés de observar várias curvas de resposta em frequência para um par e muitos $k_{s n}$, significa diminuir o custo computacional para realização dessas etapas. As dificuldades desse processo surgiram da necessidade de se garantir que o ponto retornado como resposta fosse 
realmente o de menor amplitude, sendo um mínimo global. Na Fig. 3.2, o ponto de menor amplitude é simultaneamente um mínimo local e global, porém, dentro de um número tão grande de casos analisados é difícil garantir que em todos eles o mínimo global sempre será retornado. Por isso, o desafio dessa etapa foi garantir que o ponto de mínimo correto fosse armazenado para sequência do processo.

No MATLAB ${ }^{\circledR}$ há duas funções que nos auxiliam a localizar os mínimos existentes numa curva. A função $\min (A)$ retorna, a partir de um vetor $A$, o menor valor contido nele, o qual sempre é o mínimo global da função se a faixa de valores analisada compreende todos os mínimos locais. Contudo, se a faixa analisada não contém o mínimo global, mas contém valores menores que um outro mínimo local qualquer, a função $\min (A)$ retornará o ponto de menor valor da função que não será nem um mínimo local e nem o global. Por isso, ser capaz de determinar se o ponto retornado é um mínimo local ou não é importante nesse caso. Assim, para acessar os mínimos locais de uma curva qualquer é necessário utilizar a função findpeaks( $A$ ), a qual retorna um vetor com os máximos locais do sinal de entrada $A$. Como tratam-se de máximos, inverteu-se o sinal do conjunto de dados da curva Amplitude x Rigidez de modo a transformar os mínimos em máximos. A partir daí, com o vetor de máximos resultante em cada caso, ordena-os decrescentemente e retira-se do primeiro desses o $k_{s n}$ correspondente para a continuidade do processo. Apesar da função findpeaks parecer atender bem as necessidades do projeto, ela deixa de entregar uma resposta quando não encontra um mínimo local, uma vez que ela trabalha com a mudança no sinal da derivada da curva investigada. Quando essa mudança na derivada não acontece ela não retorna uma resposta. Para resolver esse problema e definir, ao menos, o melhor $k_{s n}$ possível dentro do conjunto de valores permitido, utilizou-se uma regra condicional para que caso a função findpeaks não retornasse uma resposta, o $k_{s n}$ foi adquirido pela função min que entrega o menor valor naquele intervalo analisado.

Além da dificuldade em conseguir o valor ótimo de $k_{s n}$, também surgiram obstáculos com relação à extensão da faixa de valores em que se buscou o $k_{s n}$ ótimo, bem como na discretização desses valores. Em alguns casos notou-se a necessidade em aumentar esse conjunto de valores de modo que todas as possíveis combinações $\left[L_{0}, m_{s}, k_{s n}\right.$ ] fossem contempladas com um $k_{s n}$ ótimo selecionado como um mínimo local, via findpeaks, pois entende-se que a falta de um mínimo local implica que o $k_{s n}$ ótimo está fora dos limites estipulados para busca. Mas por que não aumentar esses limites para poder alcançar todos os valores? O primeiro motivo para não aumentar esse limite sem objeções é o elevado custo computacional, uma vez que todos os valores dos possíveis $k_{s n}$ são simulados numericamente em cada par $\left[L_{0}, m_{s}\right]$. O segundo motivo é que esse valor de rigidez deveria ter um limite, já que promover uma rigidez desproporcional ao sistema o tornaria quase estático a custa de valores sem sentido físico. 
Uma vez definidos limites de busca, espera-se determinar uma discretização de valores que não forneça elevado custo computacional e que também não impeça que a busca se aproxime do valor ótimo. Um espaço muito grande entre um valor e outro de $k_{s n}$ torna o processo computacional mais rápido, contudo diminui a chance de se encontrar o $k_{s n}$ ótimo, com sorte poderia aproximar-se dele. Diminuir esse espaço entre um e outro melhora o resultado, tornando-o mais confiável, mas em contra partida pode aumentar o tempo do processo em dias. Estimar quais seriam esses parâmetros de busca exigiu que se observasse alguns casos a parte, por exemplo, visualizar a curva Amplitude x Rigidez de três trios $\left[L_{0}, m_{s}, k_{s n}\right]$, a fim de estimar os limites e discretização adequados.

\subsubsection{Critérios de avaliação}

Esta seção discute duas formas utilizadas para avaliar os resultados obtidos ao longo deste trabalho. Esses modos de medir o desempenho do absorvedor não linear foram utilizados na seções 4.2 e 5.2 e consistem nas medidas de redução da amplitude de vibração do sistema principal (PS) e de faixa de frequência de supressão. De modo a permitir um melhor entendimento do que se trata cada medida, optou-se por exemplificá-las e discuti-las.

A Fig. 4.1a mostra que o valor atribuído à redução de amplitude $\left(\delta A_{n l}\right)$ consiste na diferença entre a amplitude de vibração do sistema principal (PS) na ressonância e a amplitude do sistema com o absorvedor acoplado na, suposta, antirressonância. Neste caso, consideraram-se os valores de redução como positivos para facilitar a interpretação dos resultados, uma vez que, quanto maior o valor, maior será a redução e, consequentemente, melhor o desempenho do absorvedor, de acordo com este critério.

$\mathrm{Na}$ Fig. 4.1b, o valor calculado para o tamanho da faixa de frequência de supressão é a extensão na qual as amplitudes de vibração do sistema com absorvedor são menores que as amplitudes do sistema sem absorvedor, sendo representado como $\delta \omega_{n l}$. Medir essa faixa é fundamental para comparar o desempenho das diferentes configurações do absorvedor não linear entre elas e também com outro tipo de absorvedor, já que uma faixa maior representa uma maior segurança em relação aos picos de ressonância que estão em ambos os lados da antirressonância. 


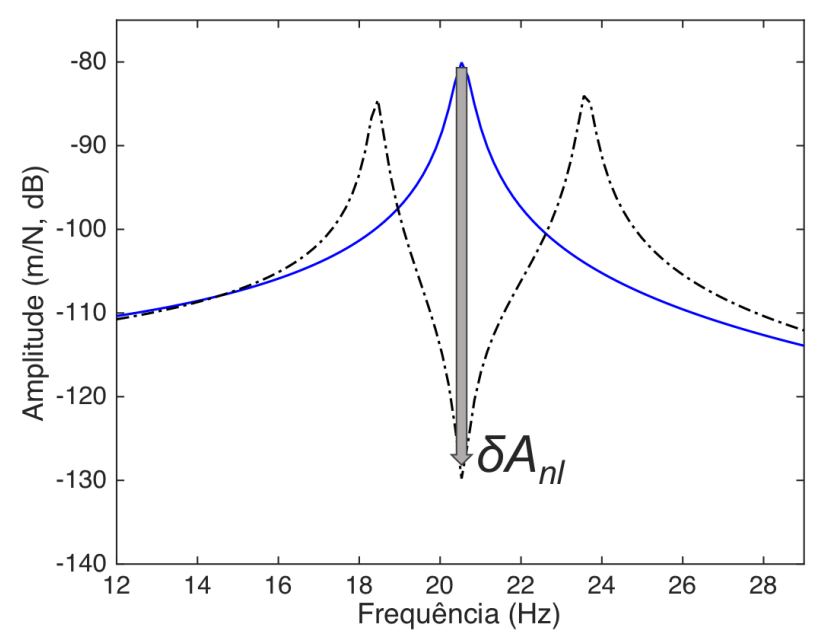

(a) Redução de amplitude na ressonância.

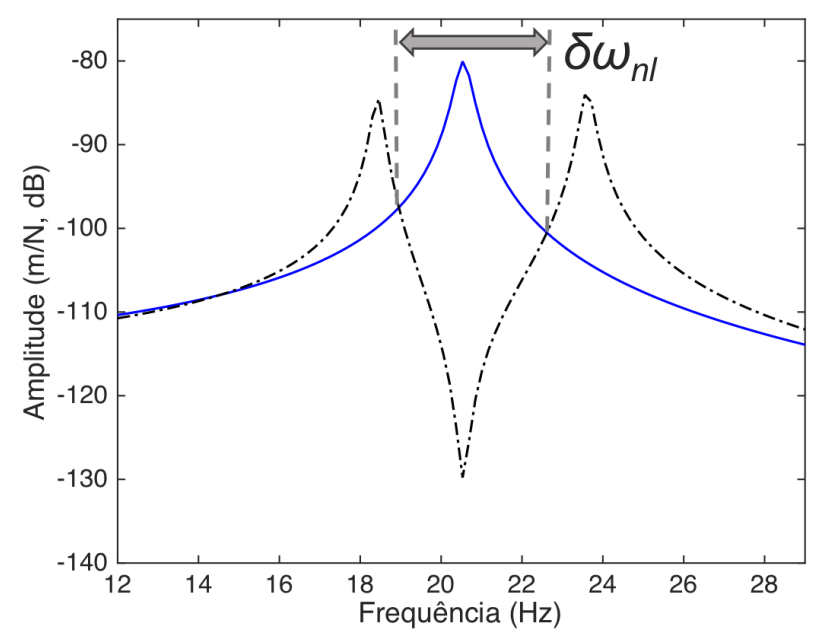

(b) Faixa de frequência de supressão.

Figura 4.1: Representação dos critérios de redução de amplitude e faixa de frequência de supressão. 


\subsection{Análise dos resultados obtidos com busca extensiva}

Nesta seção estão os melhores resultados obtidos através da busca extensiva para o sistema com absorvedor não linear acoplado (PS + NLAbs) comparados a seus correspondentes, em massa, absorvedores lineares (PS + LAbs). Para cada valor de massa $m_{s}$ obtido, foram calculados os correspondentes lineares, segundo a equação (2.34), afim de que as devidas comparações pudessem ser feitas.

$\mathrm{Na}$ Tab. 4.1 estão os parâmetros do sistema e também o intervalo de valores das grandezas que foram variadas no absorvedor não linear. Os dados do sistema primário utilizados para os casos com absorvedor linear são os mesmos do não linear.

Tabela 4.1: Valores dos parâmetros para o sistema com absorvedor não linear.

\begin{tabular}{|c|c|c|c|}
\hline Condição & Parâmetros & Símbolo & Valores \\
\hline \multirow{4}{*}{ Fixos } & Massa primária (kg) & $m_{p}$ & 60 \\
\cline { 2 - 4 } & Coeficiente de amortecimento primário (N.s/m) & $c_{p}$ & 155 \\
\cline { 2 - 4 } & Coeficiente de rigidez primário (N/m) & $k_{p}$ & $1 \times 10^{6}$ \\
\cline { 2 - 4 } & Amplitude da força(N) & $f$ & 500 \\
\hline \multirow{3}{*}{ Variáveis } & Massa do absorvedor $(\mathrm{kg})$ & $m_{s}$ & $3: 0.2: 15$ \\
\cline { 2 - 4 } & Coeficiente de rigidez do absorvedor $(\mathrm{N} / \mathrm{m})$ & $k_{s n}$ & $1:$ variável:10 \\
\cline { 2 - 4 } & Tamanho da mola $(\mathrm{m})$ & $L_{0}$ & $0.15:$ variável:0.20 \\
\hline
\end{tabular}

Para os valores de $L_{0}$ adotados no intervalo entre $0,15 \mathrm{~m}$ e $0,16 \mathrm{~m}$ utilizou-se um passo de variação de $0,002 \mathrm{~m}$, já de $0,16 \mathrm{~m}$ a $0,20 \mathrm{~m}$ o passo considerado foi de 0,01 m, uma vez que o primeiro intervalo mostrou a necessidade de um maior refinamento em uma análise preliminar. Com relação à rigidez do absorvedor, $k_{s n}$, uma discretização não linear (distribuição linear em raiz quadrada da rigidez) foi considerada com intuito de permitir uma precisão mais homogênea para pequenos e grandes valores de rigidez, tal que o intervalo foi definido como $[\sqrt{1}:(\sqrt{1000}-$ $\sqrt{1}) / 1000: \sqrt{1000}]^{2}$.

A Fig. 4.2 mostra a variação da redução efetiva na frequência de ressonância do sistema primário $\left(\delta A_{n l}\right.$, quanto maior, melhor) com a massa do absorvedor $\left(m_{s}\right)$ e o comprimento da mola não deformada $\left(L_{0}\right)$. É notório que, para valores de $L_{0}$ maior do que $0,16 \mathrm{~m}$, a faixa de frequência aumenta enquanto a amplitude de vibração diminui com o aumento da massa do absorvedor. No entanto, para os valores de $L_{0}$ entre 0,15 m e 0,16 m, a tendência é invertida e a faixa de frequência mais elevada é obtida com a massa do absorvedor igual a $6 \mathrm{~kg}$ e comprimento da mola não deformada, $L_{0}$, de 0,154 m. Nota-se que a faixa de frequência de supressão e a redução da amplitude seguem a mesma tendência, uma maior redução de amplitude de vibração também indica uma maior faixa de frequência de supressão.

A Tab. 4.2 mostra os 8 conjuntos de parâmetros mais bem classificados $\left[L_{0}, m_{s}, k_{s n}\right]$ em termos de aumento da faixa de frequência de supressão $\left(\delta \omega_{n l}\right)$. É notável que a 


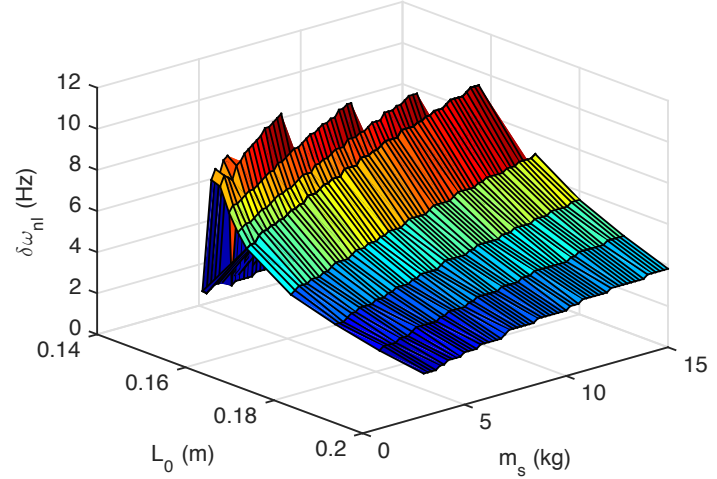

(a) $\delta \omega_{n l}($ vista 1$)$

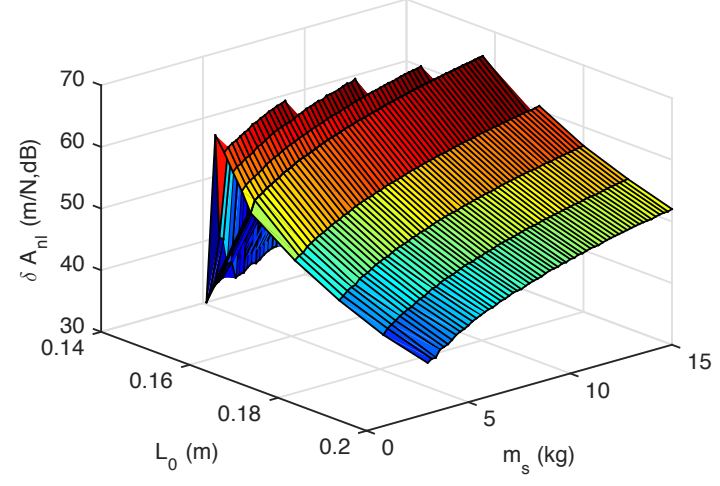

(c) $\delta A_{n l}($ vista 1$)$

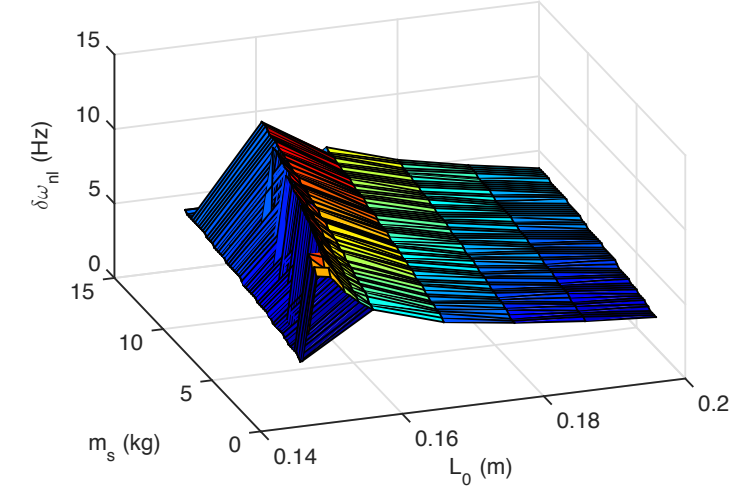

(b) $\delta \omega_{n l}$ (vista 2)

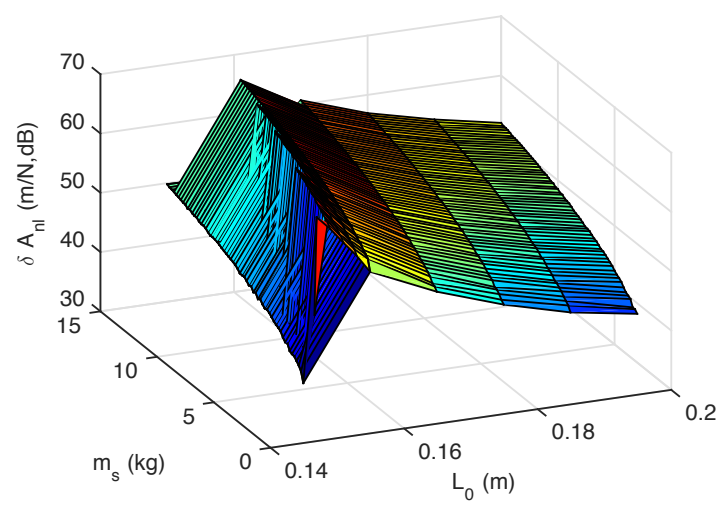

(d) $\delta A_{n l}($ vista 2$)$

Figura 4.2: Valores de faixa de frequência de supressão $\left(\delta \omega_{n l}\right)$ e redução da amplitude de vibração $\left(\delta A_{n l}\right)$ para diferentes valores de massa do absorvedor, $m_{s}$, e de comprimento indeformado das molas, $L_{0}$.

combinação $\mathrm{C} 1$ tenha o melhor desempenho com uma massa relativamente pequena, $6 \mathrm{~kg}$, que corresponde a apenas $10 \%$ da massa primária.

A Fig. 4.3 apresenta a resposta em frequência do sistema primário quando conectado ao absorvedor de vibração não linear para os oito conjuntos de parâmetros apresentados na Tab. 4.2. A Fig. 4.3a também inclui os desempenhos do absorvedor linear, as quais são explicadas quando a Tab. 4.3 é apresentada. Assim, as combinações indicadas como C1L, C2L, C3L e C4L referem-se ao absorvedor linear. A Fig. 4.3a apresenta os quatro primeiros conjuntos de parâmetros que levam a um comportamento semelhante da resposta em frequência. Este comportamento também é similar ao comportamento de um absorvedor de vibração linear com a substituição do pico de ressonância original por uma antirressonância com dois picos de ressonância ao redor. No entanto, ao contrário de absorvedores de vibração lineares típicos, esses dois picos não são bem definidos. A Fig. 4.3b apresenta os outros quatro conjuntos de parâmetros que apresentam um comportamento diferente, com a aparência de um terceiro pico de ressonância dentro da faixa de frequência de supressão. Por esta razão, estes conjuntos de parâmetros não são considerados nas análises seguintes. 
Tabela 4.2: Melhores conjuntos de parâmetros para o absorvedor não linear

\begin{tabular}{|c|c|c|c|}
\hline Combinação & $L_{0}(\mathrm{~m})$ & $m_{s}(\mathrm{~kg})$ & $k_{s n}(\mathrm{kN} / \mathrm{m})$ \\
\hline C1 & 0,154 & 6,0 & 980,73 \\
\hline C2 & 0,156 & 9,0 & 996,13 \\
\hline C3 & 0,158 & 11,8 & 996,13 \\
\hline C4 & 0,160 & 14,4 & 990,34 \\
\hline C5 & 0,170 & 15,0 & 564,19 \\
\hline C6 & 0,180 & 15,0 & 409,30 \\
\hline C7 & 0,190 & 15,0 & 331,60 \\
\hline C8 & 0,200 & 15,0 & 285,38 \\
\hline
\end{tabular}

Esta seção também apresenta os resultados comparativos para as quatro melhores combinações do absorvedor não linear que resultaram da análise paramétrica. Um sistema composto por um sistema primário e um absorvedor não-linear (PS + NLAbs) foi comparado com o seu correspondente linear (Fig. 4.3a). Para um dado $m_{s}$, os parâmetros correspondentes para o absorvedor linear equivalente $\left(k_{s n}\right)$ foram avaliados utilizando a metodologia de projeto proposto em (ORMONDROYD; HARTOG, 1928). Observe que o absorvedor linear não é otimizado para o sistema primário, mas considerou-se aqui fornecer alguma referência comparativa.

A Tab. 4.3 exibe os valores das amplitudes de vibração e o tamanho das faixas de frequência de supressão resultantes de cada conjunto $\left[L_{0}, m_{s}, k_{s n 1}\right]$. Ela foi ordenada de acordo com os valores obtidos para $\delta \omega_{n l}$, em ordem decrescente. A diferença entre a amplitude dada pelo sistema PS + NLAbs e a do sistema PS sozinho corresponde ao valor de $\delta A_{n l}$, que significa a redução de amplitude proporcionada pelo absorvedor não linear, como mostrado na Fig. 4.1a. Da mesma forma, $\delta A_{l}$ é referente à diferença de amplitude entre os sistema PS + LAbs e PS. Por consequência, a diferença entre os dois dados é fornecida na última coluna da tabela por $\delta A=\delta A_{n l}-\delta A_{l}$. Assim como na etapa 5 da análise paramétrica, $\delta \omega_{l}$ compreende também o tamanho da faixa de frequência na qual as amplitudes amp do sistema PS + LAbs são menores que as do sistema sem absorvedor acoplado. Desse modo, $\delta \omega=\delta \omega_{n l}-\delta \omega_{l}$ compara os valores de largura das faixas de frequência obtidos com os sistemas PS + NLAbs e PS + LAbs.

Tabela 4.3: Resultados dos melhores conjuntos de parâmetros para o absorvedor não linear

\begin{tabular}{|c|c|c|c|c|c|c|}
\hline Combinação & $\delta \omega_{n l}(\mathrm{~Hz})$ & $\delta \omega_{l}(\mathrm{~Hz})$ & $\delta \omega$ & $\delta A_{n l}(\mathrm{~dB})$ & $\delta A_{l}(\mathrm{~dB})$ & $\delta A(\mathrm{~dB})$ \\
\hline $\mathrm{C} 1$ & 10,2 & 3,5 & 6,7 & $-65,7$ & $-41,8$ & $-23,9$ \\
\hline C2 & 10,0 & 3,0 & 7,0 & $-67,0$ & $-45,3$ & $-21,7$ \\
\hline C3 & 9,9 & 2,6 & 7,3 & $-67,0$ & $-47,6$ & $-19,3$ \\
\hline C4 & 9,7 & 3,8 & 5,9 & $-66,7$ & $-49,4$ & $-17,3$ \\
\hline
\end{tabular}

O melhor conjunto de parâmetros $(\mathrm{C} 1)$ tem uma faixa de frequência de supressão 


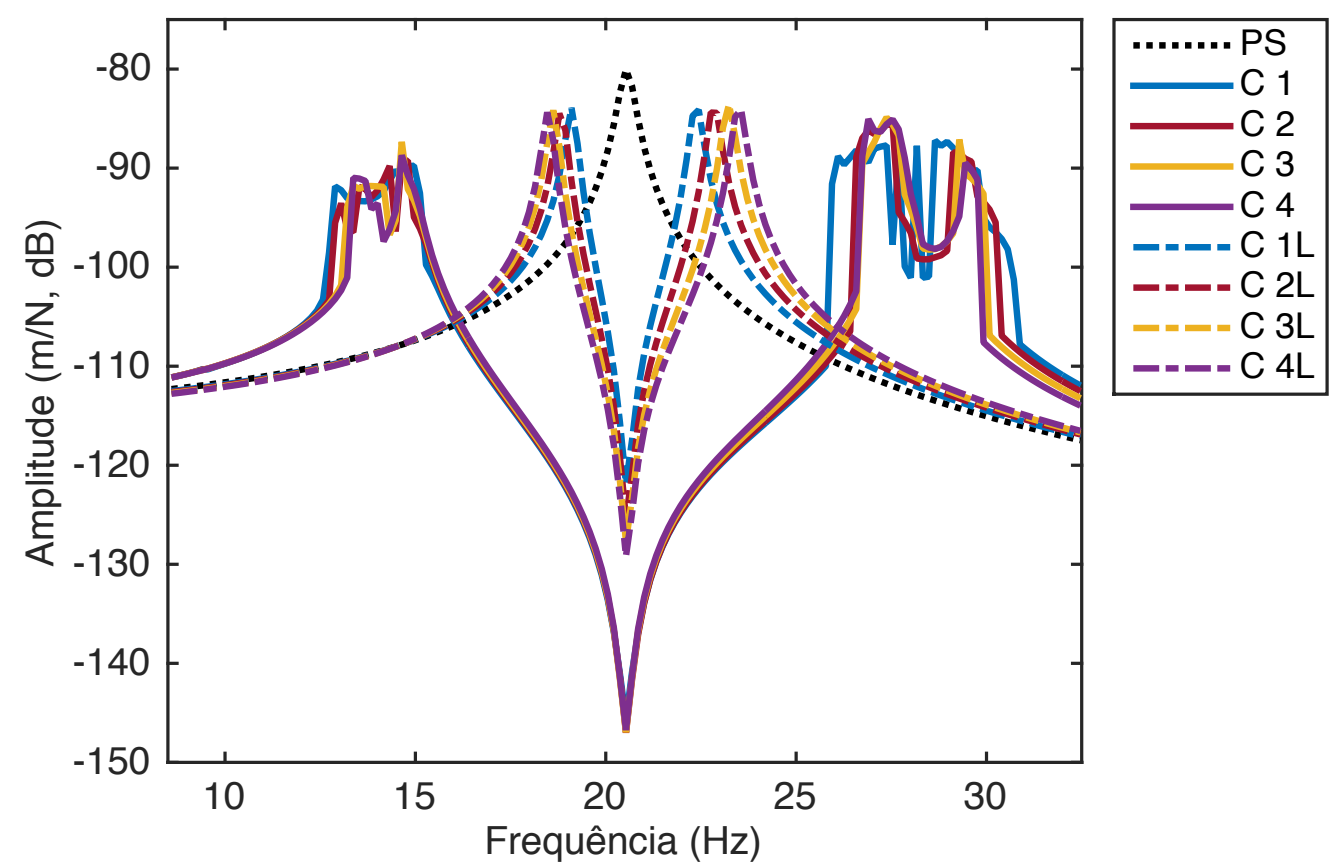

(a) Combinações de 1 a 4 .

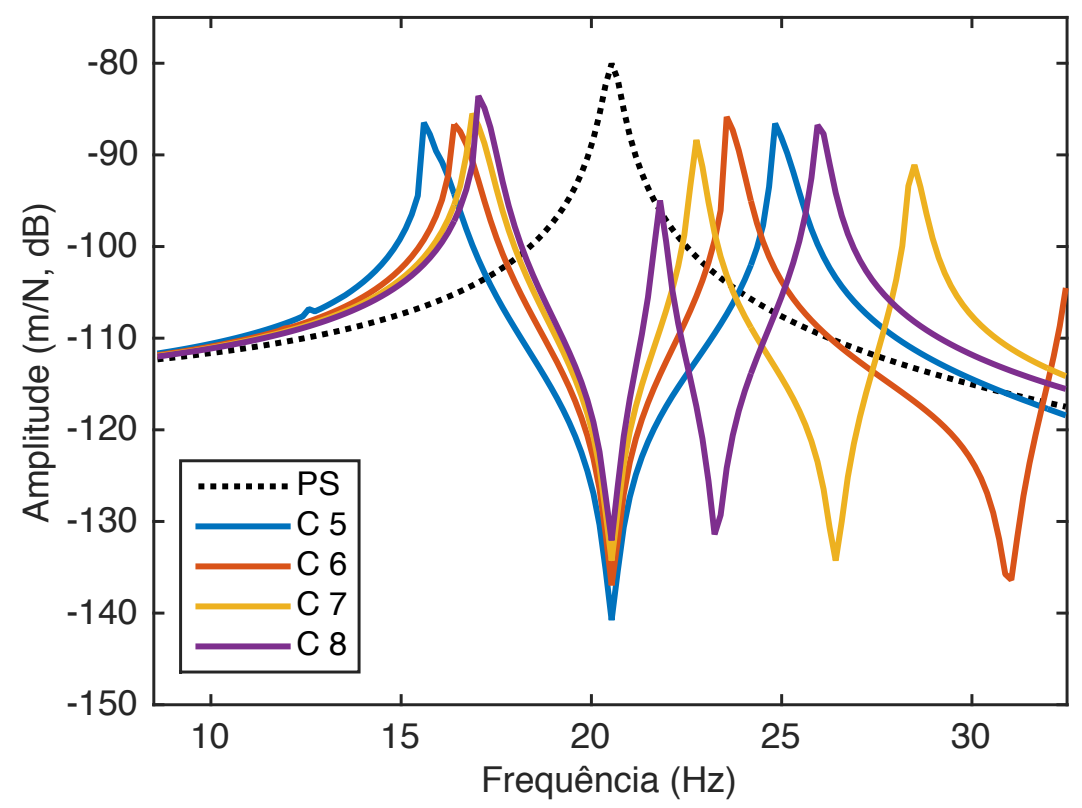

(b) Combinações de 5 a 8.

Figura 4.3: FRF do sistema primário (PS) sem absorvedor (pontilhada), com absorvedor linear (tracejada) e com absorveddor não linear (contínua) para as 8 combinações ótimas obtidas.

2,9 vezes superior ao seu correspondente linear. Mesmo o caso C4 ainda mostra um bom desempenho, mas sua massa $\left(m_{s}=14,4 \mathrm{~kg}\right)$ não é tão pequena quanto a de $\mathrm{C} 1$. Embora, a partir destes resultados, estes quatro conjuntos de parâmetros pareçam ser 
uma boa alternativa a um absorvedor de vibração linear equivalente, é geralmente vantajoso escolher uma solução com massa menor. As amplitudes de vibração foram reduzidos de 1,57 vezes (C1) e de 1,35 vezes (C4), em comparação com os casos lineares.

Um sistema linear com uma entrada periódica aplicada tem sempre uma saída periódica. Mas, ao contrário do caso linear, sabe-se que um sistema não linear pode alterar o seu comportamento em função da magnitude da força externa aplicada. Assim, é necessário verificar se este absorvedor não linear funciona da mesma maneira para diferentes magnitudes de força externa. Mudanças de comportamento podem representar desempenhos indesejáveis e possíveis limitações sobre o uso do absorvedor não linear. Uma maneira útil para identificar mudanças de comportamento é através de um diagrama de bifurcação.

A análise das posições de equilíbrio realizada anteriormente indicou que há três condições de equilíbrio válidas para este sistema não linear: I - $\left[u_{p}=-u_{e q}, u_{s}=\right.$ $\left.-u_{e q} / 2, v_{s}=0\right]$ : instável; II - $\left[u_{p}=0, u_{s}=0, v_{s}=\sqrt{L 0^{2}-L^{2}}\right]$ : estável; III - $\left[u_{p}=0\right.$, $u_{s}=0, v_{s}=-\sqrt{L 0^{2}-L^{2}}$ ]: estável. Este conhecimento é útil durante a análise de diagrama de bifurcação. Portanto, alguns gráficos do deslocamento no foram feitos para suportar estas análises.

A Fig. 4.4 é um diagrama de bifurcação. Ele foi construído tomando-se os últimos cem pontos a partir da resposta no domínio do tempo. O intervalo de tempo entre cada ponto de tomada corresponde ao período de oscilação do sistema primário. Assim, este diagrama inclui somente os pontos de resposta de regime estacionário, uma vez que foram extraídos a partir dos últimos cinco segundos do tempo de resposta. Para o caso absorvedor linear, a Fig. 4.4a é o diagrama de bifurcação e as Figs. 4.5 e 4.6 são as respostas no domínio do tempo para $500 \mathrm{~N}$ e $2500 \mathrm{~N}$ de amplitude da força. A partir destas figuras é nota-se que não há bifurcação devido ao absorvedor linear e o sistema primário estarem oscilando em torno de seus pontos de equilíbrio estáveis $\left(u_{p}=0 ; u_{s}=0\right)$. Além disso, em $2500 \mathrm{~N}$ o sistema excede os $5 \mathrm{~cm}$ impostos, transformando-se um sistema inválido no presente estudo. 


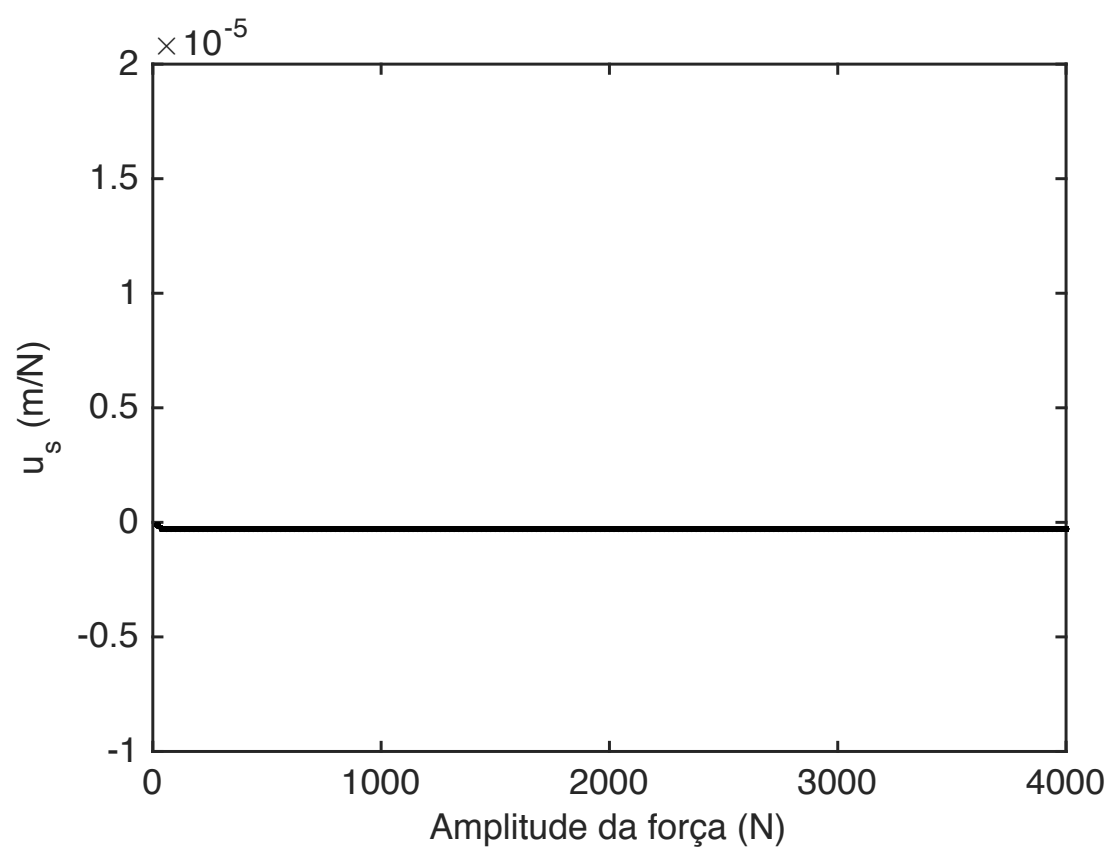

(a) PS + LAbs

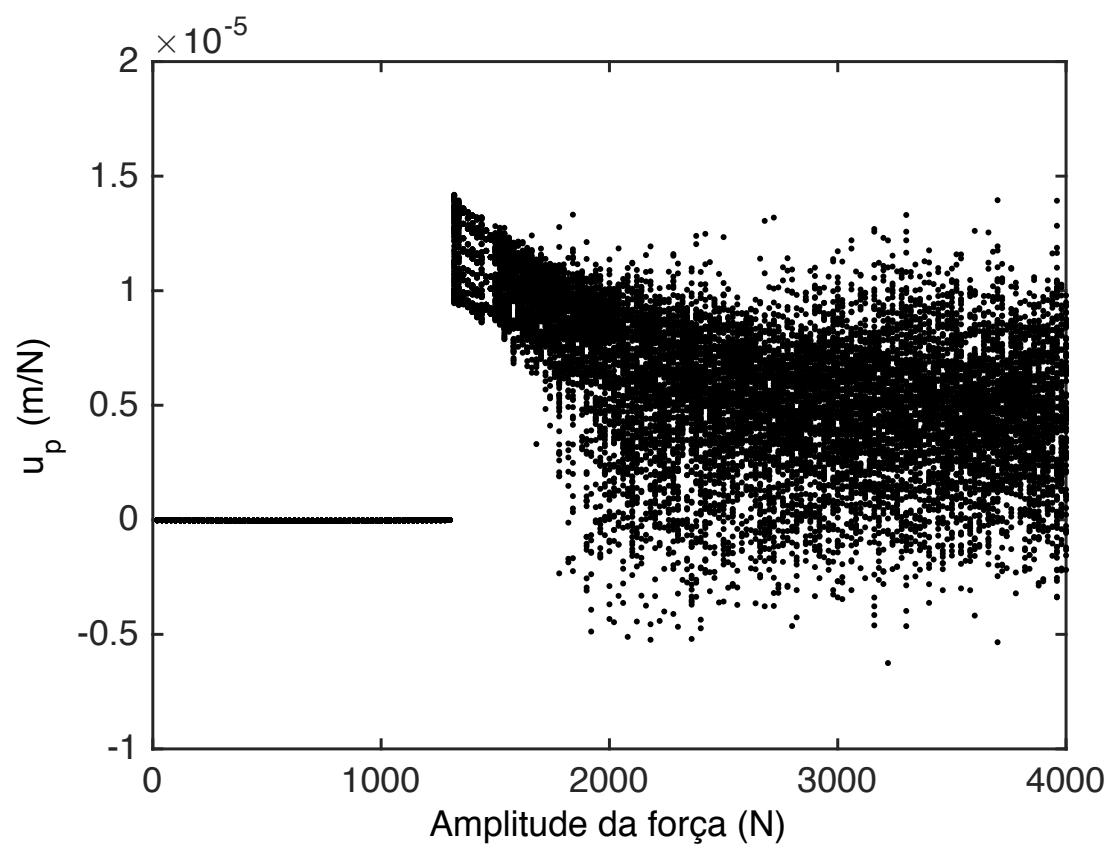

(b) PS + NLAbs

Figura 4.4: Diagrama de bifurcação da combinação $\mathrm{C} 1$ e seu correspondente linear. 


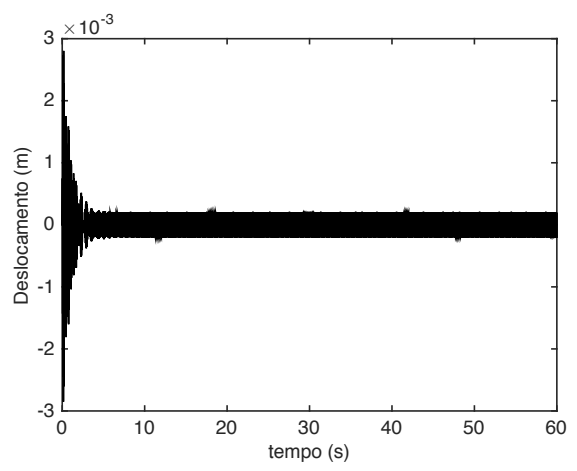

(a) Sitema primário $\left(u_{p}\right)$

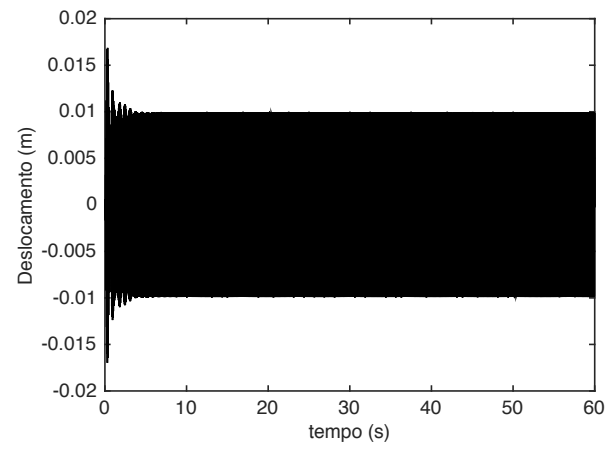

(b) LAbs horizontal $\left(u_{s}\right)$

Figura 4.5: Deslocamento do correspondente absorvedor linear da combinação C1 com amplitude da força, $f$, igual a $500 \mathrm{~N}$

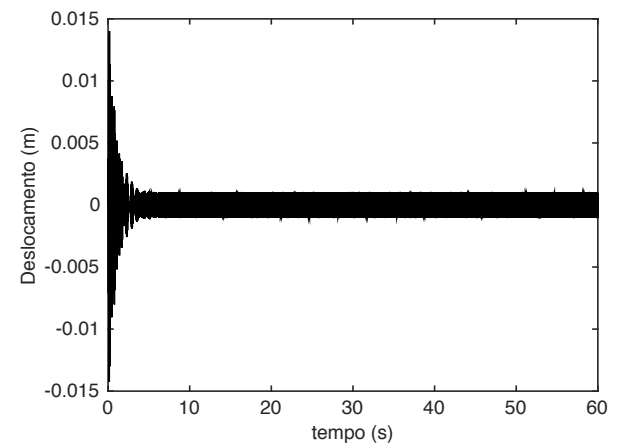

(a) Sitema primário $\left(u_{p}\right)$

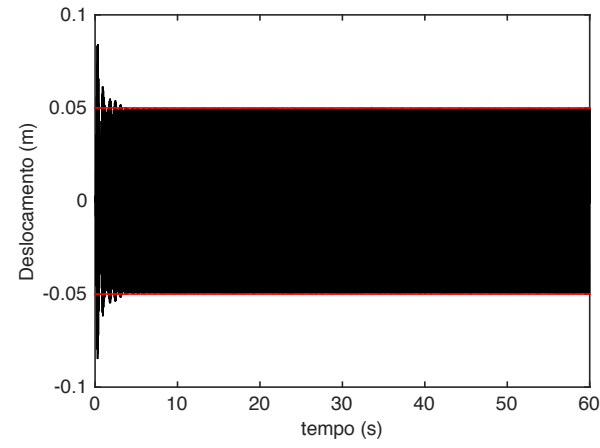

(b) LAbs horizontal $\left(u_{s}\right)$

Figura 4.6: Deslocamento do correspondente absorvedor linear da combinação C1 com amplitude da força, $f$, igual a $2500 \mathrm{~N}$ 


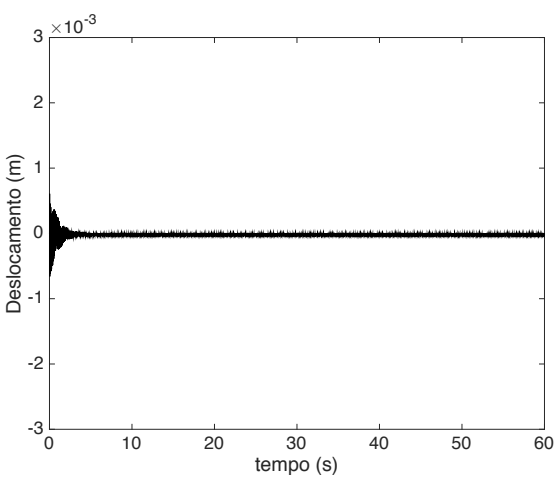

(a) Sitema primário $\left(u_{p}\right)$

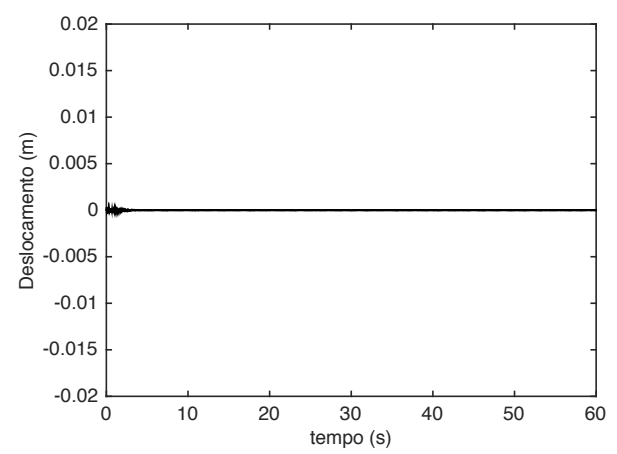

(b) NLAbs horizontal $\left(u_{s}\right)$

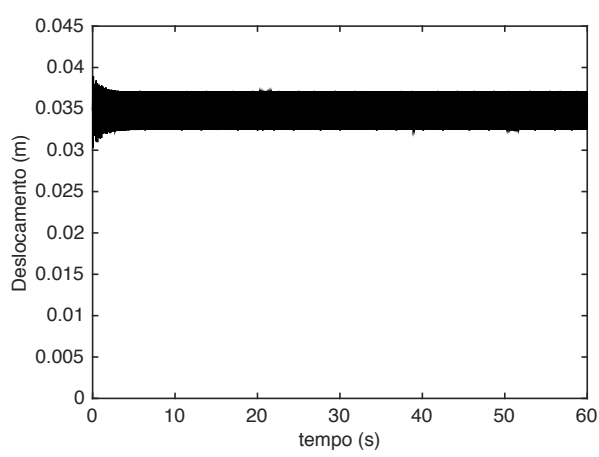

(c) NLAbs vertical $\left(v_{s}\right)$

Figura 4.7: Deslocamentos da combinação C1 com amplitude da força, $f$, igual a 500 $\mathrm{N}$

O diagrama de bifurcação e as respostas no domínio do tempo do sistema composto pelo sistema primário e o absorvedor de não linear (PS + NLAbs) foram exibidos nas Figs. 4.4b, 4.7 e 4.8. A partir de $0 \mathrm{~N}$ a $1300 \mathrm{~N}$, o diagrama mostra que o sistema tem uma resposta periódica de periodicidade um. Depois de $1300 \mathrm{~N}$ mais do que um período é visto e algumas bifurcações são vistas, entre 1320 N e 1560 N há um número limitado de períodos (cerca de oito) e a próxima região (após 1560 N) apresenta inúmeros períodos. A Fig. 4.7 mostra que, quando o NLAbs estiver oscilando em torno da posição de equilíbrio estável (II- $\left[v_{s}=\sqrt{L 0^{2}-L^{2}}=0,035 \mathrm{~m}\right]$ ) o sistema tem uma resposta periódica de periodicidade um. Quando as oscilações foram através da posição de equilíbrio instável (I) ( $f=1320 \mathrm{~N})$, como pode ser visto na Fig. 4.8c, a resposta do sistema exibe mais do que um período. Assim, para este conjunto de parâmetros (C1), é vantajoso e seguro utilizar o absorvedor não linear até $1300 \mathrm{~N}$.

Até o momento é possível afirmar que o absorvedor proposto é capaz de reduzir as amplitudes de vibração na frequência desejada. Além disso, é evidente a capacidade dele de ampliar a faixa de frequência de supressão. Porém, esses dois efeitos resultantes só são alcançados quando se garante que o absorvedor oscila verticalmente em torno de um dos seus pontos de equilíbrio estável, exclusivamente. Assim, deve-se controlar a amplitude da força para que não ocorra a passagem do absorvedor além 


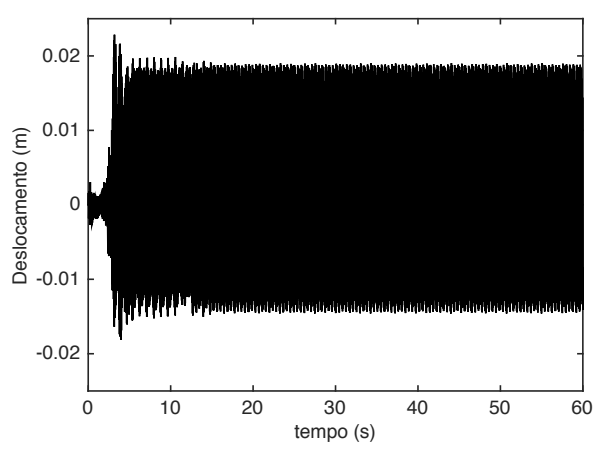

(a) Sistema primário $\left(u_{p}\right)$

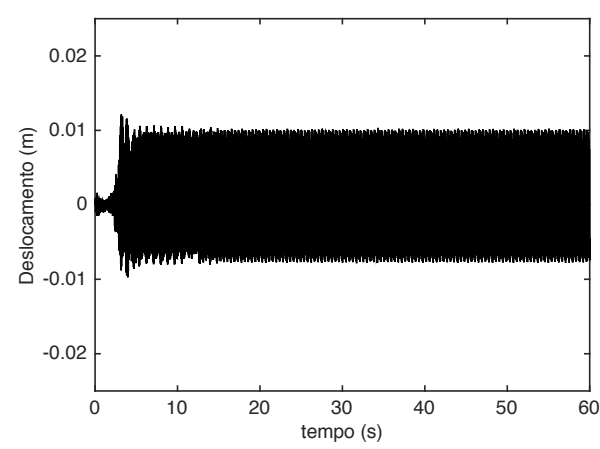

(b) NLAbs horizontal $\left(u_{s}\right)$

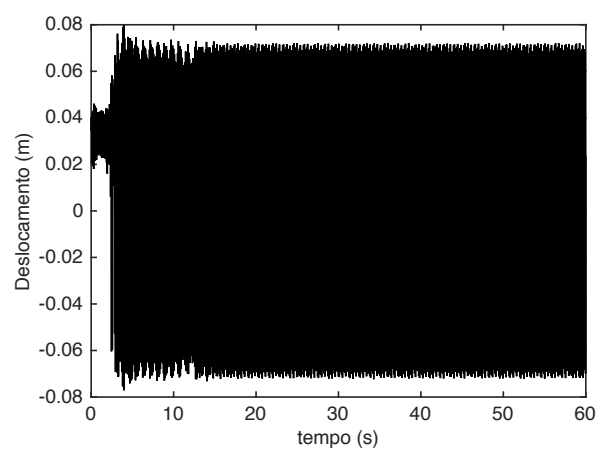

(c) NLAbs vertical $\left(v_{s}\right)$

Figura 4.8: Deslocamentos da combinação C1 com amplitude da força, $f$, igual a 1320 $\mathrm{N}$

da linha horizontal, $v_{s}=0$. Portanto, ele cumpre com seus objetivos e tal situação somente seria melhor se o sistema com absorvedor gerasse os dois picos com amplitudes menores do que as resultantes até agora. 


\section{Capítulo 5}

\section{Otimização por algoritmo genético}

A possibilidade de uso de um algoritmo de otimização surgiu da dificuldade em se estabelecer um intervalo de valores para busca do $k_{s n}$ ótimo e ao mesmo tempo não tornar esse processo demasiadamente custoso através da discretização desse intervalo. Optou-se por empregar a otimização por algoritmo genético devido à necessidade de se obter o mínimo global de uma função que pode mudar sua forma significativamente e subitamente com a alteração de um dos parâmetros sistema. Por se tratar de um método heurístico, há dificuldades e não há garantias que ele retornará o mínimo global; contudo esse tipo de método quando bem configurado representa uma ótima alternativa na busca por um mínimo global.

A configuração do sistema principal e os parâmetros do absorvedor são dados na Tab. 5.1. O amortecimento sobre o absorvedor continua sendo estabelecido da mesma forma que ocorreu no Capítulo 4, através das equações (2.25). Nessa etapa do trabalho houve uma alteração no modo de definir a condição inicial, porque com o uso da equação (2.11), quando $L_{0}=L=0,150 \mathrm{~m}$, definia-se que o absorvedor se moveria apenas na direção horizontal. Contudo, surgiu o interesse em saber o que aconteceria se o absorvedor pudesse se mover verticalmente ainda que não houvesse uma compressão nas molas do mesmo quando este está alinhado com o sistema principal na direção horizontal. Para realizar esse procedimento incluiu-se um pequeno deslocamento inicial na direção vertical, somente para permitir que o absorvedor se deslocasse também nessa direção, assim ele se move nas duas direções mas sem aquela tensão inicial nas molas. O cálculo dessa posição inicial do absorvedor referente à direção vertical foi realizado segundo a equação (5.1). Assim, a posição inicial do absorvedor já não é mais sobre um ponto de equilíbrio, mas sim muito próxima a ele. A equação (5.1) foi escrita dessa forma para garantir que o afastamento do absorvedor em relação à posição de equilíbrio fosse proporcional e pequeno em relação ao valor do mesmo. $\mathrm{O}$ valor constante de $1 \times 10^{-4}$ foi inserido a fim de fazer com que o absorvedor pudesse se mover verticalmente.

$$
x_{5}=1 \times 001 \sqrt{L_{0}^{2}-L^{2}}+1 \times 10^{-4}
$$


Tabela 5.1: Valores dos parâmetros para o sistema com absorvedor não linear.

\begin{tabular}{|c|c|c|c|}
\hline Condição & Parâmetros & Símbolo & Valores \\
\hline \multirow{4}{*}{ Fixos } & Massa primária $(\mathrm{kg})$ & $m_{p}$ & 60 \\
\cline { 2 - 4 } & Coef. amortecimento primário (N.s/m) & $c_{p}$ & 154,92 \\
\cline { 2 - 4 } & Coef. rigidez primário (N/m) & $k_{p}$ & $1 \times 10^{6}$ \\
\cline { 2 - 4 } & Amplitude da força(N) & $f$ & 500 \\
\hline \multirow{3}{*}{ Variáveis } & Massa do absorvedor $(\mathrm{kg})$ & $m_{s}$ & $3: 0,5: 15$ \\
\cline { 2 - 4 } & Coef. de rigidez do absorvedor (N/m) & $k_{s n}$ & otimização (AG) \\
\cline { 2 - 4 } & Tamanho da mola $(\mathrm{m})$ & $L_{0}$ & $0,150: 0,001: 0,160 ; 0,162 ;$ \\
& & & 0,$165 ; 0,170 ; 0,180 ; 0,200$ \\
\hline
\end{tabular}

Após a mudança no método de otimização, executaram-se as etapas semelhantes às mencionadas no Capítulo 4, nas quais se constrói um conjunto de dados referente às características do absorvedor não linear e aos resultados avaliados em cada caso segundo os critérios de avaliação citados. Entretanto, colocam-se aqui as etapas com intenção de destacar as diferenças, principalmente na etapa 2 onde, obviamente, se realiza otimização por algoritmos genéticos, na etapa 4 que faz uso de um novo critério de avaliação e na etapa 5 que ordena os resultados de diferentes modos.

Etapa 1: Planejamento dos conjuntos. Determinação dos conjuntos que envolvem os parâmetros do absorvedor considerando restrições de custo computacional e de tempo.

Etapa 2: Obtenção do $k_{s n}$. Definição do $k_{s n}$ ótimo a cada par $\left[L_{0}, m_{s}\right]$ utilizando algoritmo genético, como mostrado na seção 5.1.

Etapa 3: Variação da frequência. Cada trio $\left[L_{0}, m_{s}, k_{s n}\right]$ resultante é submetido a uma nova série de simulações numéricas, que varia a frequência de excitação $(\omega)$ do sistema. Os dados retornados permitem a construção da curva Amplitude $x$ Frequência.

Etapa 4: Critérios de avaliação (subseções 4.1 .1 e 5.1.1). A partir da comparação entre cada curva de Amplitude x Frequência do sistema PS + NLAbs com relação a curva do sistema original formado apenas pelo PS, foram propostas métricas que permitam avaliar o desempenho de cada solução $\left[L_{0}, m_{s}, k_{s n}\right]$.

Etapa 5: Ordenação dos resultados. Os 400 sistemas $\left[L_{0}, m_{s}, k_{s n}\right]$ derivados da combinação dos 25 valores de $m_{s}$ com os 16 de $L_{0}$, para os quais se encontrou um $k_{s n}$ ótimo, foram ordenados de três formas distintas. De acordo com as métricas propostas, as soluções foram ordenadas com desempenho decrescente para se identificar as melhores soluções para cada critério. 


\subsection{Otimização do absorvedor não linear usando algoritmos genéti- $\cos$ para $k_{s n}$}

A etapa 2 citada acima, na qual se define o $k_{s n}$ ótimo, empregou a otimização por algoritmos genéticos para encontrar o mínimo global da curva Amplitude $x$ Rigidez para cada par de parâmetros $\left[L_{0}, m_{s}\right]$. Para isso utilizou-se a ferramenta de otimização $g a$ do software MATLABß. Dado o fato que o emprego desse método não é tão simples e direto, por causa das muitas variáveis necessárias à configuração da função $g a$, é fundamental que se sabia a maneira como o software MATLAB® efetua o procedimento. Sendo assim, abaixo é exposto o modo como a função é executada:

1. Uma população inicial aleatória é criada. Cada indivíduo da população é representado por um valor da rigidez do absorvedor, $k_{s n}$.

2. O algoritmo gera uma sequência de novas populações e a cada passo ele utiliza a população atual para criar a próxima geração. Para criar a nova população, o algoritmo desenvolve os seguintes passos:

2.1. Pontua cada membro da população atual registrando seu valor de saída na função objetivo, definida aqui como a amplitude da resposta do sistema primário quando excitado por forçamento harmônico com frequência igual à frequência de ressonância do sistema primário.

2.2. Escalona os valores obtidos de modo a transformá-los em um conjunto melhor utilizável.

2.3. Seleciona os membros que serão pais baseado em seus valores.

2.4. Forma o grupo Elite. Os indivíduos da população atual que têm os menores valores são colocados como membros deste grupo e esses elementos são levados à próxima geração sem sofrer mutação ou cruzamento.

2.5. Gera os filhos a partir dos pais. Os filhos são gerados tanto ao introduzir mudanças aleatórias em um pai, processo chamado de mutação, quanto através da combinação de dois pais, o cruzamento.

2.6. Substitui a população atual com os filhos gerados para formar a próxima geração.

3. O algoritmo é encerrado quando alcança algum dos critérios de parada determinados.

Tendo uma visão geral do modo como o algoritmo executa a busca pelo mínimo global, trata-se agora da configuração aplicada à ferramenta de otimização ga. A configuração foi efetuada da seguinte forma: tamanho da população, 88; fração de cruzamento, 0,8; função de cruzamento, aritmética (Arithmetic); função de mutação, gaussiana (Gaussian); função de seleção, uniforme estocástica (Stochastic uniform); extensão 
da população inicial, $\left[10^{3}-10^{7}\right]$; contagem de elite (número de elementos que integram o grupo elite), 6; número de gerações, 20.

De acordo com a documentação do site Mathworks (MATHWORKS, 2016) sobre a função $g a$, aconselha-se usar o tamanho da população de até 50 elementos nos casos em que o número de variáveis é menor ou igual a 5. A situação em estudo envolve apenas uma variável, $k_{s n}$, por isso, 50 seria o número adequado quando se quer garantir que o algoritmo retorne o mínimo global da função. Todavia, é fundamental considerar a estrutura computacional à disposição para fazer o uso mais eficiente de todos os recursos, uma vez que se almeja realizar as simulações em paralelo no MATLAB $®$, que consiste em cada núcleo do processador realizar um ensaio numérico, deve-se observar que o cluster computacional disponível possui 88 núcleos e cada um corresponde a um worker para o MATLAB®. Se utilizássemos apenas 50 indivíduos por geração, 38 workers permaneceriam inativos a cada geração. Portanto, utilizar uma população com 88 indivíduos é a melhor alternativa para usufruir da estrutura computacional e garantir resultados mais confiáveis.

Para entender como funcionam a fração de cruzamento, a contagem de elite e a mutação, observe que dos 88 indivíduos a fração de $80 \%$ deverá sofrer cruzamento, 70 deles então. $\mathrm{O}$ número de elite propõe que os 6 melhores passem à próxima geração sem sofrer qualquer processo e os 12 restantes são os que sofrem mutações aleatórias. A quantidade de indivíduos disponíveis para mutação é relevante, pois a mutação se encarrega da diversidade genética e permite ao algoritmo genético procurar em um espaço de soluções maior. Em outras palavras, considere a Fig. 3.2, ela tem dois mínimos locais bem definidos. Vamos supor que por motivos aleatórios o algoritmo se aproxime do mínimo local localizado a esquerda. Um número grande de indivíduos destinados a reprodução fará com que se chegue ao valor desse mínimo de maneira mais rápida, porém, são os indivíduos que sofrem mutação que permitem ao algoritmo "enxergar" valores além daquela faixa que está sendo observada. Um indivíduo que sofre mutação pode gerar, na próxima geração, um novo indivíduo localizado próximo ao segundo mínimo local e fazer com que o algoritmo acesse o ponto de mínimo que contém a resposta esperada nessa circunstância.

A função de mutação adotada, gaussiana, função padrão do MATLAB® na otimização, seleciona um número aleatório de uma distribuição Gaussiana com média nula e desvio padrão igual à diferença entre os limites superior e inferior e o adiciona a um pai. Para garantir convergência, o desvio padrão diminui linearmente conforme passam as gerações. A função de seleção empregada define uma linha na qual cada um dos pais corresponde a uma seção da linha de comprimento proporcional ao seu valor escalonado. $\mathrm{O}$ algoritmo move-se ao longo dessa linha em passos de igual tamanho, a cada passo o algoritmo separa um pai a partir da seção em que ele está. $\mathrm{O}$ primeiro passo é um número aleatório uniforme menor que o tamanho do passo fixo. 
No caso da função de cruzamento, os filhos são gerados aleatoriamente a partir da média aritmética ponderada dos dois pais.

Com intuito de não limitar a busca do algoritmo dentro de um intervalo de valores, não foram dados os limites inferior e superior da população, no entanto, para proporcionar que os $k_{s n}$ ótimos fossem encontrados de maneira mais rápida definiuse que a população inicial estaria contida dentro do intervalo de $10^{3} \mathrm{~N} / \mathrm{m}$ a $10^{7} \mathrm{~N} / \mathrm{m}$. Por mais que essa opção possa influenciar a busca, ela não restringe a busca somente a esse intervalo e para casos extremos ainda poderia ser obtido o valor adequado.

O número de gerações foi definido para garantir que houvessem tantas gerações quanto fossem necessárias, ainda que este possa funcionar como critério de parada. Porém, utilizou-se como principal critério de parada a situação em que o valor médio da função não sofresse alteração maior que $10^{-12}$ ao longo de 7 gerações seguidas. Isso foi definido nas opções da função ga como StallGenLimit $=7$ e TolFun $=10^{-12}$.

Apesar dos bons resultados obtidos anteriormente através de uma busca extensiva para o valor de $k_{s n}$ que entregaria a menor amplitude de vibração dado um par $\left[L_{0}, m_{s}\right]$, determinar o conjunto de valores de $k_{s n}$ necessário para fazer uma busca extensiva mais efetiva e que desse origem a melhores resultados seria mais difícil. Após algumas tentativas optou-se por empregar uma nova ferramenta, a otimização por algoritmo genético. Deixar de fazer a busca extensiva e utilizar a otimização foi importante por duas razões. A primeira foi diminuir o tempo gasto a cada rodada de simulações para as muitas combinações. A segunda foi a possibilidade de calcular o valor da rigidez $k_{s n}$ de forma mais precisa sem a necessidade de um conjunto de valores para $k_{s n}$ cuja discretização resultaria num grande custo computacional. Entretanto, há a desvantagem de perder a informação de toda a curva Amplitude $x$ Rigidez que era gerada na busca extensiva para os pares $\left[L_{0}, m_{s}\right]$, uma vez que a otimização retorna somente o valor mínimo de amplitude e o $k_{s n}$ correspondente. Há também a dificuldade em configurar os parâmetros da otimização e, por se tratar de um processo aleatório, é difícil garantir que o ajuste dos parâmetros de configuração é o ideal e vai sempre entregar o resultado correto. Para tentar garantir o melhor ajuste da configuração da otimização, validou-se a otimização com base em algumas curvas obtidas via busca extensiva. Vale ressaltar que, apesar de uma configuração parecer ser adequada a um conjunto de curvas, esta pode ser inadequada a um outro conjunto. Mesmo assim, espera-se que a otimização forneça valores bem ajustados ao reais encontrados caso a caso.

\subsubsection{Terceiro critério de avaliação}

Até o momento foram empregados dois critérios para medir o desempenho do absorvedor que são, a redução de amplitude do sistema principal $\left(\delta A_{n l}\right)$ e a faixa de frequência de supressão $\left(\delta \omega_{n l}\right)$, mostrados na seção 4.1.1. Além desses, uma ter- 
ceira forma de avaliar o desempenho do absorvedor é proposta nesta seção, definida pela área calculada no gráfico Amplitude x Frequência ao longo do trecho no qual as amplitudes do sistema com absorvedor acoplado são menores que o caso sem absorvedor, conforme a Fig 5.1. Esse tipo de avaliação auxiliar foi pensado ao longo do desenvolvimento do projeto, pois notou-se que somente observar numericamente a redução e/ou a faixa de supressão não permitia determinar com facilidade quais as melhores configurações para o absorvedor, uma vez que, por exemplo, pode-se obter uma satisfatória redução ao mesmo tempo que se tem uma estreita faixa de frequência. Por isso, vincularam-se as duas características anteriores a esta terceira, uma vez que os sistemas com maiores áreas são aqueles que tendem a ter maior redução e faixa de frequência. $O$ cálculo dos valores de área foram feitos utilizando a função $\operatorname{trapz}(Y)$ do MATLAB®, que retorna o valor da integral aproximada da curva $Y$ obtido pelo método trapezoidal. Esse método aproxima a integração em um intervalo dividindo a área em trapézios de áreas mais fáceis de computar. Esse cálculo considerou as amplitudes em $\mathrm{dB}$ de modo a garantir que os resultados obtidos para área fossem distintos dos obtidos para $\delta \omega_{n l}$, uma vez que os valores de amplitude não são da mesma ordem de grandeza que os de frequência, sendo aqueles muito menores. Assim, visou-se atribuir a $\delta A_{n l}$ a mesma importância que $\delta \omega_{n l}$ na composição dos resultados da área calculada.

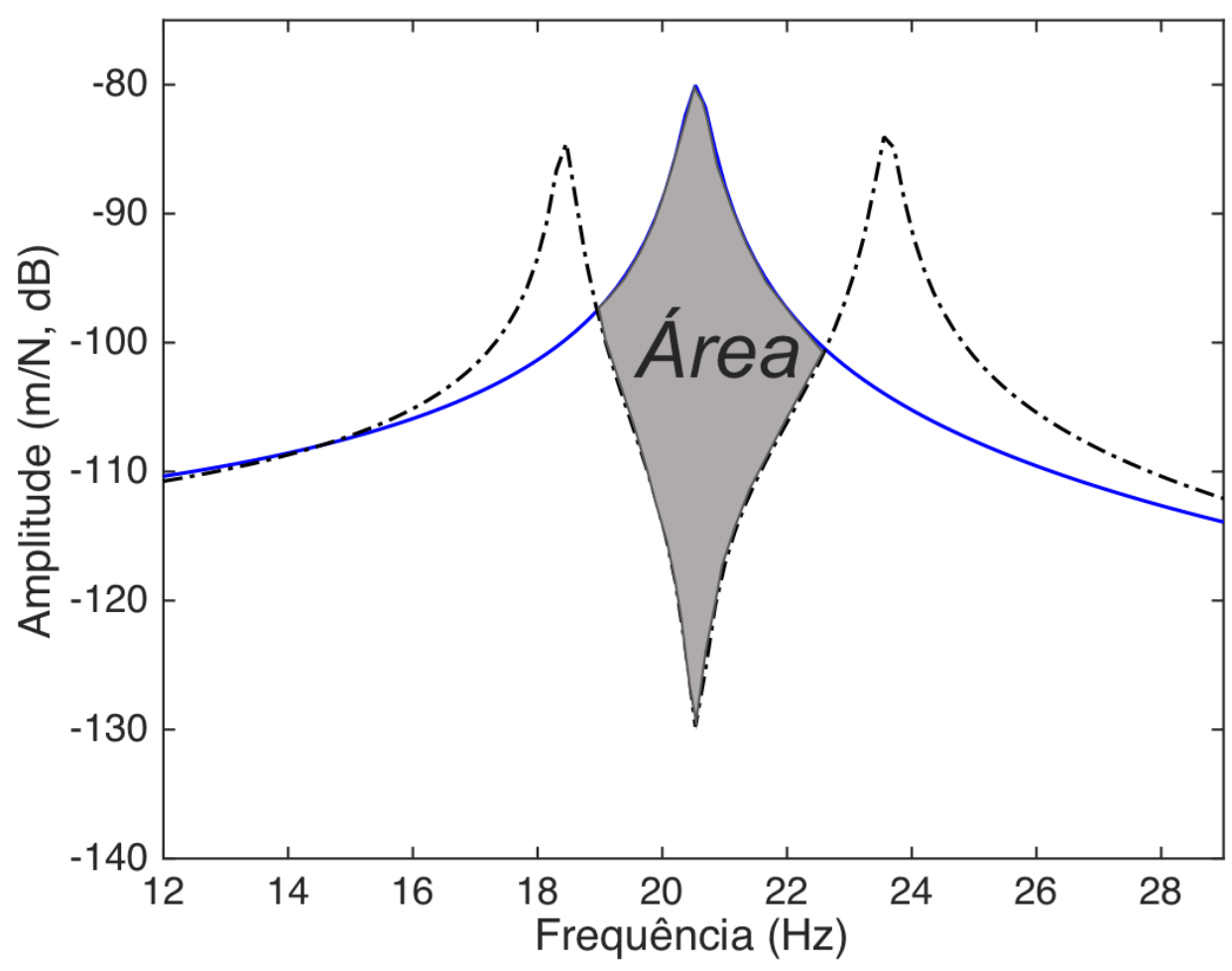

Figura 5.1: Exemplo para a medida da Área. 


\subsection{Análise dos resultados obtidos com algoritmos genéticos}

A análise dos resultados será guiada de modo a explorar as características mais gerais resultantes do conjunto de dados obtidos e conforme surgirem as particularidades estas serão estudadas. O primeiro modo de observar esse conjunto obtido é através da topologia resultante dos critérios de avaliação de acordo com os parâmetros do absorvedor. Os primeiros resultados exibem três superfícies, cada uma formada pelos pares $\left[L_{0}, m_{s}\right]$ e por um dos critérios de avaliação $\left(\delta \omega_{n l}, \delta A_{n l}\right.$ e Área). Nas três figuras, quanto maior o valor resultante para cada critério, melhor o resultado.

Nota-se na Fig. 5.2a que os maiores valores de $\delta \omega_{n l}$ estão ligados aos menores valores de $L_{0}$. Esses valores encontram-se em $0,150 \leqslant L_{0} \leqslant 0,153 \mathrm{~m}$, pois quando $L_{0} \geqslant 0,154 \mathrm{~m}$ esses valores caem significativamente. Até $L_{0}=0,153 \mathrm{~m}$, quando se aumenta $m_{s}$, percebe-se também uma tendência de aumento em $\delta \omega_{n l}$.

Além disso, quando $L_{0}=0,150 \mathrm{~m}$ a faixa de frequência tem o mesmo tamanho para todos os valores de $m_{s}$. Sobre essa situação ainda não é possível inferir sobre o que pode estar acontecendo nessa situação.

A análise do comportamento de $\delta A_{n l}$ segundo os pares $\left[L_{0}, m_{s}\right]$, na Fig. 5.2b evidencia também uma região de maiores valores de $\delta A_{n l}$ quando $L_{0} \leqslant 0,160 \mathrm{~m}$. Para $L_{0}=0,151 \mathrm{~m}$, os valores de $\delta A_{n l}$ crescem significativamente a partir de $m_{s}=6,5 \mathrm{~kg}$ e após $m_{s}=10,5 \mathrm{~kg}$ se tornam os maiores dentre todos os obtidos. Quando $L_{0}=0,150$ $\mathrm{m}, \delta A_{n l}$ mantém praticamente o mesmo valor, o que desperta interesse quando se lembra do mesmo caso ao se observar os valores de $\delta \omega_{n l}$ na Fig. 5.2a.

Através do gráfico 5.2c percebe-se que os maiores valores de Área correspondem aos casos em que $L_{0}=0,150 \mathrm{~m}$ e $L_{0}=0,151 \mathrm{~m}$. Os casos em que $L_{0}=0,150 \mathrm{~m}$ mantêm valores muito próximos de Área à medida que se altera o valor de $m_{s}$, revelando que a troca de $m_{S}$ altera muito pouco a resposta do sistema quanto aos critérios de avaliação escolhidos e que, provavelmente, o comportamento desses casos é muito semelhante ao menos nessa região do espectro de frequência.

Portanto, é possível afirmar que os melhores resultados se encontram entre os menores valores de $L_{0}$ e que dessa região sairão as combinações de parâmetros que entregarão os melhores resultados, e que apesar dos bons resultados em que $0,150 \leqslant$ $L_{0} \leqslant 0,153 \mathrm{~m}$, não foi possível ver uma relação entre $\delta \omega_{n l}$ e $\delta A_{n l}$ como era esperado a partir do resultados do capítulo anterior. Esperava-se que quanto maior a redução de amplitude, maior seria a faixa de supressão, todavia, a enorme queda nos valores de $\delta \omega_{n l}$ quando $L_{0} \geqslant 0,154$ não é refletida com uma grande mudança nos valores de redução.

Após a visualização mais geral dos resultados, torna-se válido observar ao menos alguns dos melhores resultados para cada uma das classificações acima. Com isso, analisa-se a seguir a curva Amplitude x Frequência segundo as três formas de orde- 


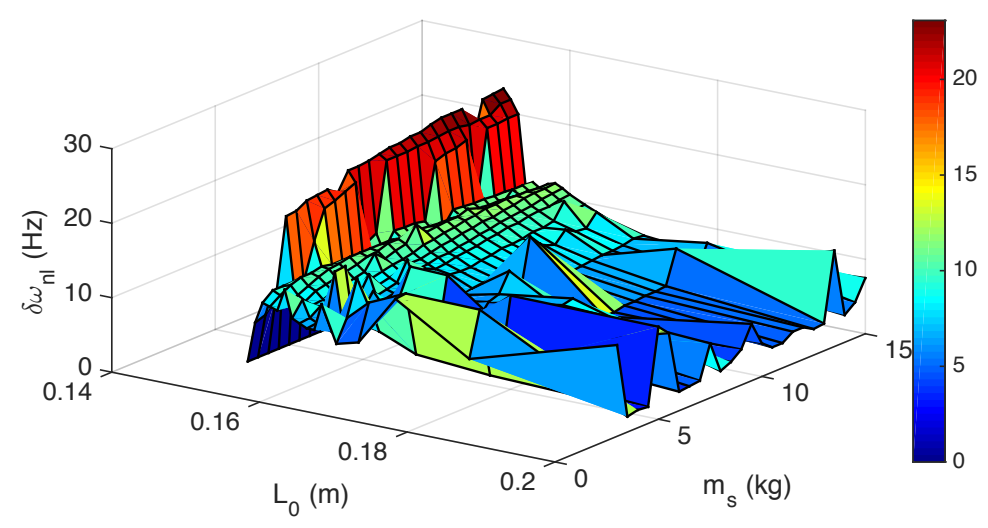

(a) $\delta \omega_{n l}$

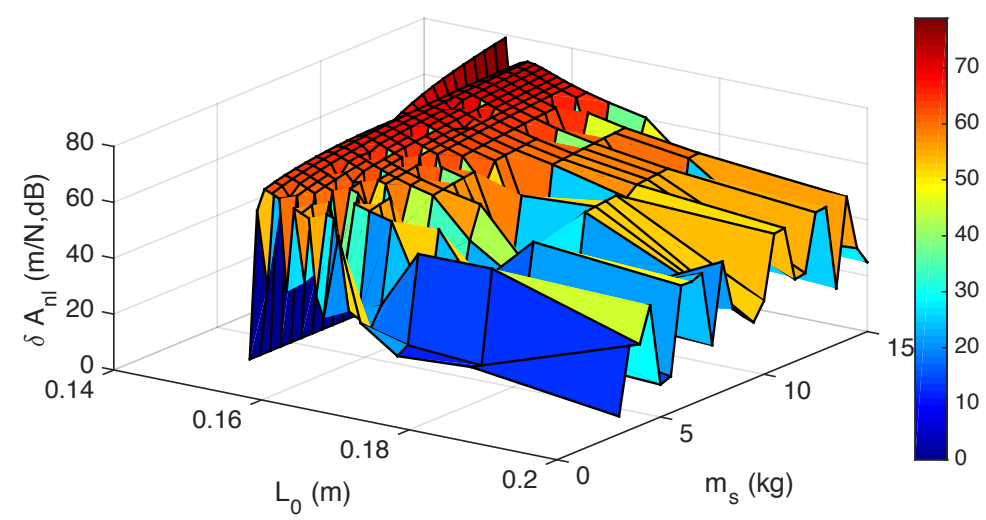

(b) $\delta A_{n l}$

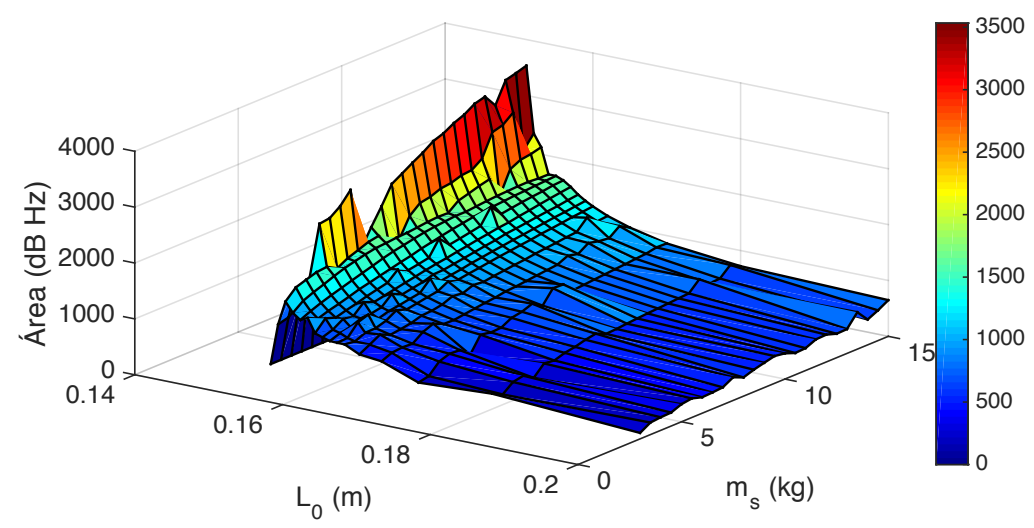

(c) Área

Figura 5.2: Valores da faixa de supressão $\left(\delta \omega_{n l}\right)$, redução da amplitude de vibração $\left(\delta A_{n l}\right)$ e Área para diferentes valores de massa do absorvedor $\left(m_{S}\right)$ e comprimento da mola indeformada $\left(L_{0}\right)$ 
nação dos resultados mencionadas na Etapa 5. Foram mostrados os 5 primeiros casos de cada lista por figura. A linha pontilhada corresponde ao sistema principal sem acoplamento do absorvedor.

A Fig. 5.3a mostra, como esperado desde a Fig. 5.2a, que todas as combinações apresentam o tamanho máximo da faixa de supressão, de $8,5 \mathrm{~Hz}$ a $32,5 \mathrm{~Hz}$. Além disso, como o comportamento nessa faixa de frequência observada é idêntico para os cinco casos observados, com auxílio das Figs. 5.2a e 5.2b, pode-se afirmar que o comportamento de todos os casos em que $L_{0}=0,150 \mathrm{~m}$ é o mesmo nessa faixa de frequência observada. Por enquanto, resta o questionamento acerca do que está acontecendo nesses casos em que $L_{0}=L=0,150 \mathrm{~m}$, por isso, mais adiante vamos analisar algum caso específico de modo a tentar compreender o que ocorre.

As Figs. 5.3c e 5.3b são muito semelhantes e, com exceção da combinação 47 que não está na seleção das que têm a maior Área, percebe-se que a busca por uma maior área resultou numa boa associação entre os critérios utilizados para avaliação. Nelas é evidente a grande redução de amplitude do PS promovida pela adição do absorvedor, não só na região próxima à antirressonância, como também em frequências mais distantes desse ponto. Ainda sem evidenciar números, esse resultado se mostra surpreendente devido à grande extensão da faixa de supressão resultante. Dentro desses resultados, observa-se que todas as curvas interceptam a curva do PS em duas regiões, uma antes dos $10 \mathrm{~Hz}$ e outra entre 14,48 Hz e 15,28 Hz. Nesta segunda região, apesar das curvas cruzarem a curva do PS, esse cruzamento não necessariamente deve ser considerado durante a avaliação de desempenho, já que os valores máximos nessa região são muito próximos ao do sistema sem acoplamento numa região de relativa baixa amplitude de vibração quando comparada à região de ressonância.

Sabendo disso, optou-se por adotar uma tolerância de $1 \mathrm{~mm}$ na amplitude de vibração do sistema principal sem absorvedor para o cálculo da Área e de $\delta \omega_{n l}$ compreendida entre as duas curvas, o que significa que todos os sistemas que cruzaram a linha pontilhada em algum momento poderiam desenvolver uma amplitude, em valores absolutos, $1 \mathrm{~mm}$ maior antes de retornar abaixo da curva do PS.

Mesmo que as amplitudes desenvolvidas na região próxima aos $15 \mathrm{~Hz}$ não sejam significativas quando comparadas às do PS sem absorvedor, é fundamental que se compreenda o que ocorre ali. Por isso, essa característica será estudada mais adiante com intuito de desvendar que tipo de fenômeno está ocorrendo. Por ora, sabe-se que a liberdade de movimento na direção vertical do absorvedor tem o potencial de promover um significativo aumento da faixa de frequência de supressão e também de reduzir consideravelmente as amplitudes de vibração do sistema primário nas proximidades da sua frequência de ressonância.

Ao observarmos a região de frequência estudada nos gráficos 5.2a e 5.3a, viu-se que para $L_{0}=0,150 \mathrm{~m}$ o comportamento era muito semelhante em todos os casos e 


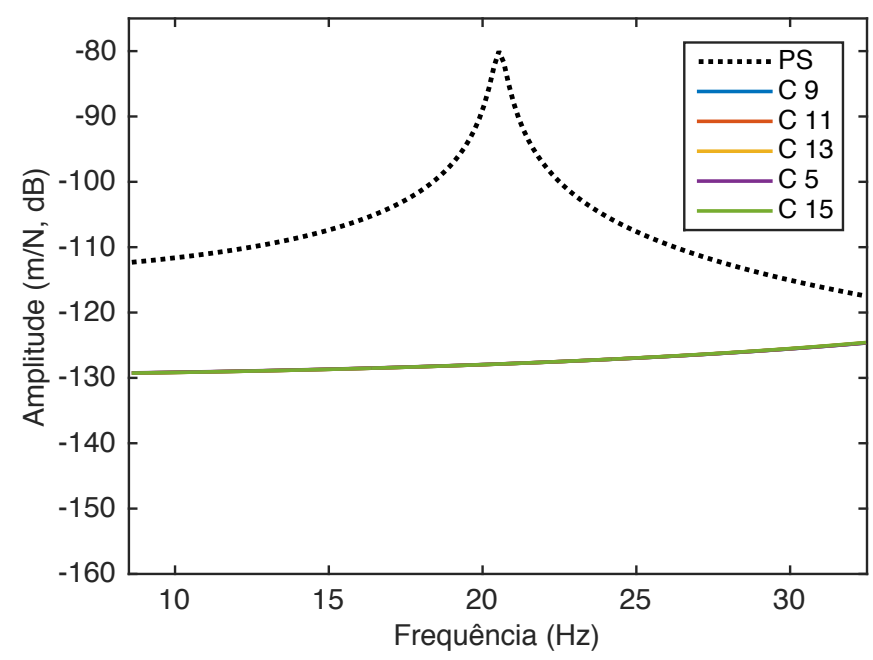

(a) Cinco maiores faixas de frequência

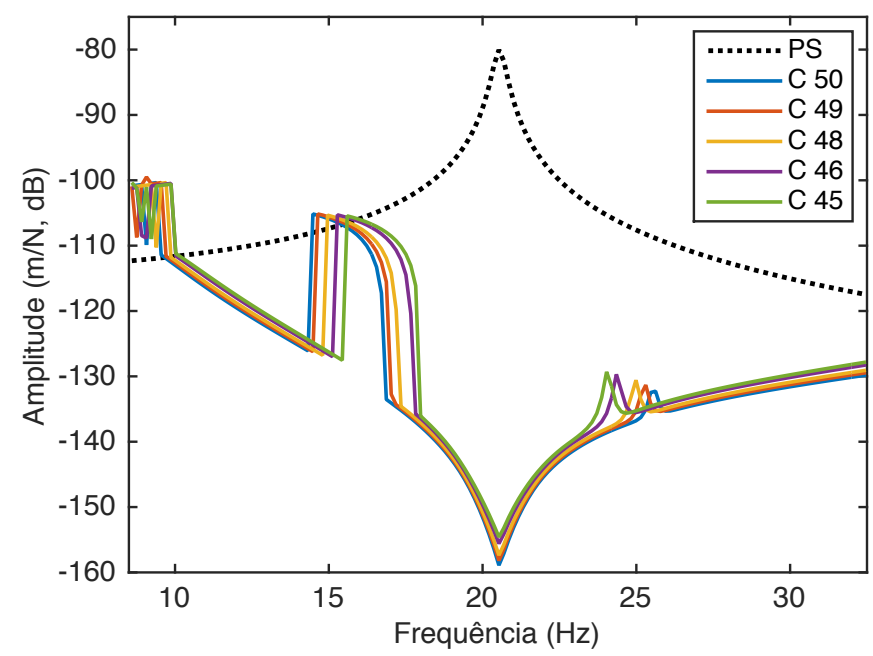

(b) Cinco maiores Áreas

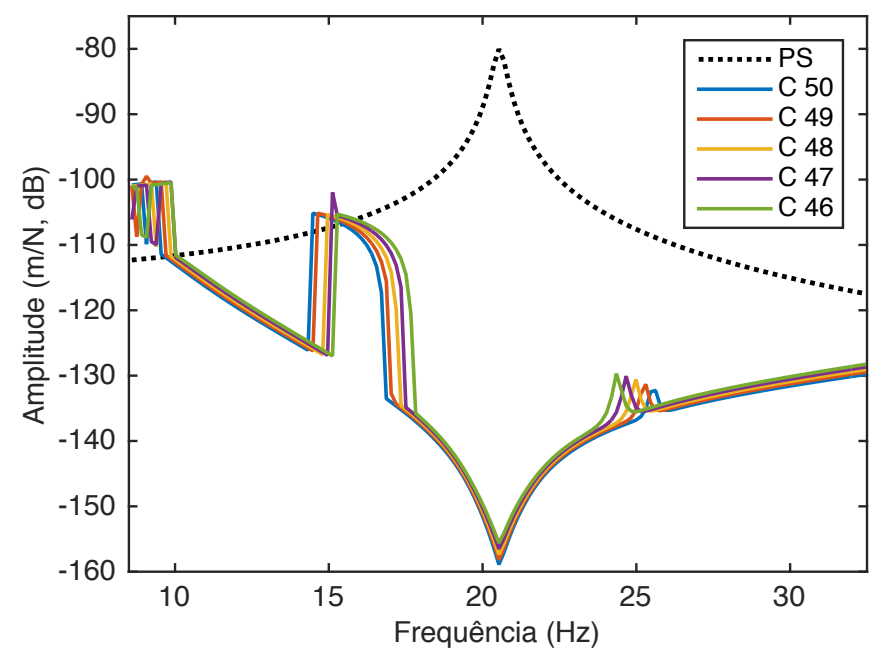

(c) Cinco maiores reduções de amplitude

Figura 5.3: Curvas Amplitude x Frequência das cinco melhores combinações resultantes de acordo com cada critério de avaliação. PS sem absorvedor: linha pontilhada; PS com absorvedor não linear: demais linhas contínuas. 
que $\delta \omega_{n l}$ correspondia a toda a faixa de frequência observada. Sendo assim, decidiuse verificar o comportamento de um desses casos em uma gama maior de frequências, observando o caso $\left[L_{0}=0,150 \mathrm{~m}, m_{s}=7 \mathrm{~kg}\right]$ com seu respectivo $k_{s n}$ ótimo.

A Fig. 5.4 mostra as amplitudes do sistema principal e do absorvedor nas direções horizontal e vertical. O primeiro fato notado é que, nas Figs. 5.2a e 5.3a, o comportamento do sistema para diferentes valores de $m_{s}$ parecia o mesmo pois não era possível observar nenhum fenômeno de ressonância ou antirressonância naquela faixa de frequência observada, de $8,5 \mathrm{~Hz}$ a $32,5 \mathrm{~Hz}$. A explicação desse fato deve-se ao valor de $L_{0}$ ser igual ao de $L$, de modo que não haja compressão nas molas do absorvedor. Sem essa compressão inicial e podendo mover-se também verticalmente, a rigidez projetada verticalmente pelas molas se torna nula, fazendo com que a única resistência ao movimento vertical seja a inércia da massa do absorvedor.

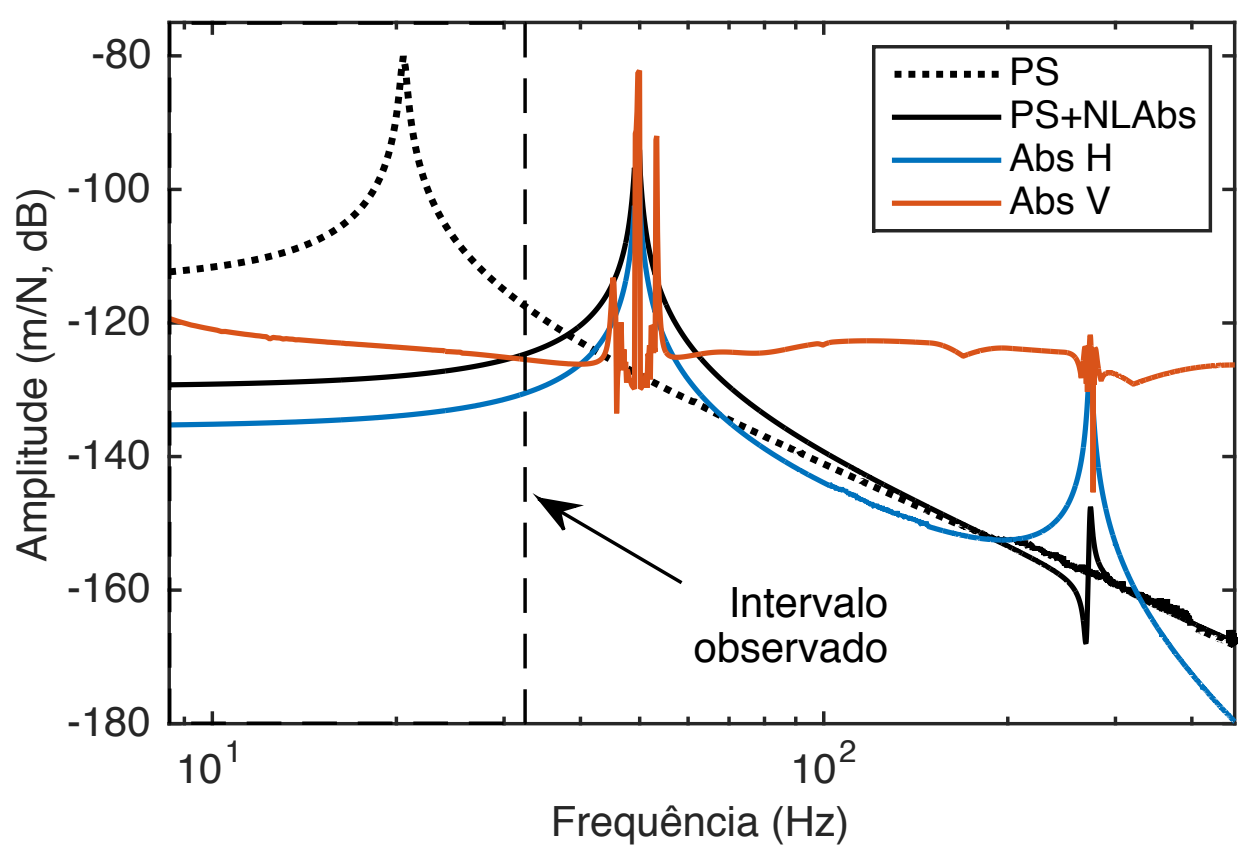

Figura 5.4: Amplitudes dos elementos do sistema observadas, quando $L_{0}=0,15 \mathrm{~m} \mathrm{e}$ $m_{s}=7 \mathrm{~kg}$, em uma faixa maior de frequência.

Provavelmente, o que deve ter ocorrido é que foi impossível durante a otimização sintonizar a frequência de vibração na direção vertical do absorvedor, pois essa deveria ser nula ou quase nula e não encontrando um valor muito pequeno, a otimização encontrou um valor que tenta compensar a falta de rigidez vertical aumentando ainda mais a rigidez projetada horizontalmente, por isso a ressonância foi deslocada à direita próxima de $50 \mathrm{~Hz}$. Para averiguar essa possibilidade gerou-se a curva da amplitude em função da rigidez $k_{s n}$.

A averiguação proposta através da Fig. 5.5 ajuda a confirmar o proposto anteriormente. O gráfico demonstra que há um mínimo local próximo de $6 \times 10^{4} \mathrm{~N} / \mathrm{m}$ 


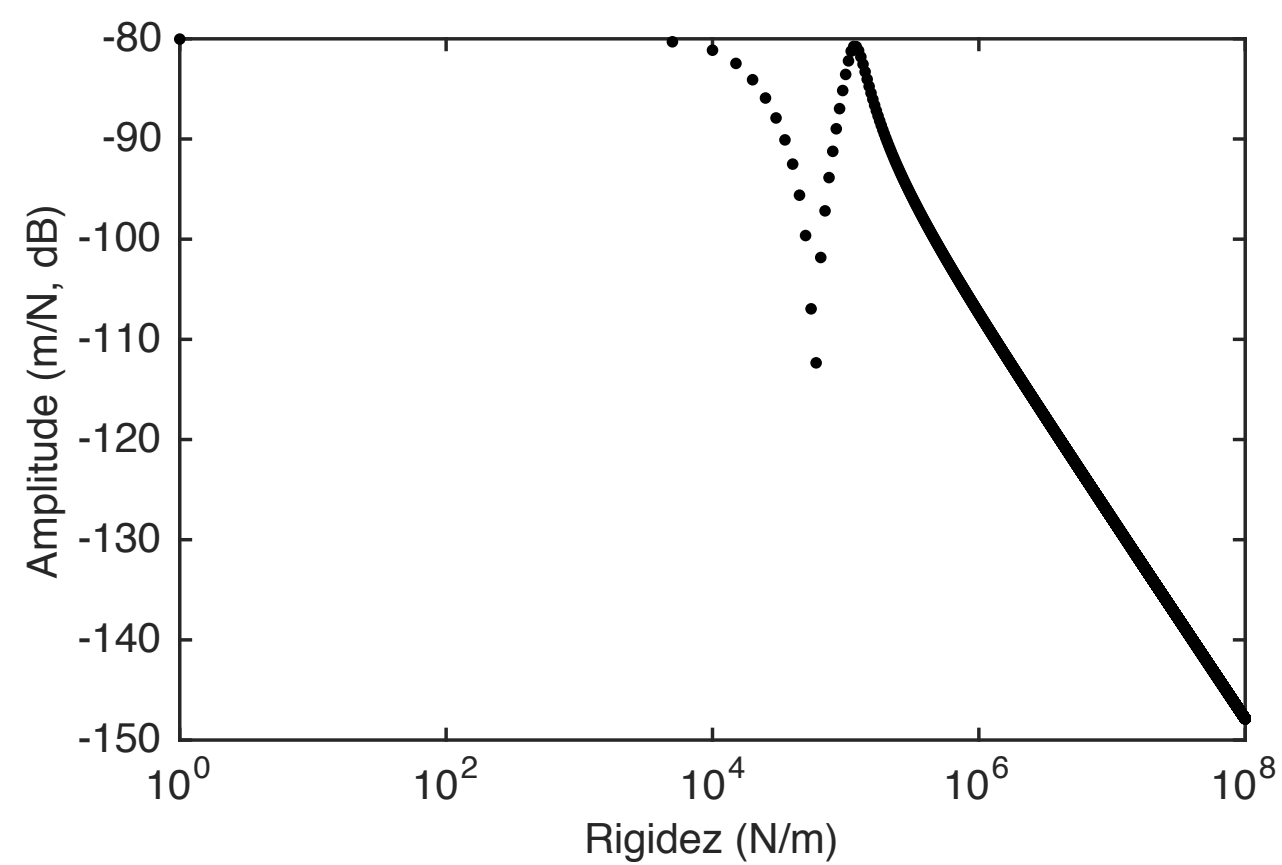

Figura 5.5: Curva Amplitude x Rigidez da combinação $9-L_{0}=0.150 \mathrm{~m}$ e $m_{s}=7.0 \mathrm{~kg}$

e que após este o aumento da rigidez leva a menores amplitudes porém não a um outro mínimo. Por isso o processo de otimização retornou altos valores de rigidez, $k_{s n}=9,9772 \times 10^{6} \mathrm{~N} / \mathrm{m}$ neste caso, mas não um $k_{s n}$ que produzisse uma antirressonância quando $L_{0}=0,150 \mathrm{~m}$. E se o valor retornado fosse o do mínimo local mostrado? A Fig. 5.6 mostra quais seriam as amplitudes do sistema na faixa de frequência desejada e como se comporta o absorvedor. Verifica-se que o absorvedor age como um absorvedor linear, evidenciando que este mínimo escolhido fora do processo de otimização corresponde ao mínimo que sintoniza o absorvedor para atuar horizontalmente, fato que é mostrado pela redução da amplitude do PS + NLAbs e pela pequena redução entre os picos nas amplitudes de vibração do absorvedor horizontalmente. Esse comportamento do absorvedor linear foi descrito por Hartog (1956). Dessa forma, conclui-se que as configurações em que $L_{0}=0,150 \mathrm{~m}$ não fornecem bons resultados e podem serem descartadas das análises futuras.

Com objetivo de fornecer um modo de medir o desempenho geral do absorvedor, optou-se por criar um sistema de penalização para avaliar e selecionar os casos de maior interesse, dada a grande quantidade de combinações possíveis e os muitos resultados encontrados, uns com ótimo valor de $\delta \omega_{n l}$, porém sem grande redução de amplitude ou, por exemplo, a possibilidade de uma combinação que não entregue o melhor resultado para algum dos três critérios de avaliação, mas que os atenda de forma satisfatória simultaneamente. Para tanto estabeleceu-se uma ponderação a cada um dos três critérios de avaliação, de forma que, caso se desejasse uma combinação que fornecesse uma ou outra característica prioritariamente, essa ponderação 


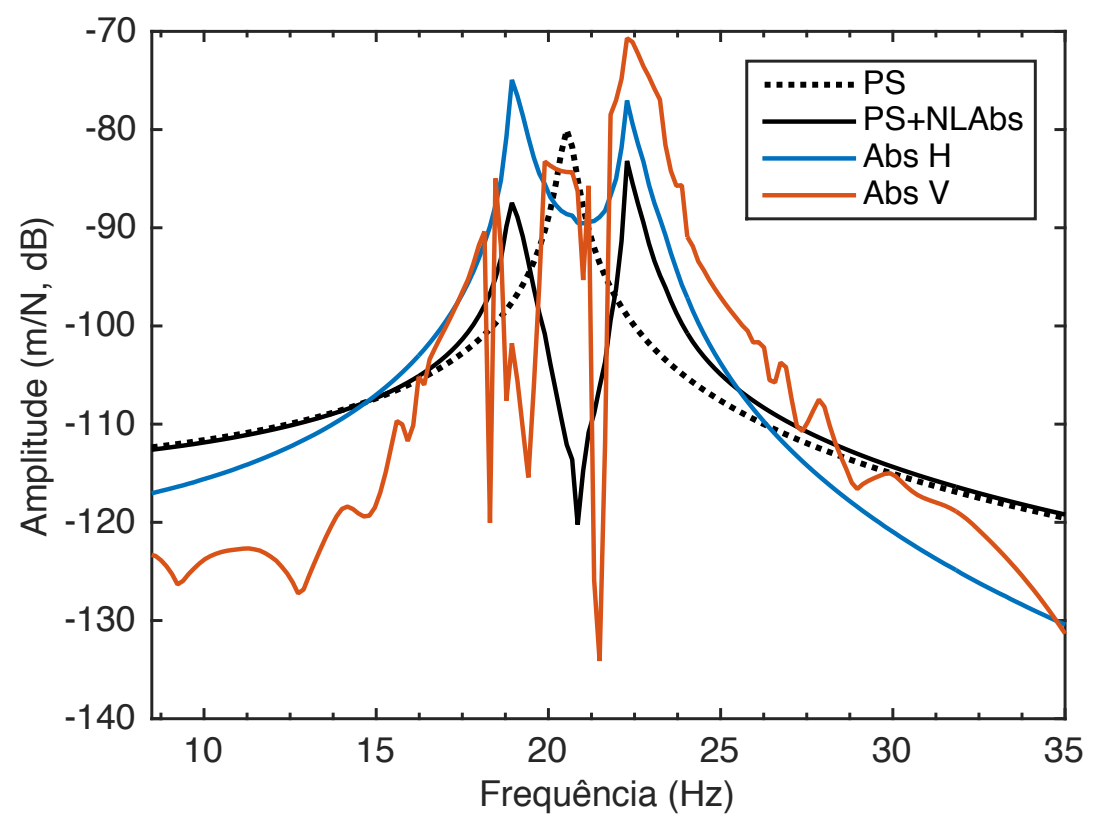

Figura 5.6: Frequência x Amplitude $-L_{0}=0.150 \mathrm{~m}$ e $m_{s}=7.0 \mathrm{~kg}$

seria a forma de fazê-lo. Por exemplo, caso se deseje um sistema que forneça majoritariamente um $\delta \omega_{n l}$ maior em detrimento às outras duas características, seria possível atribuir um peso maior a esse parâmetro em relação aos outros dois. Para isso, normalizaram-se as três formas de avaliação $\left(\delta \omega_{n l}, \delta A_{n l}\right.$ e Área) através da equação (5.2), na qual $x$ é a grandeza a ser normalizada e $y$ o valor normalizado.

$$
y=\frac{x-\min (x)}{\max (x)-\min (x)}
$$

Os fatores utilizados como penalização foram a rigidez das molas do absorvedor $k_{s n}$ e massa $m_{s}$. A rigidez foi introduzida como fator de penalização, pois entendeu-se que valores demasiado grandes para essa grandeza fugiam da realidade do sistema e produziriam um sistema tão rígido que fariam com que o sistema principal parasse, uma vez que a força das molas seria muito maior que força aplicada ao PS. Também penalizou as combinações de maior massa do absorvedor, pois o objetivo é projetar um dispositivo acessório que não acrescente uma massa tão significante ao sistema. Desse modo, também normalizaram-se os valores de $k_{s n}$ e $m_{s}$ segundo a equação (5.2). A ponderação de $\delta \omega_{n l}, \delta A_{n l}$ e da Área foi feita através de $\alpha_{\omega}, \alpha_{\text {red }}$ e $\alpha_{\text {area }}$, respectivamente. Já a ponderação para os fatores de penalização $k_{s n}$ e $m_{s}$ foi implementada por $\alpha_{k}$ e $\alpha_{m}$, respectivamente.

Com intenção de priorizar igualmente tanto os critérios de avaliação bem como os fatores de penalização forneceu-se valores iguais para cada uma dessas duas classes, portanto, $\alpha_{\omega}=\alpha_{\text {red }}=\alpha_{\text {area }}=1$ e $\alpha_{k}=\alpha_{m}=0,1$.

Sendo assim, as equações para o cálculo dos correspondentes valores de $\delta \omega_{n l}, \delta A_{n l}$ 


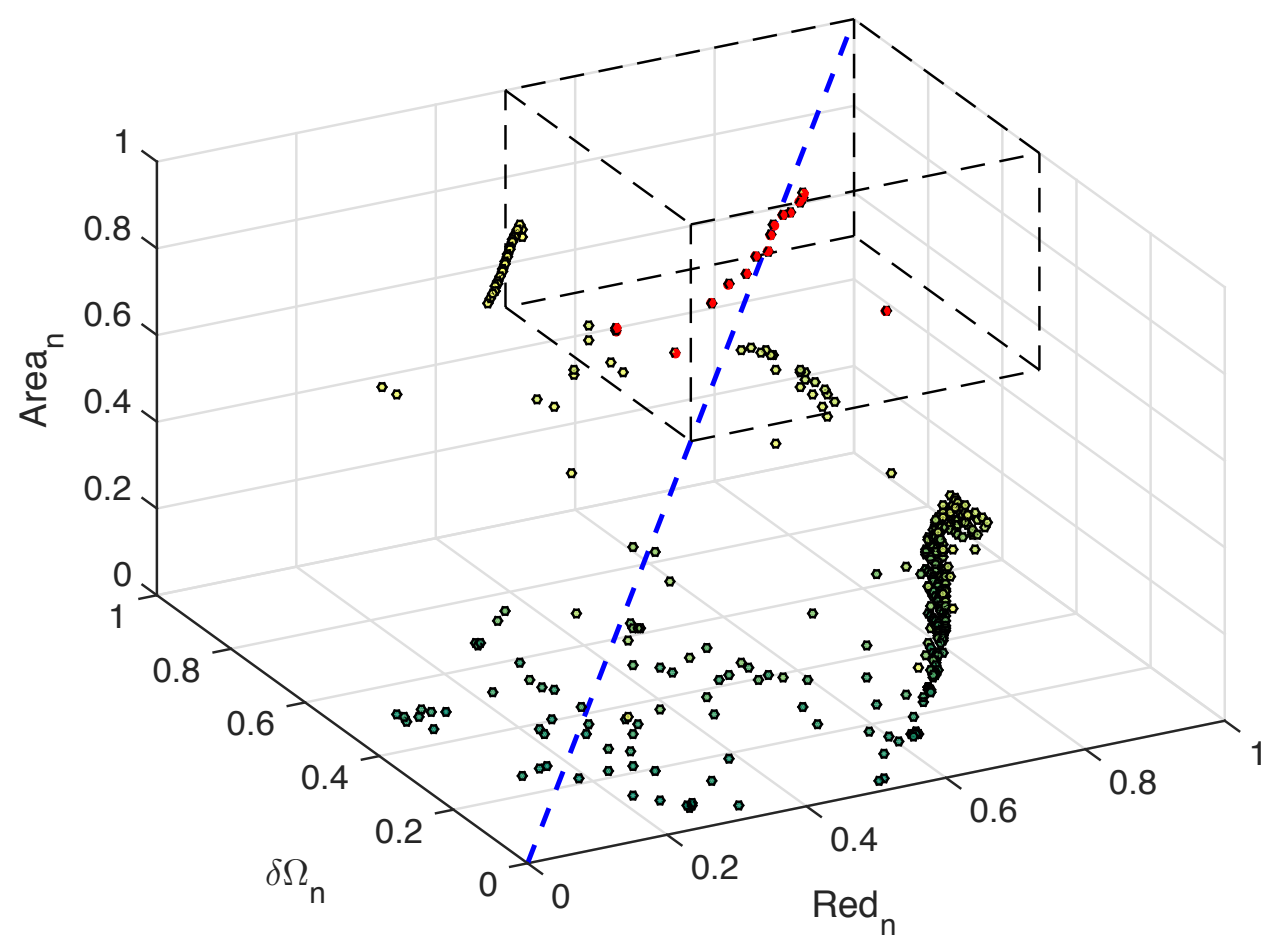

Figura 5.7: Desempenho para cada conjunto de parâmetros conforme critérios normalizados incluindo penalização.

e Área são:

$$
\begin{aligned}
& \delta \Omega_{n}(j)=\alpha_{\omega} \frac{\delta \omega_{n l}(j)-\min \left(\delta \omega_{n l}\right)}{\max \left(\delta \omega_{n l}\right)-\min \left(\delta \omega_{n l}\right)}-\alpha_{k} \frac{k_{s n}(j)-\min \left(k_{s n}\right)}{\max \left(k_{s n}\right)-\min \left(k_{s n}\right)} \\
& -\alpha_{m} \frac{m_{s}(j)-\min \left(m_{s}\right)}{\max \left(m_{s}\right)-\min \left(m_{S}\right)} \\
& \operatorname{Red}_{n}(j)=\alpha_{\text {red }} \frac{\delta A_{n l}(j)-\min \left(\delta A_{n l}\right)}{\max \left(\delta A_{n l}\right)-\min \left(\delta A_{n l}\right)}-\alpha_{k} \frac{k_{s n}(j)-\min \left(k_{s n}\right)}{\max \left(k_{s n}\right)-\min \left(k_{s n}\right)} \\
& -\alpha_{m} \frac{m_{s}(j)-\min \left(m_{s}\right)}{\max \left(m_{s}\right)-\min \left(m_{s}\right)} \\
& \operatorname{Area}_{n}(j)=\alpha_{\text {area }} \frac{\operatorname{Area}(j)-\min (\text { Area })}{\max (\text { Area })-\min (\text { Area })}-\alpha_{k} \frac{k_{s n}(j)-\min \left(k_{s n}\right)}{\max \left(k_{s n}\right)-\min \left(k_{s n}\right)} \\
& -\alpha_{m} \frac{m_{s}(j)-\min \left(m_{s}\right)}{\max \left(m_{s}\right)-\min \left(m_{s}\right)} \\
& j=1: 400
\end{aligned}
$$

A Fig. 5.7 fornece um conjunto de pontos correspondente a resposta das 400 combinações obtidas nesse estudo. Ao observá-la, deve-se buscar os pontos que mais se aproximam do vértice na posição $[1,1,1]$, pois atribuiu-se igual importância aos três critérios de avaliação quando determinou-se que $\alpha_{\omega}=\alpha_{\text {red }}=\alpha_{\text {area }}=1$. Além disso, a 
linha pontilhada azul serve para informar quais pontos se encontram mais próximos da proporção adequada entre $\delta \Omega_{n}, \operatorname{Red}_{n}$ e $A r e a_{n}$. O cubo inserido no canto superior delimita o volume e auxilia a observarmos os pontos vermelhos que tem os valores de $\delta \Omega_{n} \geq 0,5, \operatorname{Red}_{n} \geq 0,5$ e Area $_{n} \geq 0,5$, simultaneamente.

Na Fig. 5.7 há um conjunto de pontos com grandes valores de Área e $\delta \Omega_{n}$ localizados na parte superior, praticamente em linha e do lado externo ao cubo, esses pontos correspondem àqueles em que $L_{0}=0,150 \mathrm{~m}$, que apresentam a maior extensão na faixa de supressão e uma grande área, mas que não tem grande redução de amplitude. Nota-se também uma grande quantidade de pontos concentrados na lateral, próximos ao eixo $\operatorname{Red}_{n}$, com fraco desempenho sobretudo no que se refere $\delta \Omega_{n}$. Entretanto, o mais importante são os pontos vermelhos próximos à linha azul e com maiores valores dentro do gráfico. Os cinco pontos que entregam os melhores resultados estão descritos na Tab. 5.2 e suas curvas Amplitude x Frequência mostrados na Fig. 5.8.

A Tab. 5.2 mostra que as 5 combinações que entregam as melhores performances do absorvedor correspondem às configurações com $L_{0}=0,151 \mathrm{~m}$ e as maiores massas, de acordo com os parâmetros especificados para construção da Fig. 5.7, com exceção da massa de 13,5 kg. Isso atesta que, apesar dos grandes valores de massa, essas configurações ainda são superiores em desempenho em relação às demais e reforça a ideia de que quanto menor $L_{0}$ e maior a massa $m_{s}$, melhor o desempenho obtido.

\section{Tabela 5.2: Cinco melhores configurações do absorvedor não linear}

\begin{tabular}{|c|c|c|c|}
\hline Combinação & $L_{0}(\mathrm{~m})$ & $m_{S}(\mathrm{~kg})$ & $k_{s n}(\mathrm{MN} / \mathrm{m})$ \\
\hline C50 & 0,151 & 15,0 & 9,5191 \\
\hline C49 & 0,151 & 14,5 & 9,2039 \\
\hline C48 & 0,151 & 14,0 & 8,8890 \\
\hline C46 & 0,151 & 13,0 & 8,2593 \\
\hline C45 & 0,151 & 12,5 & 7,9448 \\
\hline
\end{tabular}

Na Fig. 5.8 também são mostrados os absorvedores lineares correspondentes em massa de cada uma das 5 combinações do absorvedor não linear. Nela é evidente a enorme vantagem em desempenho quando comparados os dois tipos de absorvedor para qualquer uma das configurações do absorvedor não linear. Para melhor interpretação desses dados, a Tab. 5.3 traz os valores da extensão da faixa de supressão, da redução de amplitude e da Área tanto para o absorvedor não linear como para o linear. Além disso, $r \delta \omega, r \delta A$ e $\mathrm{r}$ Area representam as razões entre as grandezas correspondentes aos absorvedores não linear e linear em cada um dos critérios.

Entre os dados apresentados na Tab. 5.3 nota-se, quando comparadas as reduções proporcionadas pelos dois dispositivos, uma significativa vantagem do absorvedor não linear ao alcançar valores até 1,60 vezes maiores. Já a faixa de supressão do ab- 
sorvedor não linear em relação ao linear é no mínimo seis vezes maior. Entretanto, leva-se em conta que o absorvedor não linear desenvolve amplitudes que se diferenciam muito pouco das amplitudes do PS (linha pontilhada), na região dos $15 \mathrm{~Hz}$. Esses são ótimos resultados, pois conseguiu-se diminuir a amplitude de vibração do PS apenas permitindo que o absorvedor se mova em uma direção perpendicular ao que se moveria no absorvedor linear tradicional.

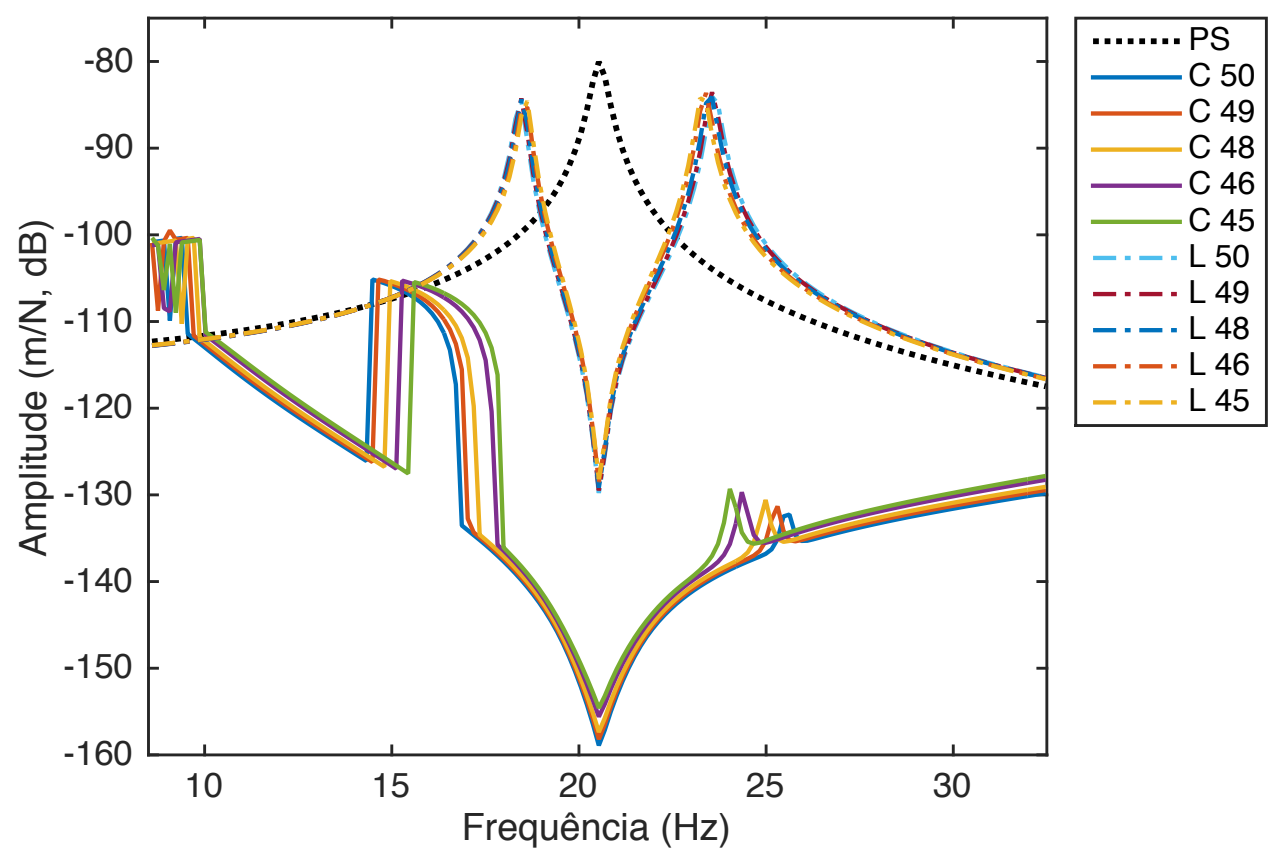

Figura 5.8: Comparação entre Absorvedor Linear e Não Linear. PS sem absorvedor: linha pontilhada; PS com absorvedor linear: linha e ponto; PS com absorvedor não linear: linha contínua.

Tabela 5.3: Resultados dos melhores parâmetros para o absorvedor não linear

\begin{tabular}{|c|c|c|c|c|c|c|c|c|c|}
\hline Comb. & $\delta \omega_{n l}(\mathrm{~Hz})$ & $\delta \omega_{l}(\mathrm{~Hz})$ & $r \delta \omega$ & $\delta A_{n l}(\mathrm{~dB})$ & $\delta A_{l}(\mathrm{~dB})$ & $r \delta A$ & Area $_{n l}$ & Area $_{l}$ & rArea \\
\hline C50 & 23,08 & 3,82 & 6,04 & 78,85 & 49,73 & 1,59 & 3533 & 443 & 7,96 \\
\hline C49 & 22,92 & 3,66 & 6,26 & 78,13 & 49,43 & 1,58 & 3476 & 436 & 7,97 \\
\hline C48 & 22,76 & 3,66 & 6,21 & 77,31 & 49,11 & 1,57 & 3427 & 427 & 8,02 \\
\hline C46 & 22,60 & 3,66 & 6,17 & 75,54 & 48,47 & 1,56 & 3283 & 408 & 8,04 \\
\hline C45 & 22,60 & 3,50 & 6,45 & 74,54 & 48,14 & 1,55 & 3233 & 400 & 8,08 \\
\hline
\end{tabular}

O que chama muita atenção nas curvas apresentadas na Fig. 5.8 é o pico que surge nas curvas do absorvedor não linear em torno dos $16 \mathrm{~Hz}$. Esse comportamento pode ser explicado pelo fenômeno do Salto descrito por Nayfeh e Mook (1995) em seu livro. Nayfeh faz o estudo de um oscilador não linear, tipo Duffing, que contém uma mola cúbica em paralelo com uma mola linear.

A Fig. 5.9 mostra a característica da rigidez para diferentes tipos de mola. Quando o coeficiente de rigidez $(\alpha)$ da mola não linear é nulo, ela tem característica linear. 
Quando esse coeficiente é positivo têm-se o que é chamado de mola dura ou hardening spring, e quando ele é negativo caracteriza-se como mola mole ou softening spring.

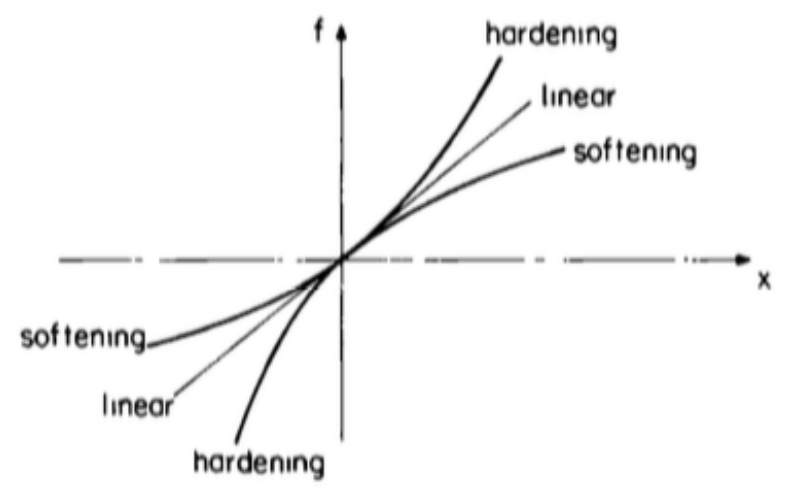

Figura 5.9: Características das molas (NAYFEH; MOOK, 1995).

Utilizando o método de múltiplas escalas, Nayfeh demonstrou analiticamente como a curva de resposta em frequência do oscilador é influenciada pelo sinal do coeficiente $(\alpha)$ associado à componente cúbica da rigidez. Nesta curva de resposta em frequência $\sigma$ é o parâmetro de desintonização que, da expressão $\Omega=\omega_{0}+\varepsilon \sigma$, corresponde ao termo responsável por desintonizar a frequência de excitação $\Omega$ em relação a frequência natural $\omega_{0}$, sendo $\varepsilon<<1$. De acordo com ele, como exibido na Fig. 5.10a, sem a componente não linear $(\alpha=0)$ a resposta obtida é de um sistema linear. Se $\alpha>0$, a curva é dobrada à direita e se $\alpha<0$, a curva é dobrada à esquerda, situações que levam a múltiplos valores de amplitude. Fisicamente, isso determina um fenômeno conhecido como Salto.

Para entender esse fenômeno, observe a Fig. 5.10b, que apresenta um aspecto semelhante ao encontrado nos resultados obtidos. Com a amplitude da força externa mantida constante, realiza-se a variação do frequência de excitação em torno da frequência de ressonância do sistema principal. Diminuindo-se a frequência do ponto 1 até chegar ao 3, as amplitudes de movimento crescem. No próximo decréscimo de frequência essa amplitude sofre uma drástica queda para o ponto 4 e continua em direção ao ponto 5 à medida que se diminui a frequência. Ao realizar o caminho inverso, a amplitude vai do ponto 5 ao 4 e quando no ponto 4 a amplitude passa ao ponto 6 e não ao 3 que representa o mesmo caminho percorrido com o decréscimo de frequência. Do ponto 6 a amplitude salta para o ponto 2 e continua em direção ao ponto 1 posteriormente.

Com intuito de explicar um pouco mais esse fenômeno, analisa-se a região de frequências entre os pontos CE e BF na Fig. 5.10a. Nesse espaço há três possíveis valores de amplitude para cada valor de frequência, sendo a região interior uma solução instável que não se obtém fisicamente e as outras duas são estáveis e possíveis de se alcançar. Desse modo, para uma determinada frequência há dois possíveis valores e 


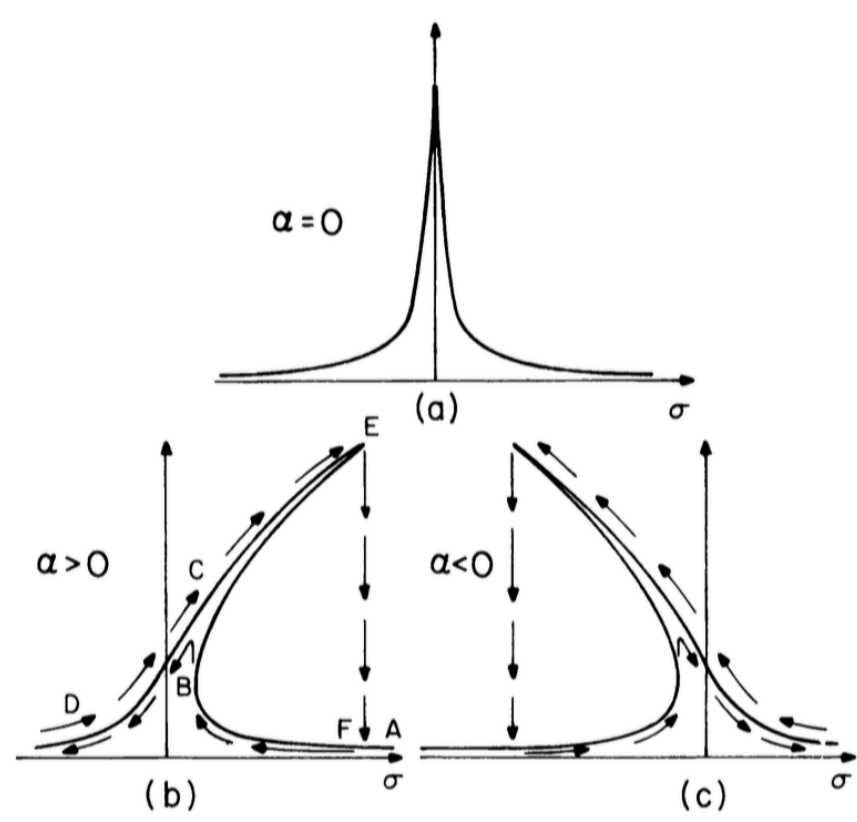

(a) Tipos de não linearidade.

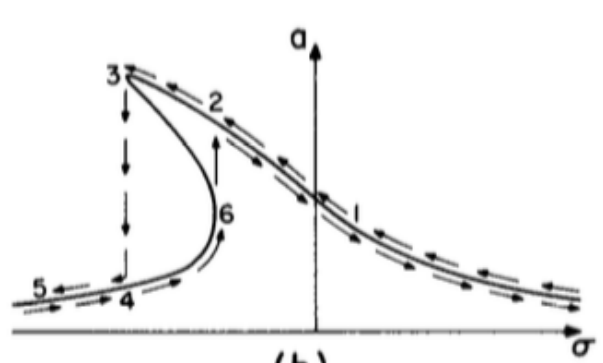

(b)

(b) Fenômeno do Salto.

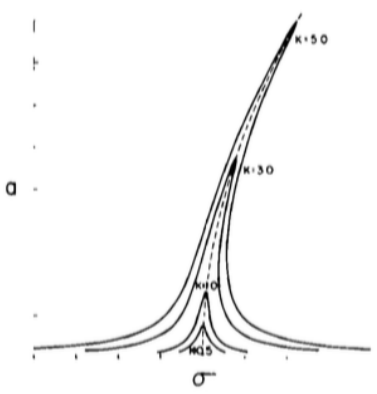

(c) Efeito da amplitude da força.

Figura 5.10: Características de um oscilador não linear Duffing (NAYFEH; MOOK, 1995)

a definição sobre qual deles será o resultante é dada pelas condições do sistema. Essa dependência entre a solução observada e as condições iniciais é uma característica dos sistemas não lineares. Voltando ao exemplo do salto, ao se aumentar ou diminuir a frequência de excitação lentamente em intervalos de tempos definidos faz-se como que a cada mudança o sistema utilize como condição inicial o estado final que ele mesmo apresentava na frequência anterior, gerando a diferença entre os pontos de subida e descida no salto.

Outra característica desse fenômeno não linear é apresentada na Fig. 5.10c, que mostra como a amplitude da força atua sobre a resposta do sistema na região de ressonância. Verifica-se por essa figura que o aumento da amplitude proporciona cada vez mais o dobramento da curva. Como consequência do curvamento, deve-se notar que o aumento de amplitude amplia a base dessa curva e faz com que antes do salto se tenha amplitudes de movimento maiores para uma mesma frequência.

Portando, o fenômeno do Salto pode ser caracterizado pela ocorrência de: saltos no valor de amplitude; diferença nos caminhos percorridos quando se aumenta e diminui a frequência de excitação; e aumento da curvatura a medida que se aumenta a amplitude de excitação. Se for possível encontrar essas 3 características de forma aceitável pode-se afirmar que um salto ocorre na resposta do sistema com absorvedor não linear acoplado.

Com a intenção de responder a esse questionamento, utilizaram-se duas abordagens. A primeira abordagem traduz-se em excitar o sistema principal com distintos 
valores para a amplitude da força e verificar se a curvatura do suposto salto é influenciada. A segunda consistiu em promover uma lenta alteração nos valores da frequência de excitação através de uma discretização maior desses valores. Porém, diferentemente dos casos anteriores, a condição inicial do sistema a cada nova frequência não é sempre a mesma, a condição inicial do sistema é a condição final do sistema quando excitado na frequência anterior. Esse processo foi realizado tanto aumentando a frequência até $32,5 \mathrm{~Hz}$ como também diminuindo-a de $32,5 \mathrm{~Hz}$ até $8,5 \mathrm{~Hz}$. Nesse procedimento espera-se verificar se o sistema principal realiza os saltos de ida (elevação da frequência) e volta (diminuição da frequência) para valores de frequência diferentes. As duas análises foram realizadas para o melhor caso resultante, a combinação 50 .

A Fig. 5.11 traz os resultados para a primeira análise, promovendo a variação da amplitude da força nos seguintes valores: 100 N, 125 N, 200 N, 350 N e 500 N. Para que houvesse melhor compreensão, a figura mostra a amplitude exibidas em $\mathrm{m} / \mathrm{N}$ e não em dB.

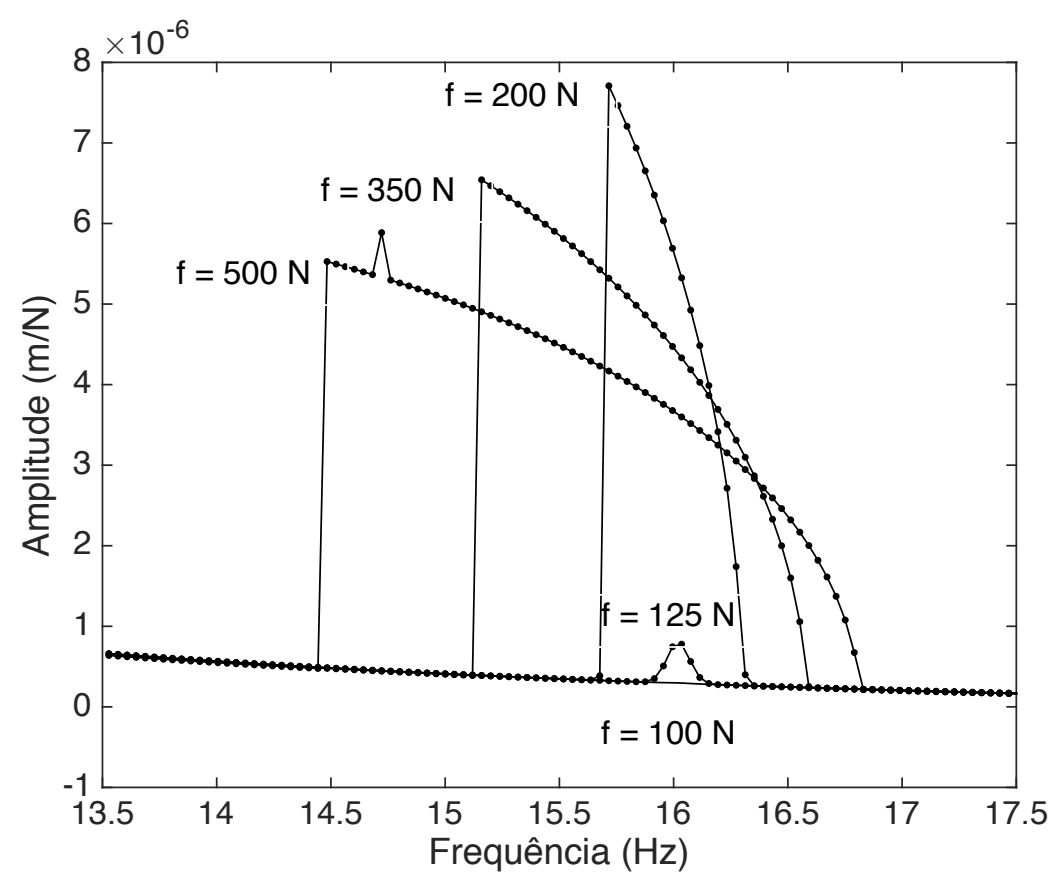

Figura 5.11: Curvatura da ressonância segundo a variação da amplitude da força.

Pela Fig. 5.11 percebe-se que o aumento da amplitude gera maior curvatura da resposta obtida, sendo capaz de curva-la além do esperado após observar o exemplo da literatura (NAYFEH; MOOK, 1995). Quando $f=125 \mathrm{~N}$ a resposta é semelhante à de um sistema linear, sem inclinação da curva, fato esperado pela comparação com a Fig. 5.10c. Outra característica observada é o alongamento da base do salto consequência do dobramento da curva de resposta, a qual fica evidente quando se observa as amplitudes da resposta no sentido crescente da frequência e a partir de $16 \mathrm{~Hz}$. Note que, 
ao passo que se eleva a amplitude do forçamento o início da subida nos valores de resposta se afastam dos $16 \mathrm{~Hz}$, assim como esperado numa situação de salto. Apesar do sistema estudado não permitir a reprodução dos gráficos como na literatura, a comparação destas leva a forte evidência de que trata-se de um fenômeno de salto.

Com relação à segunda abordagem proposta, a Fig. 5.12 exibe os resultados com a frequência crescente (ida) e decrescente (volta) para dois valores de amplitude. Em ambas ocasiões é possível verificar que o salto acontece em diferentes frequências entre a ida e a volta. Todavia, vê-se na Fig. 5.12b que os pontos de descida e subida ficam difíceis de serem determinados uma vez que a instabilidade natural dessa região se torna maior quanto maior é $f$. Isso leva ao surgimento de outros pontos e evidencia uma condição crítica.

Em vista da caracterização exposta, afirma-se que essa região com drástica mudança nos valores de amplitude da resposta do sistema consiste em um fenômeno não linear chamado Salto e que a presença deste fenômeno indica que esta frequência é um dos pontos de ressonância do sistema.

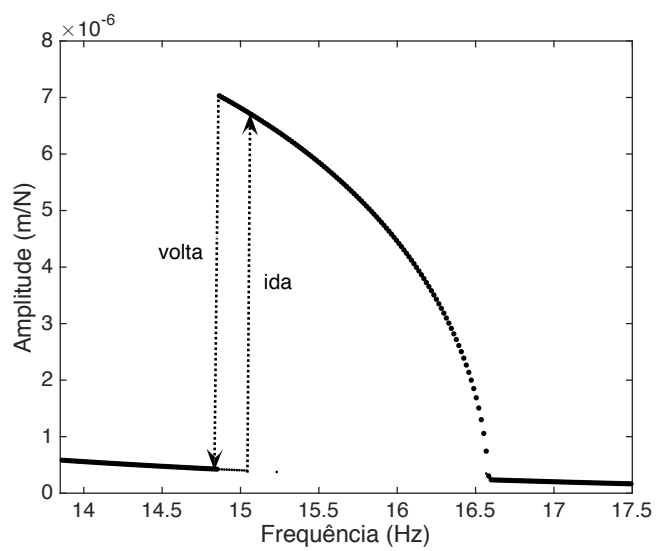

(a) $f=350 \mathrm{~N}$

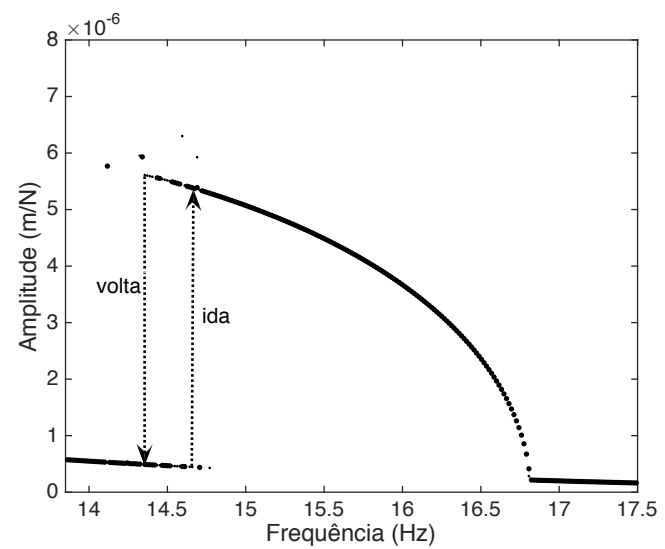

(b) $f=500 N$

Figura 5.12: Fenômeno do Salto.

Toda a avaliação dos resultados foi feita considerando a faixa de frequência entre 8.5 Hz e $32.5 \mathrm{~Hz}$, que compreende uma boa extensão de valores em torno da frequência natural na qual o sistema principal é excitado. Contudo, como visto nos resultados anteriores, há no mínimo a pergunta de onde a curva do sistema com absorvedor encontrará a curva do sistema principal sem absorvedor. Além disso, seria interessante poder saber como as amplitudes de deslocamento do absorvedor se comportam quando este realiza a atenuação das amplitudes de vibração. Outra visualização interessante de uma gama maior de frequências é a comparação do desempenho dos absorvedores não linear e seu linear correspondente em massa.

Sendo assim, geraram-se duas curvas Amplitude x Frequência de 0 a $80 \mathrm{~Hz}$, até onde é possível visualizar o segundo maior pico de ressonância resultante da inclu- 
são do absorvedor. O gráfico 5.13 mostra como as curvas do sistema principal sem absorvedor (PS), do sistema com absorvedor acoplado (PS+NLabs), das amplitudes de vibração na direção horizontal (Abs $\mathrm{H})$ e na direção vertical (Abs V). Já o gráfico 5.14 compara as amplitudes do PS com as amplitudes do sistema com absorvedor linear e com não linear.

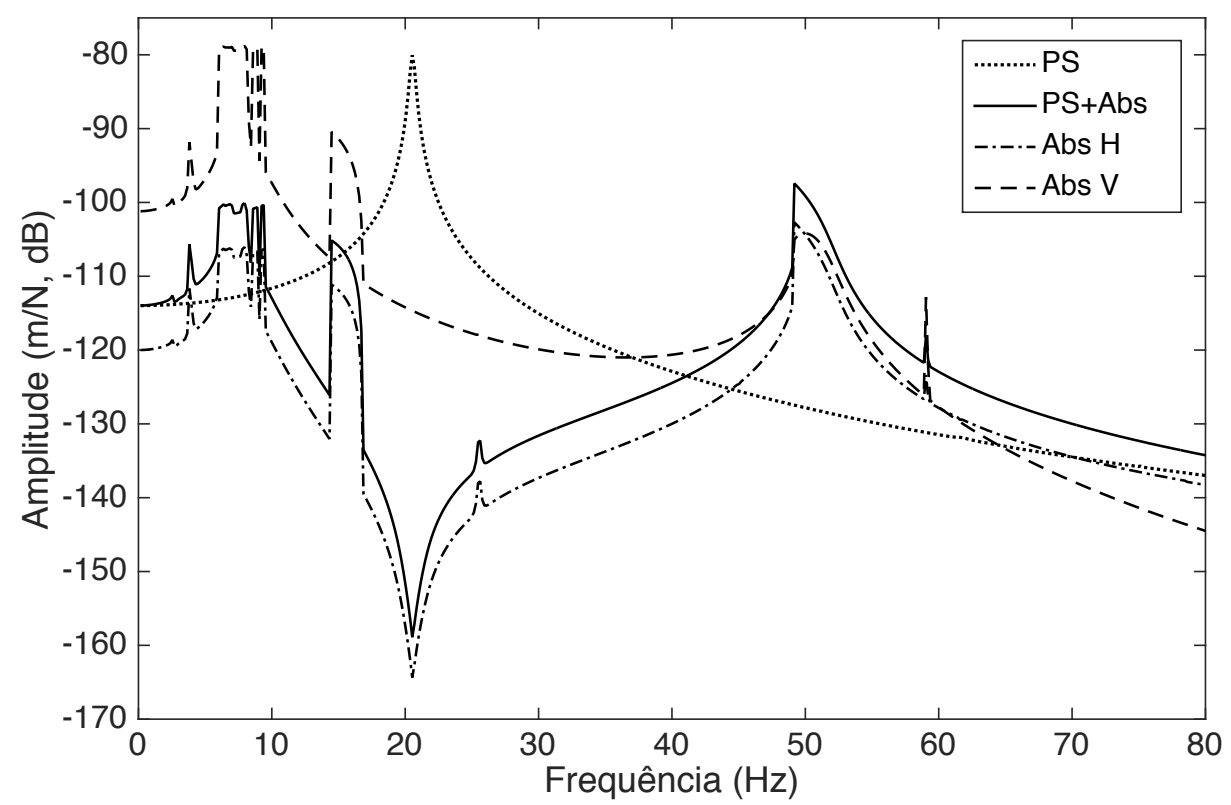

Figura 5.13: Amplitudes de movimento do absorvedor nas direções horizontal e vertical até $80 \mathrm{~Hz}$.

A partir da Fig. 5.13 notam-se as baixas amplitudes desenvolvidas tanto pelo sistema principal bem como pelo absorvedor horizontalmente na frequência de antirressonância gerada, ao passo que as amplitudes do absorvedor verticalmente são maiores e traduzem o comportamento de um absorvedor na atenuação das vibrações. Dois pontos são evidenciados quando olhamos essa frequência, um é que nessa frequência a energia do PS é transferida ao NLAbs sobretudo para vibração vertical, sendo esta a responsável pela atenuação das amplitudes de vibração, o outro ponto é que as baixas amplitudes horizontais do absorvedor são insignificantes nesse processo de atenuação na região da antirressonância produzida. No entanto, eliminar o grau de liberdade horizontal do absorvedor no modelo não é aconselhável pois esse movimento ocorre na prática, sendo esse movimento necessário a representação com maior fidelidade do modelo proposto.

A fim de contrastar os resultados obtidos com os absorvedores linear e não linear e promover uma visão mais ampla do resultado final, na Fig. 5.14 colocaram-se as amplitudes resultantes obtidas com cada um deles acoplado também numa faixa de frequência superior a que foi observada durante as análises realizadas. Ressalta-se que nenhum dado foi computado para análise a partir dessa faixa mais extensa. 


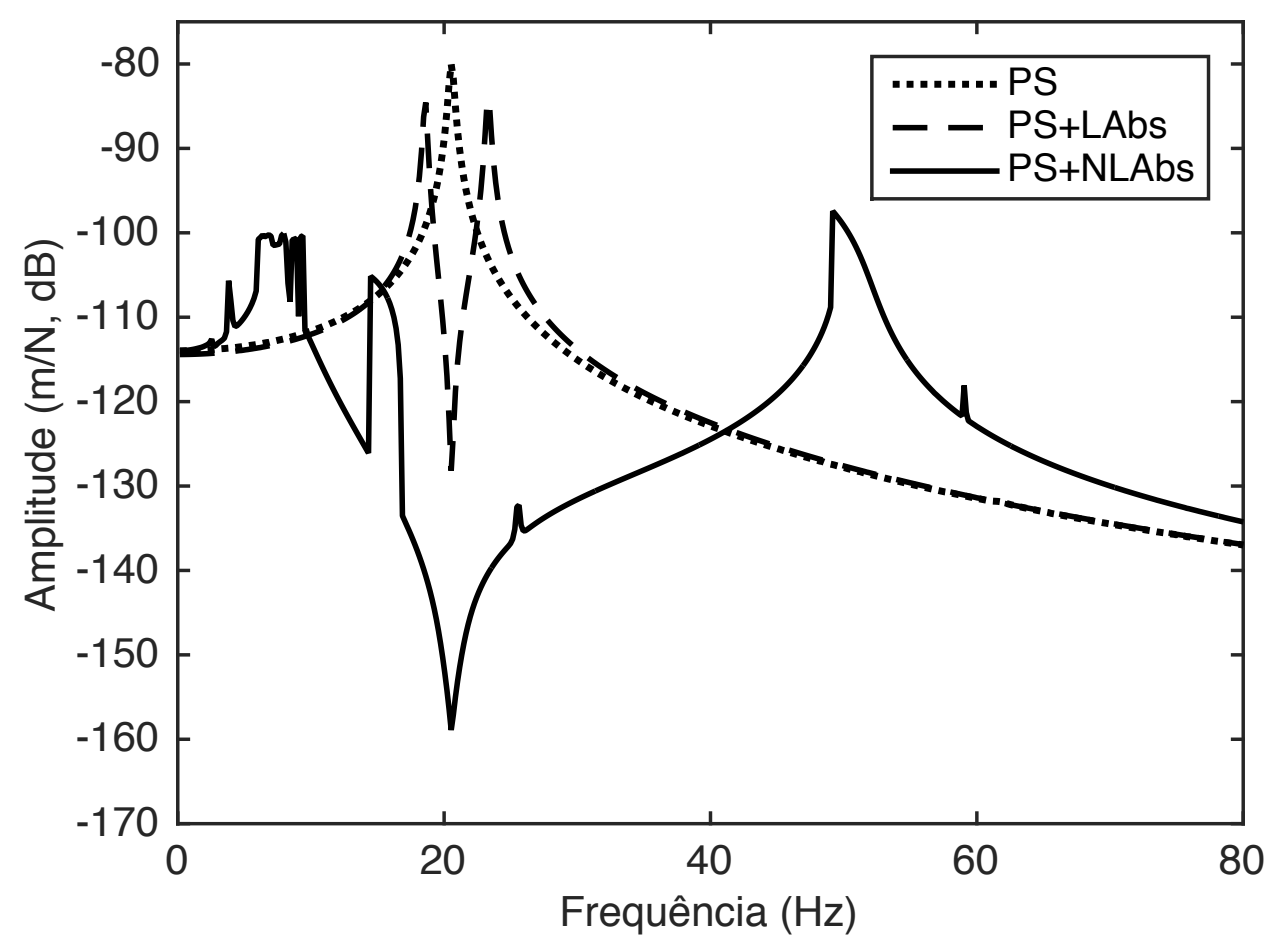

Figura 5.14: Comparação dos absorvedores linear e não linear até $80 \mathrm{~Hz}$.

A primeira vantagem do emprego do absorvedor não linear em relação ao linear pode ser vista através da faixa de supressão, que neste trabalho foi considerada como o intervalo entre os pontos que a curva do sistema com absorvedor (PS + NLAbs ou PS + LAbs) encontra a curva PS. No caso com absorvedor não linear, desconsiderado o ponto em que há o salto, próximo de $16 \mathrm{~Hz}$, a faixa de supressão vai de $10 \mathrm{~Hz}$ a $40 \mathrm{~Hz}$, totalizando uma extensão de aproximadamente $30 \mathrm{~Hz}$ onde é vantajoso o uso do absorvedor. Mesmo que o tamanho da faixa seja medido a partir dos $16 \mathrm{~Hz}$ onde ocorre o salto até os $40 \mathrm{~Hz}$, esse valor é nitidamente muito superior ao obtido com o linear, que é menor que $4 \mathrm{~Hz}$. Dado que se trata do maior $m_{s}$ permitido na análise, essa é a máxima extensão possível de ser obtida com esse tipo de absorvedor linear e não há nenhum outro relato na literatura de outro dispositivo capaz de promover tal alargamento da faixa de supressão e nenhuma otimização promovida no absorvedor linear renderia resultado semelhante. A segunda vantagem observada aqui e que pôde ser vista também anteriormente é a diferença na redução da amplitude de vibração do PS sem e com os dois tipos de absorvedor, sendo que a redução promovida com dispositivo proposto neste projeto é também maior que a resultante do sistema com o dispositivo linear, que era de 49,73 dB com o linear passou a 78,85 dB com o não linear.

Além dessas características mencionadas, a visualização através de uma faixa mais extensa permitiu notar uma substancial redução na altura dos picos de ressonância resultantes do sistema acoplado com absorvedor não linear, onde a maior amplitude 
é de -97,43 dB próximo dos $49 \mathrm{~Hz}$ enquanto com o absorvedor linear é de $-84.25 \mathrm{~dB}$ no segundo pico. Isso mostra que, comparado ao dispositivo linear, o absorvedor não linear reduz as amplitudes na antirressonância, amplia a faixa de supressão e ainda diminui a altura dos picos de ressonância resultantes.

Dado que o limite proposto para a massa do absorvedor é de $15 \mathrm{~kg}$, que corresponde a um quarto da massa do PS, e uma vez que o melhor resultado encontrado para o desempenho do absorvedor corresponde ao caso de maior massa, é esperado que o leitor fique curioso a respeito da atuação do absorvedor quando configurado com massas distintas. Nesses casos, quais seriam os melhores resultados obtidos considerando apenas a massa do dispositivo secundário? Para isso, criaram-se três gráficos, um para cada critério em relação a massa do absorvedor, onde é possível identificar a cada massa o melhor resultado para a redução de amplitude, faixa de supressão e área. Ressalta-se que os gráficos apresentados são independentes entre si, o que significa, por exemplo, que a maior redução para um $m_{s}$ não está necessariamente relacionada a configuração que entrega a maior faixa de supressão.

Mesmo destacando que não há uma ligação direta entre as figuras mostradas, foram destacados os pontos que pertencem a uma mesma configuração de acordo com a massa observada. O pontos destacados com asterisco $\left(^{*}\right)$ significam que para um dado $m_{s}$ há um $L_{0}$ e um $k_{s n}$ que resultam simultaneamente na maior faixa de supressão, maior redução de amplitude e maior área. Assim como esperado a partir dos resultados anteriores, estes casos assinalados se referem a $L_{0}=0,151 \mathrm{~m}$ e cinco deles puderam ser observados na Fig. 5.3b, bem como são visíveis na Fig. 5.2 devido ao fato de possuírem os melhores desempenhos.

Agora, considere que por questões de projeto a maior massa do absorvedor permitida corresponda a $10 \mathrm{~kg}$, um sexto da massa primária, $m_{p}$. Nesta situação o responsável pelo projeto deveria escolher entre o objetivo desejado e escolher entre uma das montagens do dispositivo com $m_{s}=10 \mathrm{~kg}$ que entrega ou uma faixa de supressão de $21,5 \mathrm{~Hz}$, ou $70 \mathrm{~dB}$ de redução de amplitude ou uma área de $2742 \mathrm{~Hz}$ dB. Se houvesse a necessidade de uma massa menor ainda, $6 \mathrm{~kg}$ por exemplo, esses valores seriam $\delta \omega_{n l}=19 \mathrm{~Hz}, \delta A_{n l}=66 \mathrm{~dB}$ e Area $=2394 \mathrm{~Hz} \mathrm{~dB}$. Diante desses resultados nota-se que a configuração de absorvedor proposta é capaz de entregar bons resultados e permite ao projetista escolher o desempenho requerido à situação confortavelmente. Uma nova verificação da Tab. 5.3 pode confirmar a afirmação feita, pois frente ao melhor absorvedor linear analisado, o qual possui a maior massa e $\delta \omega_{l}=3,82 \mathrm{~Hz}$, $\delta A_{l}=49,73$ e Area $=443$ como desempenho, mesmo o desempenho mais modesto do absorvedor não linear mostrado na Fig. 5.15 , com $m_{s}=3 \mathrm{~kg}$, é capaz de garantir um ou mais resultados superiores ao melhor linear, uma vez que com $3 \mathrm{~kg}$ obtêm-se ou 12,41 Hz de faixa de supressão, ou redução de $62 \mathrm{~dB}$ ou uma área de $1174 \mathrm{~Hz} \mathrm{~dB}$.

Ainda explorando as múltiplas possibilidades que podem resultar dos pares $\left[L_{0}\right.$, 


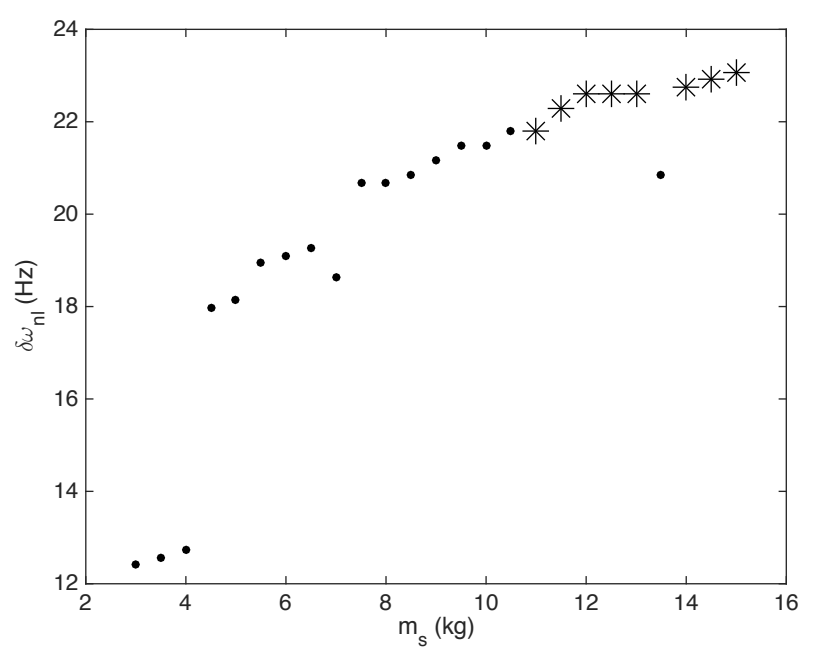

(a) Faixa de frequência de supressão

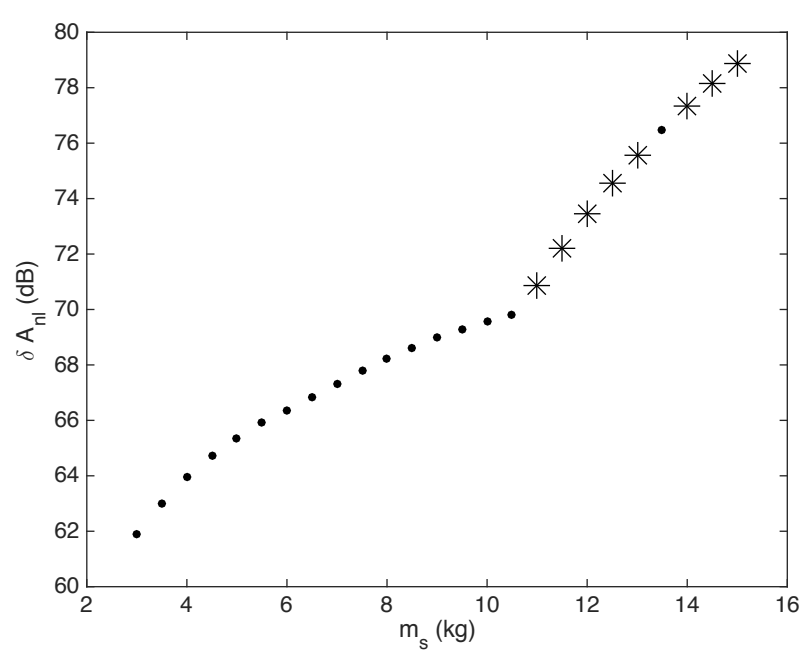

(b) Redução de amplitude

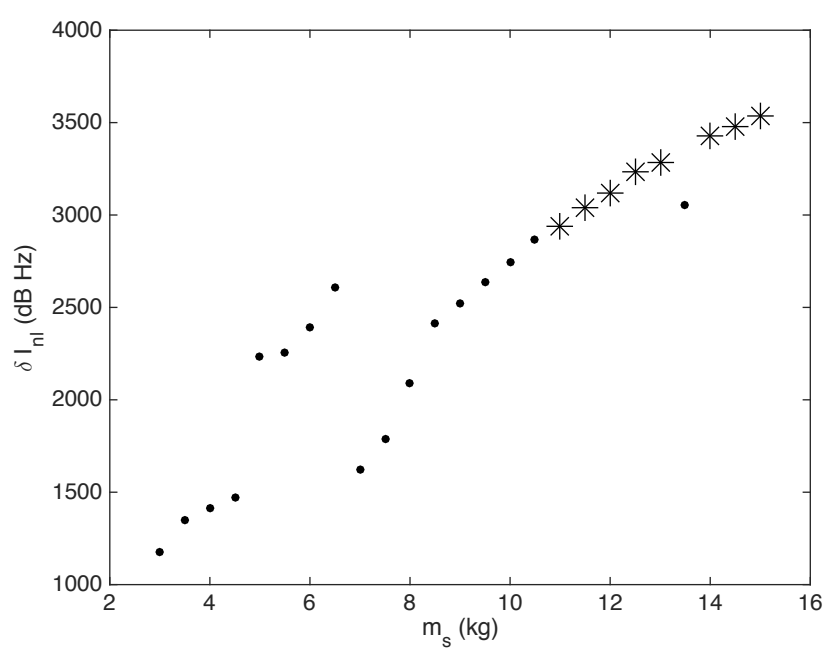

(c) Área

Figura 5.15: Melhores resultados para os três critérios para diferentes valores de massa do absorvedor $m_{s}$. 
$\left.m_{s}\right]$, utilizou-se o método proposto para avaliação de desempenho das combinações, que deu origem à Fig. 5.7, e observaram-se as curvas de resposta em frequência para os 4 melhores desempenhos conforme as massas: $3 \mathrm{~kg}$, $6 \mathrm{~kg}$, $9 \mathrm{~kg}$ e $12 \mathrm{~kg}$. Com isso, pretende-se atestar que mesmo empregando massas menores o absorvedor ainda oferece bons desempenhos.

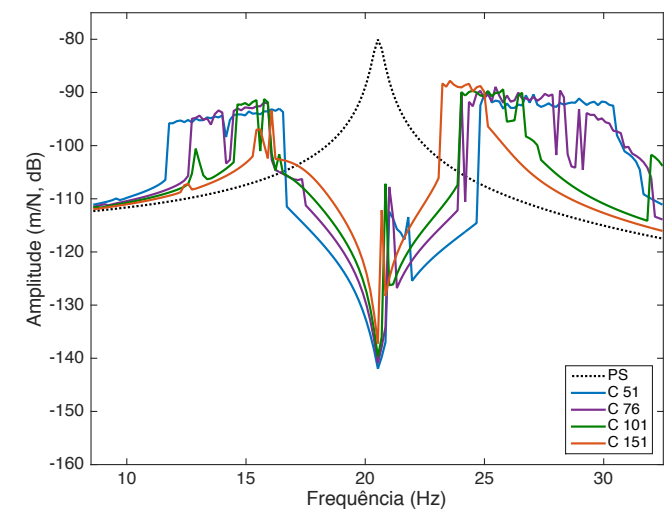

(a) $m_{s}=3 \mathrm{~kg}$

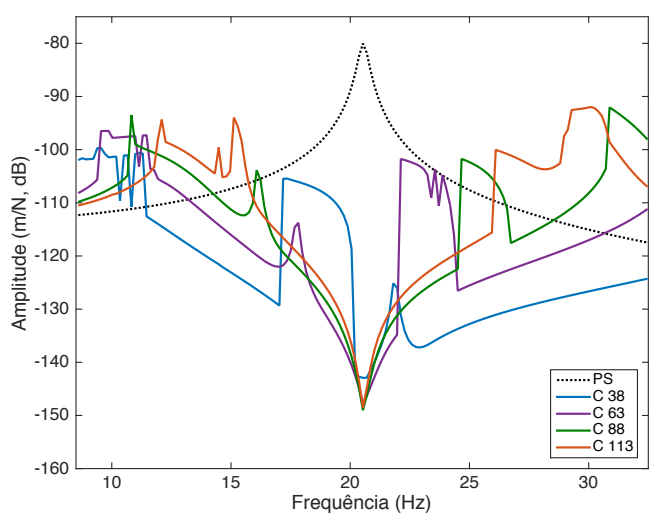

(c) $m_{\mathrm{s}}=9 \mathrm{~kg}$

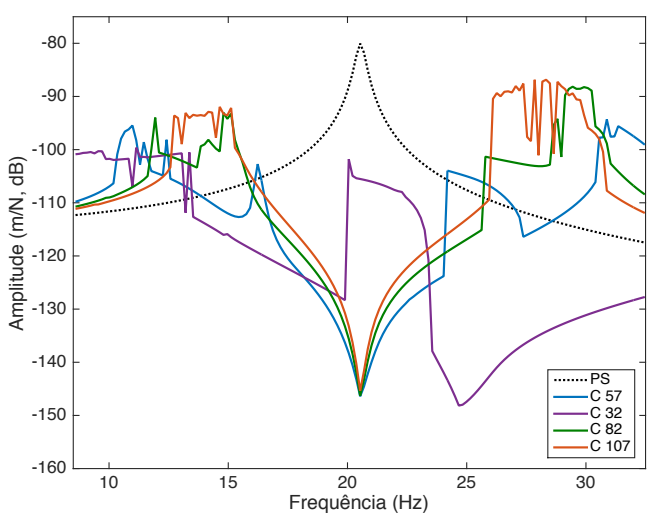

(b) $m_{s}=6 \mathrm{~kg}$

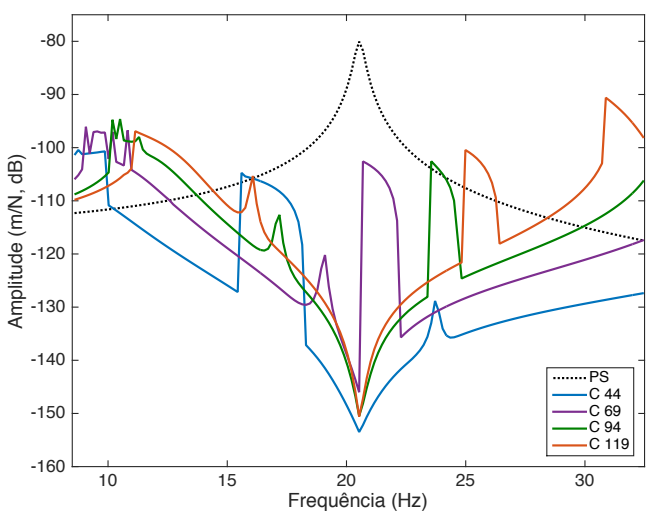

(d) $m_{\mathrm{s}}=12 \mathrm{~kg}$

Figura 5.16: Curvas de Frequência x Amplitude dos 4 melhores desempenhos para diferentes massas do absorvedor.

Os valores de $m_{s}, L_{0}$ e $k_{s n}$ referentes às curvas mostradas na Fig. 5.16 estão dispostos na Tab. 5.4. 
Tabela 5.4: Configurações do absorvedor não linear para os casos da Fig. $\mathbf{5 . 1 6}$

\begin{tabular}{|c|c|c|c|}
\hline Combinação & $L_{0}(\mathrm{~m})$ & $m_{s}(\mathrm{~kg})$ & $k_{s n}(\mathrm{MN} / \mathrm{m})$ \\
\hline C51 & 0,152 & 3,0 & 0,9882 \\
\hline C76 & 0,153 & 3,0 & 0,6635 \\
\hline C101 & 0,154 & 3,0 & 0,5017 \\
\hline C151 & 0,156 & 3,0 & 0,3404 \\
\hline C57 & 0,152 & 6,0 & 1,9316 \\
\hline C32 & 0,151 & 6,0 & 5,5056 \\
\hline C82 & 0,153 & 6,0 & 1,2991 \\
\hline C107 & 0,154 & 6,0 & 0,9832 \\
\hline C38 & 0,151 & 9,0 & 5,8337 \\
\hline C63 & 0,152 & 9,0 & 2,8830 \\
\hline C88 & 0,153 & 9,0 & 1,9401 \\
\hline C113 & 0,154 & 9,0 & 1,4688 \\
\hline C44 & 0,151 & 12,0 & 7,6303 \\
\hline C69 & 0,152 & 12,0 & 3,8348 \\
\hline C94 & 0,153 & 12,0 & 2,5824 \\
\hline C119 & 0,154 & 12,0 & 1,9554 \\
\hline
\end{tabular}

\subsection{Limitações do absorvedor não linear empregado}

Dentro do campo da dinâmica não linear é amplamente sabido que a resposta do sistema é influenciada não somente pela frequência de vibração mas também por fatores como a amplitude da força de excitação e as condições iniciais do sistema.

Uma vez demonstrado que o absorvedor é capaz de alongar a faixa de supressão fica o questionamento sobre quais são as possíveis limitações do uso deste dispositivo. Sabe-se desde o início do trabalho que o posicionamento do absorvedor numa posição de equilíbrio estável é fundamental para que este dissipe energia recebida a partir do sistema principal, portanto, um estudo sobre as condições iniciais não se faz tão necessário quanto uma análise a cerca da amplitude da força aplicada. Por isso, utiliza-se novamente o diagrama de bifurcação como forma de análise, para que se possa enxergar o papel de $f$ na resposta do sistema para frequência de excitação igual a frequência de ressonância do PS. Gerou-se o diagrama de bifurcação para $f$ variando de $1 \mathrm{~N}$ a $1500 \mathrm{~N}$ com passo de $20 \mathrm{~N}$. Limitou-se a $1500 \mathrm{~N}$ pois entendeu-se que uma força acima não faria sentido, uma vez que isso poderia fazer com que o sistema ultrapassasse os limites físicos da configuração projetada, já que o espaço horizontal é limitado.

A Fig. 5.17 mostra que até $f=1500 \mathrm{~N}$ o comportamento do sistema com absorvedor acoplado possui apenas um período, não ocorrendo bifurcação. Esta informação é muito importante e positiva, pois significa que mesmo elevando a força aplicada, o sistema responderá de modo previsível e sem instabilidades.

Saber se o sistema possui múltiplos períodos ou não quando excitado na frequên- 


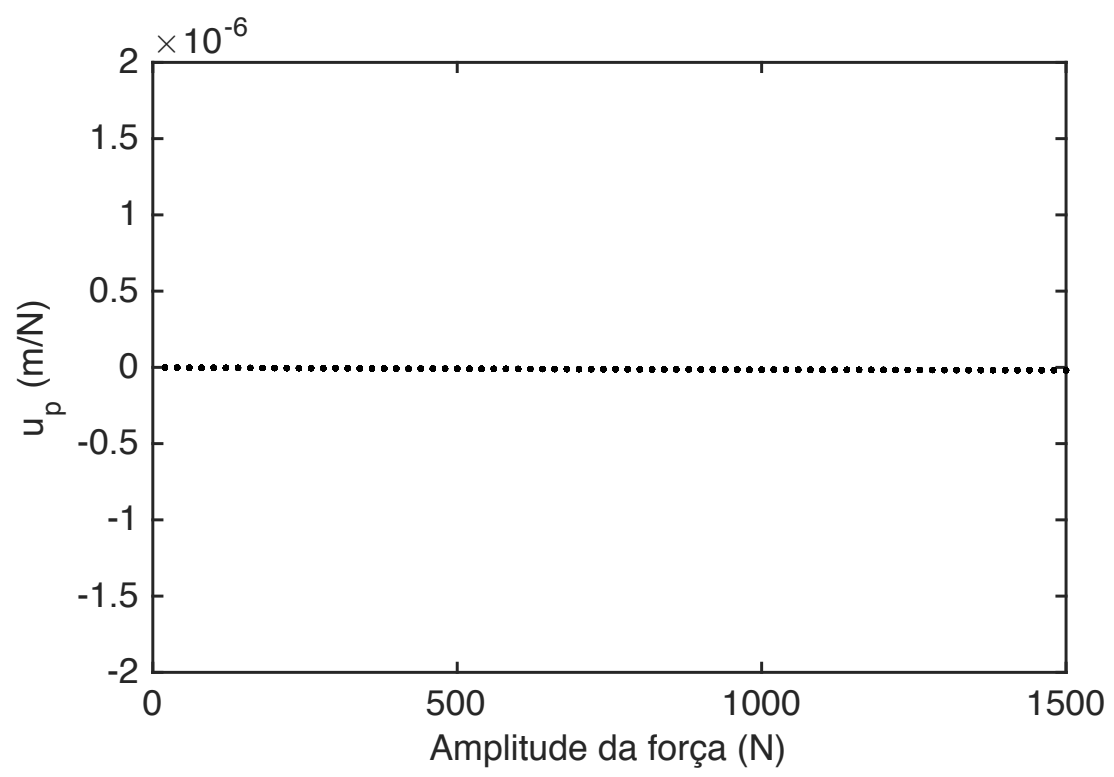

Figura 5.17: Diagrama de bifurcação do sistema principal $\left(u_{p}\right)$ excitado na frequência de ressonância.

cia desejada é fundamental, entretanto, além de verificar o comportamento do sistema via diagrama de bifurcação, optou-se por observar como a amplitude de vibração é alterada conforme $f$ é variado ao longo de uma extensa faixa de frequência. Para isso, analisou-se a amplitude da resposta do sistema principal segundo a força aplicada em dois conjuntos, um para valores de $f$ menores que $500 \mathrm{~N}(100 \mathrm{~N}, 125 \mathrm{~N}, 200 \mathrm{~N}$ e 350 $\mathrm{N})$ e outro de valores maiores $(600 \mathrm{~N}, 800 \mathrm{~N}$ e $1000 \mathrm{~N})$. Os gráficos produzidos permitem observar como a curva Amplitude x Frequência se comporta, proporcionando uma visão completa dos efeitos causados pelas mudanças na amplitude da força.

Para os casos em que a amplitude da força é menor que 500 N, Fig. 5.18a, há dois pontos a serem observados, que são os dois picos mais externos, um em torno de 8 e o outro em $50 \mathrm{~Hz}$. Quando se olha o pico na região de $50 \mathrm{~Hz}$, percebe-se que, apesar da forma diferente em relação salto em $16 \mathrm{~Hz}$, o aumento de $f$ resulta também na curvatura do pico à esquerda. Com relação ao pico em $8 \mathrm{~Hz}$, a elevação de $f$ gerou a curvatura do pico mas, além disso, resultou em tamanha instabilidade que houve uma espécie de colapso do pico, que se "desmancha" e apresenta amplitudes bem diferentes num pequeno trecho de frequências, como pode ser verificado quando se compara as curvas de $100 \mathrm{~N}, 125 \mathrm{~N}$ e $200 \mathrm{~N}$ com as de $350 \mathrm{~N}$ e $500 \mathrm{~N}$. Com essas poucas informações, é muito provável que nesses picos, em $8 \mathrm{~Hz}$ e $50 \mathrm{~Hz}$, também esteja ocorrendo o fenômeno do salto.

Observando os dois picos em $8 \mathrm{~Hz}$ e $50 \mathrm{~Hz}$ na Fig. 5.18b, vê-se que o pico em $50 \mathrm{~Hz}$ também se torna muito instável, assim como se apresentou o pico em $8 \mathrm{~Hz}$ quando se tinha $f$ menor que $500 \mathrm{~N}$. A intensidade da força maior que $500 \mathrm{~N}$ afetou mais ainda o pico em $8 \mathrm{~Hz}$, fazendo com que a região instável se estendesse até a região dos 


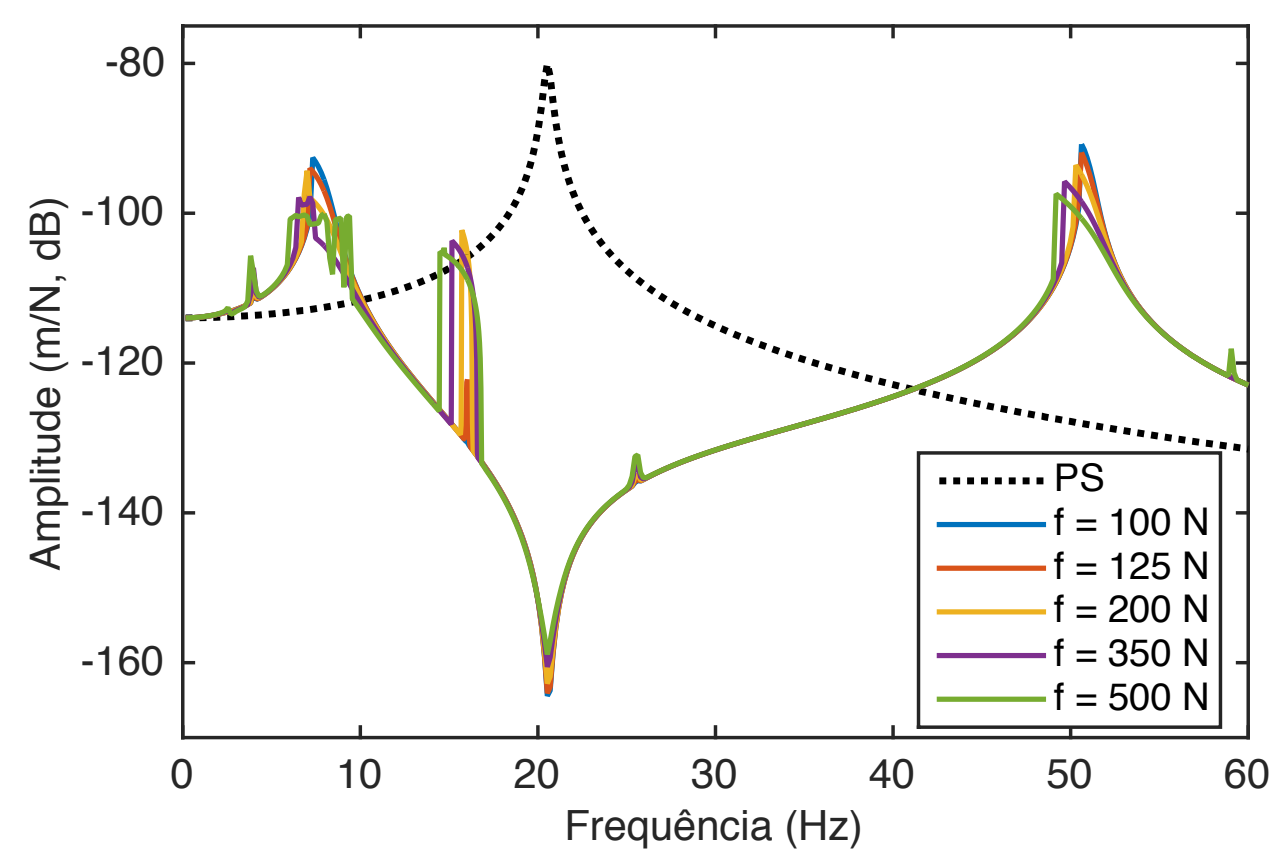

(a) Amplitude da força abaixo de $f=500 \mathrm{~N}$

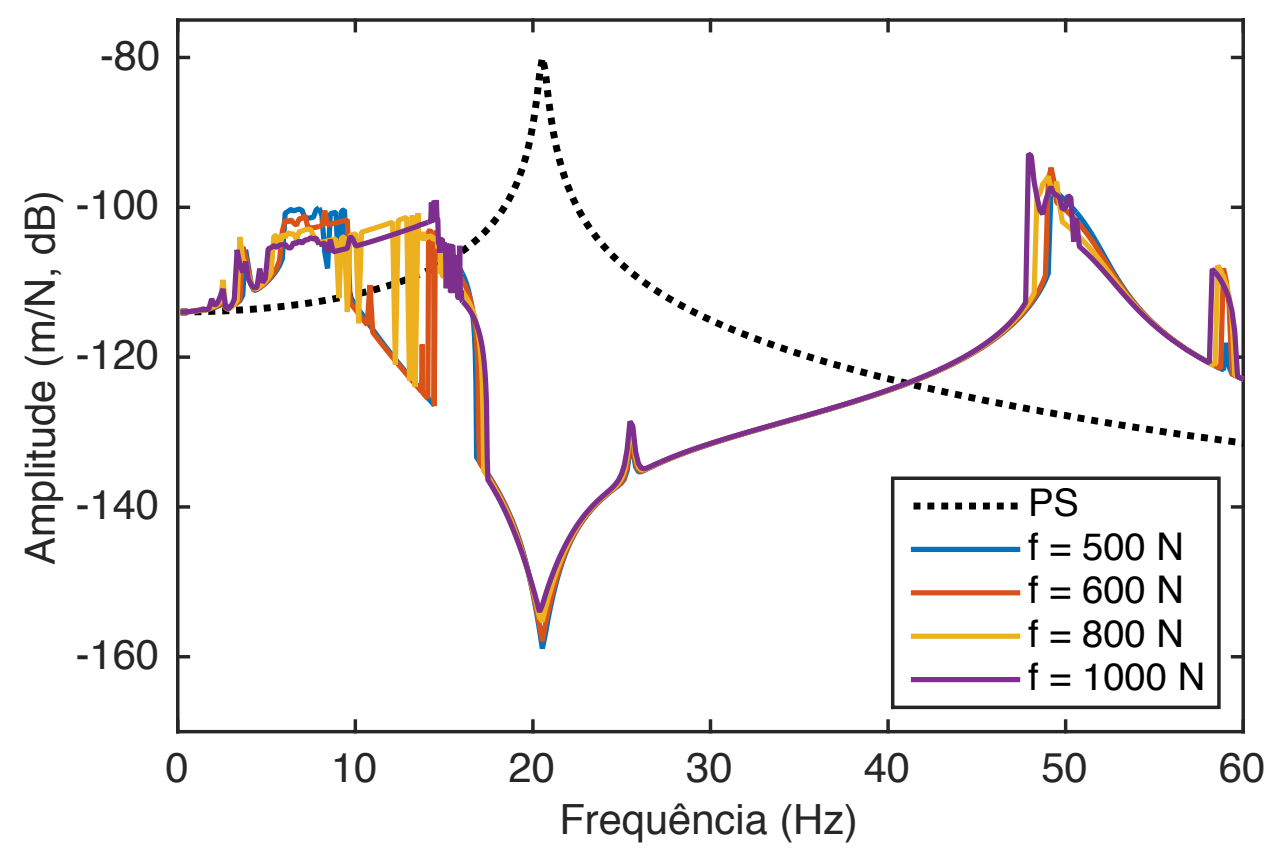

(b) Amplitude da força acima de $f=500 \mathrm{~N}$

Figura 5.18: Comportamento do sistema para diferentes amplitudes da força aplicada. 
$16 \mathrm{~Hz}$, praticamente unindo essas regiões nos casos de $800 \mathrm{~N}$ e $1000 \mathrm{~N}$. Isso mostra a sensibilidade diferente de cada região observada, mas sobretudo revela que acima de $500 \mathrm{~N}$ as instabilidades aumentam e há de se atentar mais a essas regiões se a frequência de excitação passar por elas.

Assim, conclui-se que praticamente não há limitações do absorvedor proposto quanto ao uso de uma força externa com maior intensidade, já que próximo da antirressonância o sistema não apresenta instabilidades e as regiões onde ocorrem fenômenos não lineares pode ser evitadas, e quando não, ainda apresentam amplitudes menores do que seriam observadas com o acoplamento de um absorvedor linear, como visto na Fig. 5.14. 


\subsection{Projeto do absorvedor e suas dificuldades}

Quando iniciaram-se os estudos acerca do absorvedor considerado, questionava-se principalmente sobre como estabelecer o valor da rigidez $k_{s n}$ do absorvedor para que houvesse a atenuação das amplitudes de movimento. Uma vez que o intuito era promover o estudo do absorvedor permitindo que este realizasse seu movimento tanto vertical como horizontalmente, tornou-se difícil inferir sobre os possíveis caminhos para determinar tal valor. Contudo, um conjunto consistente de dados foi obtido após a realização do processo de otimização do absorvedor, o que permitiu que uma análise sobre esses valores fosse realizada. Sendo assim, nesse capítulo esses dados são analisados com objetivo de descobrir uma possível maneira de se determinar a rigidez ótima de maneira mais fácil ou menos custosa computacionalmente.

Como foi possível verificar ao longo do desenvolvimento do projeto, as curvas Amplitude $x$ Rigidez sempre apresentavam pontos de mínimo referentes a sintonização do absorvedor tanto para o movimento prioritariamente na direção horizontal e como na direção vertical. Esse fato foi verificado logo nos resultados iniciais e exibido no capítulo 3. Entretanto, mais à frente no projeto notou-se que alguns dos casos observados apresentavam regiões de instabilidade, com descontinuidades por exemplo, o que tornava a determinação dos mínimos uma tarefa mais complicada.

A principal suspeita sobre como precisar o ponto de mínimo correspondente partiu do processo de linearização realizado no capítulo 2 para o cálculo do amortecimento do absorvedor. A relação entre a rigidez equivalente das duas molas do absorvedor projetada em ambas as direções $\left(k_{s h}\right.$ e $\left.k_{s v}\right)$ e a rigidez $k_{s n}$ de cada mola é dada pela relação (2.23) e repetida aqui.

$$
\left\{\begin{array}{l}
k_{s h}=2 k_{s n} \cos ^{2}(\theta) \\
k_{s v}=2 k_{s n} \sin ^{2}(\theta)
\end{array}\right.
$$

Admitindo-se que $k_{s n}$ corresponde a rigidez de cada uma das molas do absorvedor sintonizado e dado que $k_{s h}$ e $k_{s v}$ referem-se a rigidez equivalente das duas molas, o valor de $k_{s n}$ seria dado por $k_{s n}=k_{s h} / 2$ para sintonização horizontal e por $k_{s n}=k_{s v} / 2$ no caso vertical. Sabendo que o mínimo global obtido na otimização da rigidez deve corresponder a sintonização para vibrações majoritariamente verticais, confrontou-se os dados obtidos por algorítimos genéticos com a relação descrita na equação (5.4), sendo $\theta$ o ângulo inicial formado entre o eixo horizontal e a mola do absorvedor quando $L_{0} \neq L$. Lembra-se aqui que na linearização admitiu-se que os ângulos formados entre o eixo horizontal e as molas do absorvedor são iguais. Desta maneira, o cosseno e o seno ao quadrado de $\theta$ são dados por $\cos ^{2}(\theta)=\left(L / L_{0}\right)^{2}$ e 
$\sin ^{2}(\theta)=1-\cos ^{2}(\theta)$, respectivamente.

$$
k_{s n}=\frac{k_{s}}{2 \sin ^{2}(\theta)}
$$

Portanto, uma vez que se quer sintonizar o absorvedor para o movimento prioritariamente vertical, $k_{s v}$ deve ser a rigidez equivalente a ser sintonizada. Feito isto, deve-se calcular o $k_{s n}$ que resulta em tal configuração.

Assim sendo, a Fig. 5.19 exibe os valores de rigidez obtidos por otimização e os calculados através da linearização quanto ao valor de $L_{0}$ e quanto a massa $m_{s}$ do absorvedor. Levando em conta que quanto mais próximo o valor de $L_{0}$ de $L$, menor o ângulo $\theta$ formado e por consequência menor o seno correspondente, sabe-se que quanto menor $L_{0}$, maior o $k_{s n}$ resultante. Também é sabido que a sintonização do absorvedor linear corresponde ao cálculo de uma rigidez para um determinado $m_{S}$ que resulte em $\omega_{n p}=\omega_{n s}$, e assim quanto maior $m_{s}$ maior o $k_{s n}$ obtido. Como guia, as setas na Fig. 5.19 indicam o sentido crescente dos valores de $m_{s}$ e $L_{0}$.

Através da Fig. 5.19a vê-se que o conjunto obtido por algoritmos genéticos e a regra estabelecida na equação (5.4) se encaixam satisfatoriamente de acordo com padrão dos pontos sobre as linhas, apesar da difícil visualização. Já pela Fig. 5.19b é possível notar que muitos pontos coincidem com as curvas calculadas, havendo maior diferença para os maiores $(0,20 \mathrm{~m} ; 0,18 \mathrm{~m} ; 0,17 \mathrm{~m})$ e menores valores $(0,151 \mathrm{~m}$ e $0,152 \mathrm{~m})$ de $L_{0}$, e que para valores intermediários de $L_{0}$ os pontos coincidem bem com suas curvas correspondentes. As possíveis razões para a ocorrência dessas diferenças são: nos casos dos maiores $L_{0}$, um pequeno movimento em $u_{p}$ resulta em maior alteração do ângulo formado entre a mola do absorvedor e o eixo horizontal, o que pode afastar os resultados do sistema linearizado e dos resultantes da otimização; além disso, outra possível resposta para a diferença encontrada nesta comparação é o fato de que, embora bem configurado o método de otimização, a execução do método não garante que o mínimo global seja realmente alcançado, o que levaria a valores distintos em relação aos calculados na linearização; uma outra possibilidade é que as curvas de Amplitude x Rigidez apresentem vários mínimos locais, além de descontinuidades, fato que dificultaria a definição do mínimo global da função.

Visto que as configurações do absorvedor que resultam nos melhores desempenhos são as de menor $L_{0}$, optou-se por averiguar como essa diferença de valores no $k_{s n}$ resulta sobre as curvas de Amplitude x Frequência em alguns dos casos de $L_{0}=0,151$ $\mathrm{m}$ e $L_{0}=0,152 \mathrm{~m}$. Assim, as figuras posicionadas à esquerda correspondem ao absorvedor com rigidez adquirida por otimização e as figuras à direita a rigidez calculada analiticamente.

Para os pontos que são compatíveis não é necessário que se visualize muitas cur- 


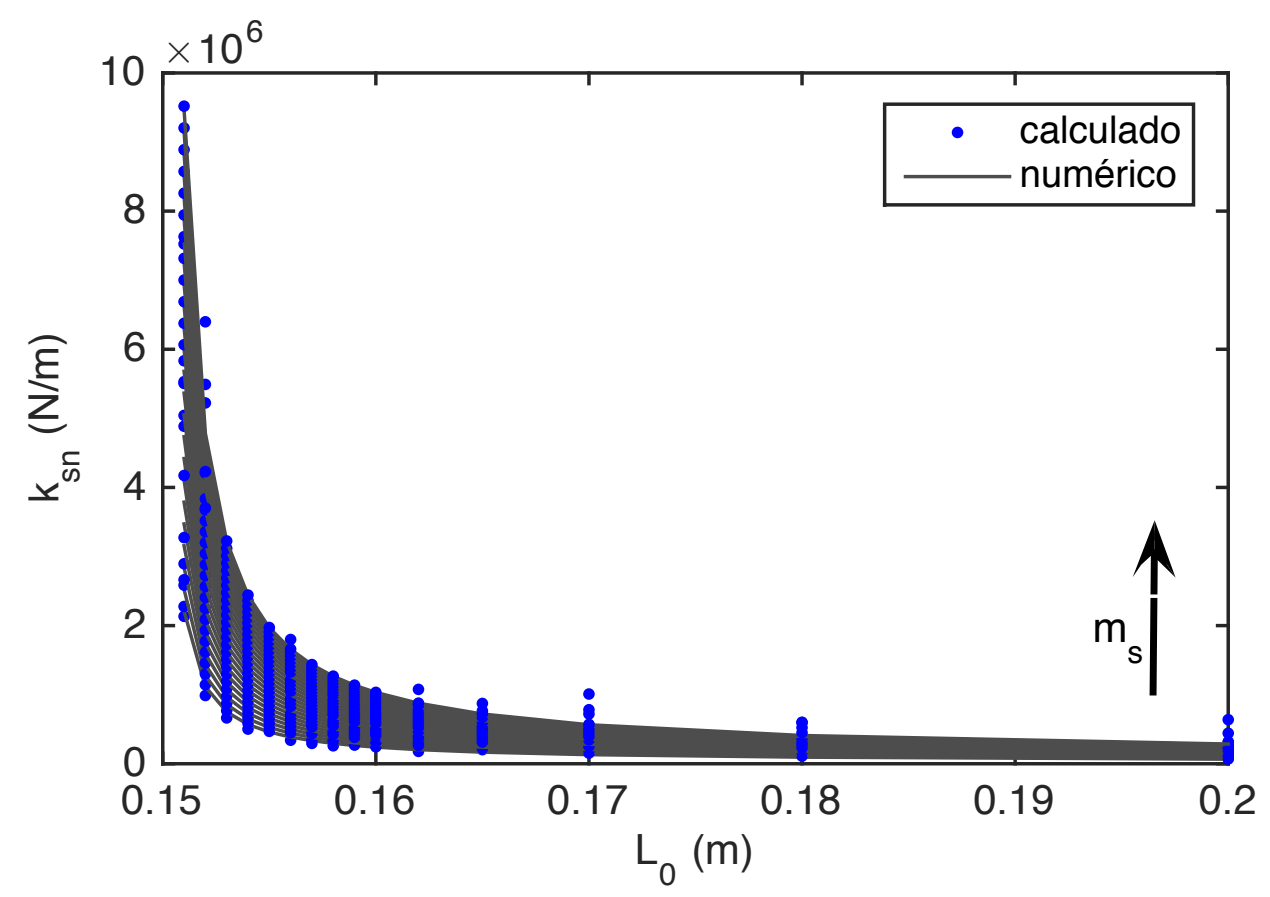

(a) Valores de rigidez em relação ao comprimento da mola

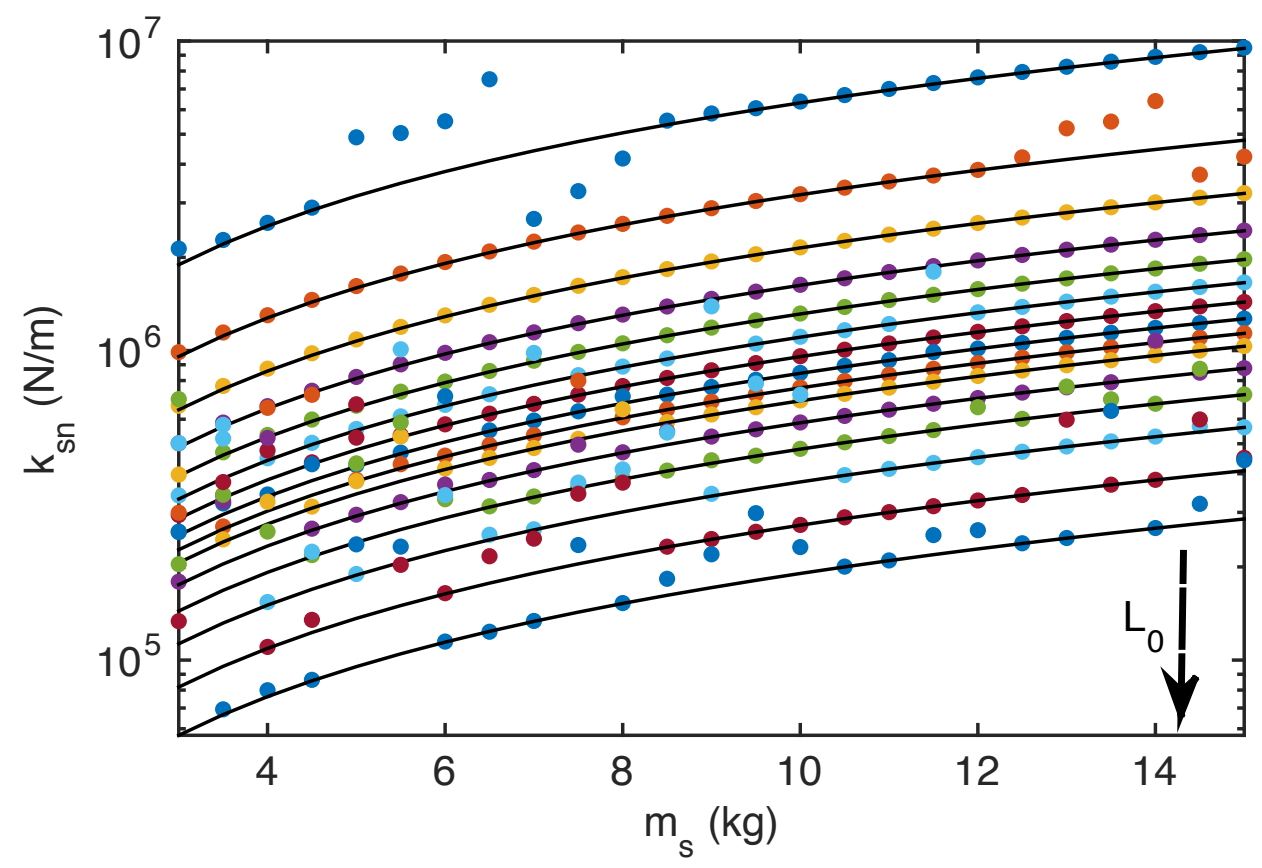

(b) Valores de rigidez em relação a massa do absorvedor

Figura 5.19: Rigidez calculada (linha sólida) x Rigidez obtida (pontos). 
vas, pois uma pequena diferença na rigidez empregada deve gerar desempenhos muito semelhantes ao longo da faixa de frequência observada. Para exemplificar esses casos escolheu-se na Fig. $5.19 \mathrm{~b}$ os casos de $L_{0}=0,152 \mathrm{~m}$ e massas de 10,5 kg, $11 \mathrm{~kg}$, $11,5 \mathrm{~kg}, 12 \mathrm{~kg}, 12,5 \mathrm{~kg}$. Esse comparação é mostrada a seguir nas Figs. 5.21a e 5.21b.

Considerando as ocorrências onde o valor calculado e obtido por otimização são muito distintos observaram-se duas regiões na Fig. $5.19 \mathrm{~b}$, uma quando $L_{0}=0,151 \mathrm{~m}$ com massas de 5,5 kg, 6,0 kg, 6,5 kg, 7,0 kg e 7,5 kg, na Fig. 5.20 e outra quando $L_{0}=0,152 \mathrm{~m}$ com as massas de $13,0 \mathrm{~kg}, 13,5 \mathrm{~kg}, 14,0 \mathrm{~kg}, 14,5 \mathrm{~kg}, 15,0 \mathrm{~kg} \mathrm{~kg}$ na Figs. $5.21 \mathrm{c}$ e $5.21 \mathrm{~d}$.

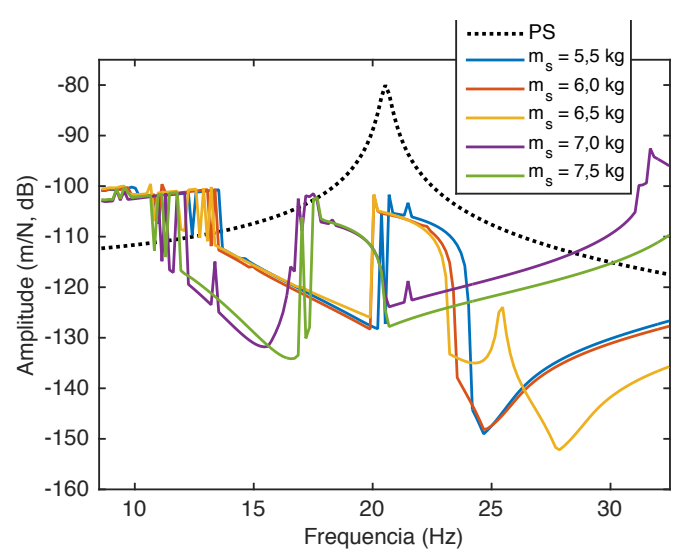

(a) Rigidez obtida por otimização para $m_{s}$ de 5,5 a $7,5 \mathrm{~kg}$

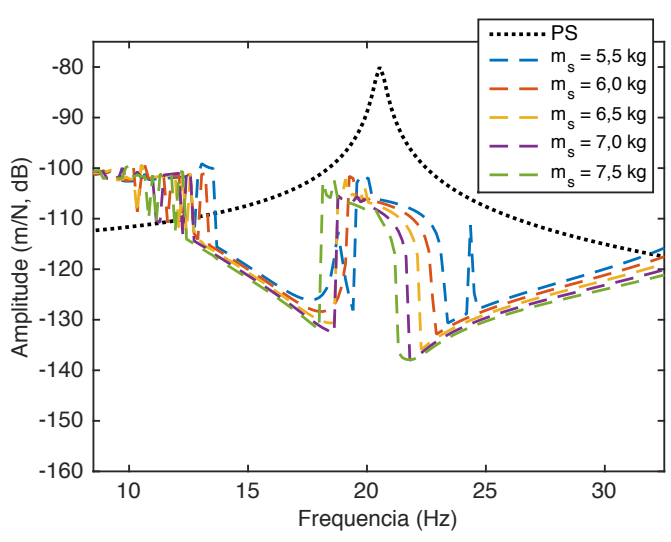

(b) Rigidez calculada analiticamente para $m_{s}$ de 5,5 a $7,5 \mathrm{~kg}$

Figura 5.20: Curvas de Frequência x Amplitude para casos de rigidez calculada (tracejada) e rigidez obtida via otimização (linha sólida) quando $L_{0}=0,151 \mathrm{~m}$.

Conforme visto na Fig. 5.19b, $L_{0}=0,152 \mathrm{~m}$ corresponde a segunda linha de cima para baixo, as configurações que contém massa entre 10,5 kg e 12,5 kg têm uma boa concordância entre os dois modos de obtenção da rigidez e conforme mostrado nas Figs. 5.21a e 5.21b o desempenho do absorvedor é muito semelhante nos cinco casos exibidos.

Já para as situações que os valores de rigidez são muito distintos entre os dois conjuntos, quando $L_{0}=0,151$ e $m_{s}$ está entre $5,5 \mathrm{~kg}$ e $7,5 \mathrm{~kg}$ ou quando $L_{0}=0,152$ e $m_{s}$ vai de $13 \mathrm{~kg}$ a $15 \mathrm{~kg}$, é evidente que os valores calculados analiticamente de $k_{s n}$ levam à situação que a região de salto fica situada bem onde se deseja produzir uma antirressonância, sendo este um resultado indesejado. Ao mesmo tempo, vêse que através da otimização foi possível determinar uma rigidez que na maioria dos casos evita a região do salto colocando-o antes ou depois de onde deve haver a antirressonância, por isso o processo de otimização ainda se mostra necessário, pois ainda não se sabe garantir para quais situações esse fenômeno ocorrerá próximo a região de antirressonância desejada.

Desse modo, conclui-se que o processo de linearização e sintonização analítica é 
uma ferramenta pode ser explorada em conjunto com algum método de otimização que não necessariamente seja o de algoritmos genéticos. Este $k_{s n}$ encontrado analiticamente pode e dever servir, ao menos por enquanto, como uma referência para o método de otimização desejado, isso economizaria tempo e custo computacional. Além disso, dispor de um processo de otimização ainda é necessário e vantajoso na situação atual, pois deve-se considerar também que tanto o sistema principal como o absorvedor possuem amortecimentos que alteram a resposta e consequentemente a frequência de sintonização, circunstância que pode ser contornada pelo emprego de qualquer método de otimização adequado.

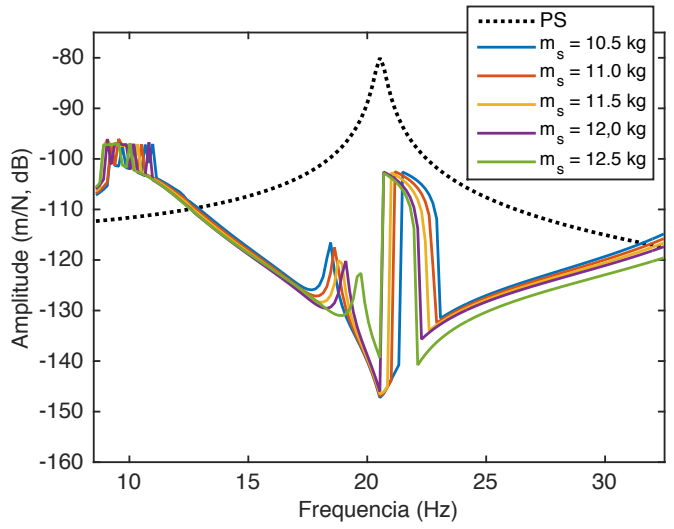

(a) Rigidez obtida por otimização para $m_{s}$ de 10,5 a $12,5 \mathrm{~kg}$

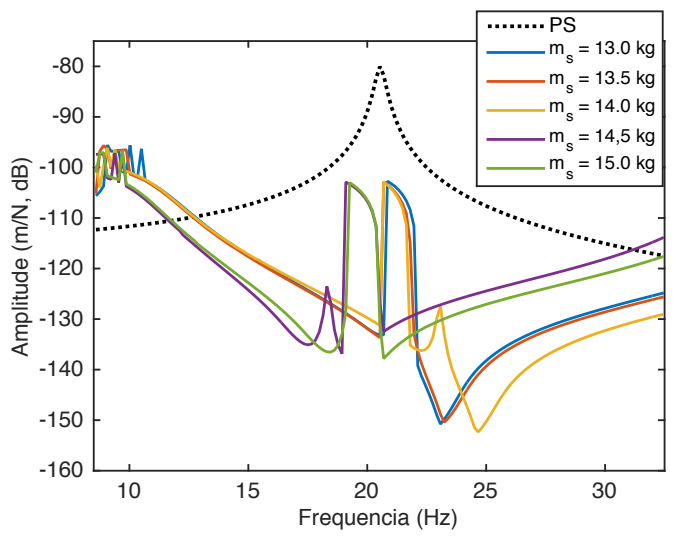

(c) Rigidez obtida por otimização para $m_{s}$ de 13 a $15 \mathrm{~kg}$

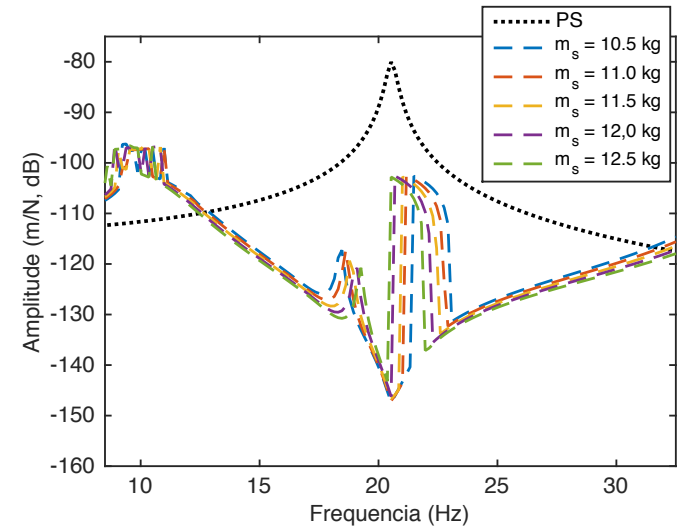

(b) Rigidez calculada analiticamente para $m_{s}$ de 10,5 a $12,5 \mathrm{~kg}$

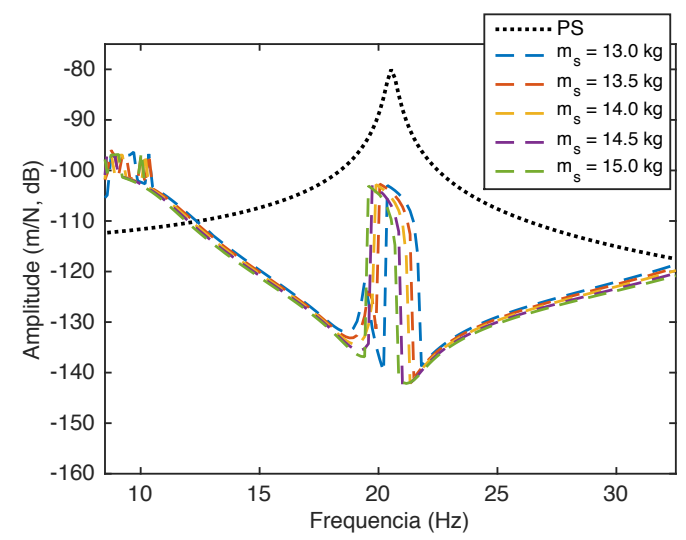

(d) Rigidez calculada analiticamente para $m_{s}$ de 13 a $15 \mathrm{~kg}$

Figura 5.21: Curvas de Frequência x Amplitude para casos de rigidez calculada (tracejada) e rigidez obtida via otimização (linha sólida) quando $L_{0}=0,152 \mathrm{~m}$. 


\section{Capítulo 6}

\section{Conclusões e Trabalhos Futuros}

Este último capítulo visa consolidar as informações oriundas do desenvolvimento do projeto apresentado anteriormente com propósito de situar o trabalho desenvolvido e suas contribuições à área de interesse, apresentando assim as conclusões alcançadas e os trabalhos futuros que podem ser provenientes deste.

\subsection{Conclusões}

Este trabalho apresentou o desenvolvimento e a otimização de um absorvedor não linear baseado na formação encontrada na literatura do absorvedor tipo snap-through truss. Fez-se questão de diferenciar o dispositivo estudado em relação ao encontrado na literatura, pois este último não levava em conta as oscilações desempenhadas na direção horizontal e ainda considerava que o absorvedor deveria oscilar verticalmente cruzando a origem do eixo vertical, fato que aqui mostrou-se ser indesejado. Desde os primeiros resultados ficou claro que, para atenuar as vibrações do sistema principal, o dispositivo deveria desenvolver pequenas amplitudes na direção horizontal e, ao mesmo tempo, amplitudes significantemente maiores na direção vertical, entretanto, este não deveria se acercar ou cruzar o ponto de equilíbrio instável residente na origem do eixo vertical, dado que a passagem por esse ponto leva a uma resposta com múltiplos períodos, como visto nas primeiras bifurcações.

O método de otimização por algoritmos genéticos foi usado neste trabalho devido às dificuldades em se trabalhar com o método de busca extensiva, mesmo que isso representasse a não obtenção da curva que retrata a relação da amplitude de vibração do sistema principal em função da rigidez do absorvedor. Ainda assim, o uso dessa ferramenta foi fundamental ao trabalho, porque significou a diminuição do tempo gasto para encontrar a rigidez ótima das molas do absorvedor, transformando um processo que durava 20 minutos em média em um de 5 minutos. Levando em conta que havia 400 combinações possíveis, o tempo que era de aproximadamente 5 dias e meio passou a menos de 1 dia e meio somente para essa parte de sintonização da rigidez ótima.

Embora não tenha havido um levantamento sobre como a inclusão da área entre 
as curvas do sistema com e sem absorvedor acoplado como um critério de avaliação colaborou para que se chegasse as melhores combinações de configuração do absorvedor, notou-se ao longo do trabalho que esse critério engloba muito bem os outros dois empregados e ainda consegue levar em consideração o salto ou qualquer outro fenômeno que faça com que as amplitudes se elevem por um pequeno trecho abaixo da curva do sistema primário sem absorvedor. Assim, recomenda-se que esse critério continue sendo usado na avaliação de desempenho deste ou qualquer outro dispositivo absorvedor.

A respeito da ampliação da faixa de supressão promovida pelo absorvedor ficou claro que o dispositivo não linear é capaz de produzir uma faixa de supressão extremamente maior do que o melhor caso linear, atingindo valores quase 6,5 vezes maior dentro do intervalo observado. Os resultados referentes ao tamanho da faixa de supressão foram sempre muito promissores desde início do trabalho, pois a medida que o processo de otimização foi sendo aperfeiçoado cada vez mais esses resultados eram melhores, mas foi somente através da otimização por algoritmos genéticos que foram obtidos os melhores resultados. Há de se mencionar aqui que em nenhum momento esperava-se conseguir faixas de supressão com valores tão grandes, uma vez que dobrar ou triplicar os resultados adquiridos com um absorvedor linear já parecia um grande passo. Ainda assim, quando foi observado o comportamento do sistema ao longo de um intervalo maior de frequências pôde-se ver que alguns resultados são melhores do que haviam sido computados, mesmo que para o seguimento do trabalho não se tenha atualizado os valores com vista nesse intervalo maior. Estes resultados não utilizados para análise mostraram que no intervalo de 0 a $80 \mathrm{~Hz}$ a faixa de supressão atinge $31 \mathrm{~Hz}$ para o par $m_{s}=15 \mathrm{~kg}$ e $L_{0}=0,151 \mathrm{~m}$, revelando um valor 8,1 vezes acima em relação ao seu correspondente linear.

A redução das amplitudes de vibração na frequência de ressonância considerada não só revelou a capacidade do absorvedor não linear criar uma antirressonância no lugar da ressonância como também mostrou que ele é capaz de suprimir ainda mais essas amplitudes quando olhamos o melhor caso linear relacionado, alcançando uma redução aproximadamente $60 \%$ superior. Um olhar geral sobre os principais resultados indica que há um vínculo entre a redução gerada e o tamanho da faixa de supressão, pois nota-se que quanto maior o primeiro, maior também será o segundo. É importante ressaltar que essa relação não está clara no texto e nem é adequada a todo o conjunto analisado, mas que nos casos onde não há presença do Salto muito próximo ou na antirressonância, essa tendência é verificada.

Quando estudou-se o absorvedor linear e os trabalhos publicados a seu respeito ficou entendido que a redução dos picos de ressonância presentes lado a lado da antirressonância acontece com a inconveniente elevação das amplitudes na frequência sintonizada. Ao contrário do que se viu, no caso não linear, a habilidade do sistema de 
afastar entre si os picos de ressonância resultantes ao mesmo tempo que diminui as amplitudes na antirressonância resulta no abaixamento completo da curva respostafrequência, criando um resultado de grande destaque.

Além dessas características citadas há ainda a versatilidade de configurações que o sistema oferece ao projetista, visto que essa versatilidade acontece de dois modos. O primeiro vem dos muitos valores possíveis de massa e tamanho da mola aplicados ao projeto. $\mathrm{O}$ segundo modo reside no fato de que, dois ou mais pares $\left[L_{0}\right.$ e $\left.m_{s}\right]$ podem oferecer desempenhos parecidos, permitindo que se adote o mais adequado à situação, ou que os pares observados tenham desempenhos diferentes mas que um dos critérios observados atenda às necessidades do projetista em alguma das possibilidades. Assim, esse dispositivo revela-se muito mais interessante frente ao linear por sua flexibilidade quando está sendo projetado.

Sobre as limitações do absorvedor conclui-se que o único aspecto ao qual se deve ficar atento é a amplitude da força de excitação, uma vez que uma força muito grande pode fazer com que o sistema não respeite as limitações físicas e de projeto. Fora isso, o dispositivo, se apropriadamente projetado, pode ser empregado sem limitações.

Define-se aqui que considerar o dispositivo apropriadamente projetado significa que o projetista deve primeiro calcular analiticamente a rigidez ótima com intuito de fornecer um valor próximo ao ótimo e após isto realizar o processo de otimização para obter o $k_{s n}$ ótimo. Após isso, deve-se observar a curva resposta em frequência com intuito de garantir que um ou mais dos critérios de avaliação atendam as necessidades de projeto.

Assim, entendem-se como principais contribuições deste trabalho:

Formulação de metodologia para análise de desempenho de um absorvedor não linear acoplado.

Proposição de métricas de desempenho para absorvedores não lineares.

\subsection{Trabalhos futuros}

Embora o trabalho atual tenha buscado abordar todos os aspectos relativos ao dispositivo proposto, alguns temas não puderam ser estudados a tempo e outros nasceram como fruto do trabalho desenvolvido.

O efeito da variação do amortecimento sobre o absorvedor deve ser primeiro tema a ser explorado, pois tem a capacidade de fornecer resultados interessantes. Se o amortecimento atuar sobre o dispositivo não linear da mesma forma que atua sobre o linear, o aumento deste resultaria na redução das amplitudes nas frequências de ressonância resultantes do acoplamento ao mesmo tempo que aumentaria as amplitudes na antirressonância. Contudo, um amortecimento maior poderia ser responsável pela atenuação dos fenômenos não lineares presentes, tornado-se uma proposta atrativa. 
Dentro deste tópico há ainda a possibilidade de se inserir um amortecedor magnetoreológico e com uma lei de controle buscar enriquecer ainda mais o desempenho do dispositivo.

Uma segunda proposta de trabalho futuro consiste em tentar estabelecer as frequências de ressonância resultantes do sistema acoplado e relacionar a posição destas, para um mesmo $m_{s}$, com o comprimento de mola $L_{0}$ empregado. Muito provavelmente, a definição dessas frequências possibilitaria o projeto do absorvedor sem o auxílio de métodos de otimização ou pelo menos informaria quais configurações evitar, pois previne-se a ocorrência de saltos sobre o ponto no qual se quer realizar a sintonização.

Uma última proposta consiste em realizar a análise experimental desse modelo, de modo a explorar e solucionar problemas relacionados à construção, montagem e desenvolvimento do experimento; e também obter resultados semelhantes aos obtidos na simulação computacional. 


\section{Referências Bibliográficas}

ARNOLD, F. R. Steady-state behavior of systems provided with nonlinear dynamic vibration absorbers. Journal of Applied Mechanics, n. 22, p. 487-492, 1955.

AVRAMOV, K.; GENDELMAN, O. Interaction of elastic system with snap-through vibration absorber. International Journal of Non-Linear Mechanics, v. 44, n. 1, p. 81 - 89, 2009.

AVRAMOV, K. V.; MIKHLIN, Y. V. Forced oscillations of a system, containing a snapthrough truss, close to its equilibrium position. Nonlinear Dynamics, v. 35, n. 4, p. 361-379, 2004.

AVRAMOV, K. V.; MIKHLIN, Y. V. Snap-through truss as a vibration absorber. Journal of Vibration and Control, v. 10, n. 2, p. 291-308, 2004.

AVRAMOV, K. V.; MIKHLIN, Y. V. Snap-through truss as an absorber of forced oscillations. Journal of Sound and Vibration, v. 290, n. 35, p. 705 - 722, 2006.

BARTEL, D. L.; KRAUTER, A. I. Time Domain Optimization of a Vibration Absorber. Journal of Engineering for Industry, ASME, v. 93, n. 3, p. 799-803, 1971.

BAVASTRI, C. A.; ESPINDOLA, J. J. de; TEIXEIRA, P. H. A hybrid algorithm to compute the optimal parameters of a system of viscoelastic vibration neutralizers in a frequency band. In: CITESEER. Proceedings of MOVIC. [S.1.], 1998. v. 98, p. 577-582.

BRENNAN, M. J.; GATTI, G. The characteristics of a nonlinear vibration neutralizer. Journal of Sound and Vibration, v. 331, n. 13, p. 3158-3171, 2012.

EASON, R. et al. Steady-state response attenuation of a linear oscillatornonlinear absorber system by using an adjustable-length pendulum in series: Numerical and experimental results. Journal of Sound and Vibration, v. 344, p. 332-344, 2015.

EGLE, D. An investigation of an impact vibration absorber. Journal of Engineering for Industry, American Society of Mechanical Engineers, v. 89, n. 4, p. 653-657, 1967.

FELIX, J. L. P.; BALTHAZAR, J. M. On a nonlinear dynamics of a non-ideal oscillator, with a snap-through truss absorber(stta). In: Proceedings COBEM 2009. Gramado, RS: [s.n.], 2009.

GENDELMAN, O. et al. Energy pumping in nonlinear mechanical oscillators: Part i dynamics of the underlying hamiltonian systems. ASME Journal of Applied Mechanics, v. 68, p. $34,2001$.

GENDELMAN, O. V. Transition of energy to a nonlinear localized mode in a highly asymmetric system of two oscillators. Nonlinear Dynamics, v. 25, p. 237-253, 2001. 
GODOY, W. R. A. et al. Using of a snap-through truss absorber in the attenuation of the sommerfeld effect. MATEC Web of Conferences, v. 1, p. 08002, 2012.

GODOY, W. R. A. et al. A note on non-linear phenomena in a non-ideal oscillator, with a snap-through truss absorber, including parameter uncertainties. Proceedings of the Institution of Mechanical Engineers, Part K: Journal of Multi-body Dynamics, v. 227, n. 1, p. 76-86, 2013.

HARTOG, J. P. D. Mechanical vibrations. 4th ed. ed. [S.1.]: New York, N.Y.: McGraw-Hill, 1956.

HAXTON, R. S.; BARR, A. D. S. The autoparametric vibration absorber. Journal of Engineering for Industry, American Society of Mechanical Engineers, v. 94, n. 1, p. 119$125,1972$.

HOLLAND, J. H. Adaptation in natural and artificial systems: an introductory analysis with applications to biology, control, and artificial intelligence. [S.l.]: University of Michigan Press, 1975.

HUNT, J. B.; NISSEN, J. C. The broadband dynamic vibration absorber. Journal of Sound and Vibration, v. 83, n. 4, p. $573-578,1982$.

IBRAHIM, R. Recent advances in nonlinear passive vibration isolators. Journal of Sound and Vibration, v. 314, n. 3-5, p. 371-452, 2008.

JORDANOV, I.; CHESHANKOV, B. Optimal design of linear and non-linear dynamic vibration absorbers. Journal of Sound and Vibration, v. 123, n. 1, p. 157 - 170, 1988.

KITIS, L.; WANG, B.; PILKEY, W. Vibration reduction over a frequency range. Journal of Sound and Vibration, v. 89, n. 4, p. 559-569, 1983.

KOJIMA, H.; YAMAKAWA, I. Analysis of the magnetic dynamic vibration absorber with unsymmetrical nonlinear restoring force. Journal of the Japan Society of Precision Engineering, v. 47, p. 568-573, 1981.

KWAK, B. M.; ARORA, J. S.; HAUG, E. J. Optimum Design of Damped Vibration Absorbers Over a Finite Frequency Range. AIAA Journal, American Institute of Aeronautics and Astronautics, v. 13, n. 4, p. 540-542, 1975.

MASRI, S. Forced vibration of a class of non-linear two-degree-of-freedom oscillators. International Journal of Non-Linear Mechanics, v. 7, n. 6, p. 663-674, 1972.

MATHWORKS. Opções da função de otimização por Algoritmos Genéticos do software Matlab. 2016. <http://www.mathworks.com/help/gads/genetic-algorithm-options. html>. Acessado em 31/08/2016.

MILLER, H. M.; GARTNER, J. R. Tunable Nonlinear Vibration Absorber. 1975.

NAYFEH, A. H.; MOOK, D. T. Nonlinear Oscillations. [S.1.]: Wiley-VCH, 1995.

ORMONDROYD, J.; HARTOG, J. P. D. The theory of the dynamical vibration absorber. ASME Journal of Applied Mechanics, v. 50(7), p. 9-22, 1928. 
PAI, P. F.; SCHULZ, M. J. A refined nonlinear vibration absorber. International Journal of Mechanical Sciences, v. 42, n. 3, p. $537-560,2000$.

PIPES, L. A. Analysis of a nonlinear dynamic vibration absorber. Journal of Applied Mechanics, v. 20, p. 515-518, 1953.

RADE, D. A.; STEFFEN, V. Optimisation of dynamic vibration absorbers over a frequency band. Mechanical Systems and Signal Processing, v. 14, n. 5, p. 679-690, 2000.

RAO, S. S. Engineering Optimization: Theory and Practice. [S.1.]: Wiley, 2009.

RECHENBERG, I. Cybernetic solution path of an experimental problem. Ministry of Aviation, Royal Aircraft Establishment, 1965.

RICE, H.; MCCRAITH, J. Practical non-linear vibration absorber design. Journal of Sound and Vibration, v. 116, n. 3, p. 545-559, 1987.

ROBERSON, R. E. Synthesis of a nonlinear dynamic vibration absorber. Journal of the Franklin Institute, v. 254, n. 3, p. 205 - 220, 1952.

SARAVANAMURUGAN, S.; ALWARSAMY, T.; DEVARAJAN, K. Optimization of damped dynamic vibration absorber to control chatter in metal cutting process. Journal of Vibration and Control, v. 21, n. 5, p. 949-958, 2015.

SHAW, J.; SHAW, S. W.; HADDOW, A. G. On the response of the non-linear vibration absorber. International Journal of Non-Linear Mechanics, v. 24, n. 4, p. 281 - 293, 1989.

SOOM, A.; LEE, M.-s. Optimal Design of Linear and Nonlinear Vibration Absorbers for Damped Systems. Journal of Vibration, Acoustics, Stress, and Reliability in Design, ASME, v. 105, n. 1, p. 112-119, 1983.

VAKAKIS, A. F.; GENDELMAN, O. Energy pumping in nonlinear mechanical oscillators: Part ii resonance capture. ASME Journal of Applied Mechanics, v. 68, p. 42, 2001.

VAKAKIS, A. F. et al. Nonlinear target energy transfer in mechanical and structural systems. [S.1.]: Springer Verlag Holland, 2008.

VIANA, F. A. C. et al. Tuning dynamic vibration absorbers by using ant colony optimization. Computers E Structures, v. 86, n. 13, p. 1539-1549, 2008.

VIGUIE, R.; KERSCHEN, G. Nonlinear vibration absorber coupled to a nonlinear primary system: A tuning methodology. Journal of Sound and Vibration, v. 326, n. 35, p. $780-793,2009$.

VIGUIE, R.; KERSCHEN, G. On the functional form of a nonlinear vibration absorber. Journal of Sound and Vibration, v. 329, n. 25, p. 5225 - 5232, 2010.

WANG, Y.; CHENG, S. The optimal design of dynamic absorber in the time domain and the frequency domain. v. 28, n. 1, p. 67-78, 1989.

XUE, S. D.; KO, J. M.; XU, Y. L. Optimal Performance of the TLCD in Structural Pitching Vibration Control. Journal of Vibration and Control, v. 8, n. 5, p. 619-642, 2002. 